\title{
APPLICATION OF PARAMETERS SCREENING IN THE DESIGN OF SWITCHED RELUCTANCE MOTOR
}

\author{
by
}

Iain Cameron Davis, B.Eng

Lakehead University, 2006

\author{
A project \\ presented to Ryerson University \\ in partial fulfillment of the \\ requirement for the degree of \\ Master of Engineering \\ in the Program of
}

Electrical and Computer Engineering

Toronto, Ontario, Canada, 2011

(C) Iain Cameron Davis, 2011 


\section{Author's Declaration}

I hereby declare that I am the sole author of this thesis. I authorize Ryerson University to lend this thesis to other institutions or individuals for the purpose of scholarly research.

Signature

I further authorize Ryerson University to reproduce this thesis by photocopying or by other means, in total or in part, at the request of other institutions or individuals for the purpose of scholarly research.

Signature
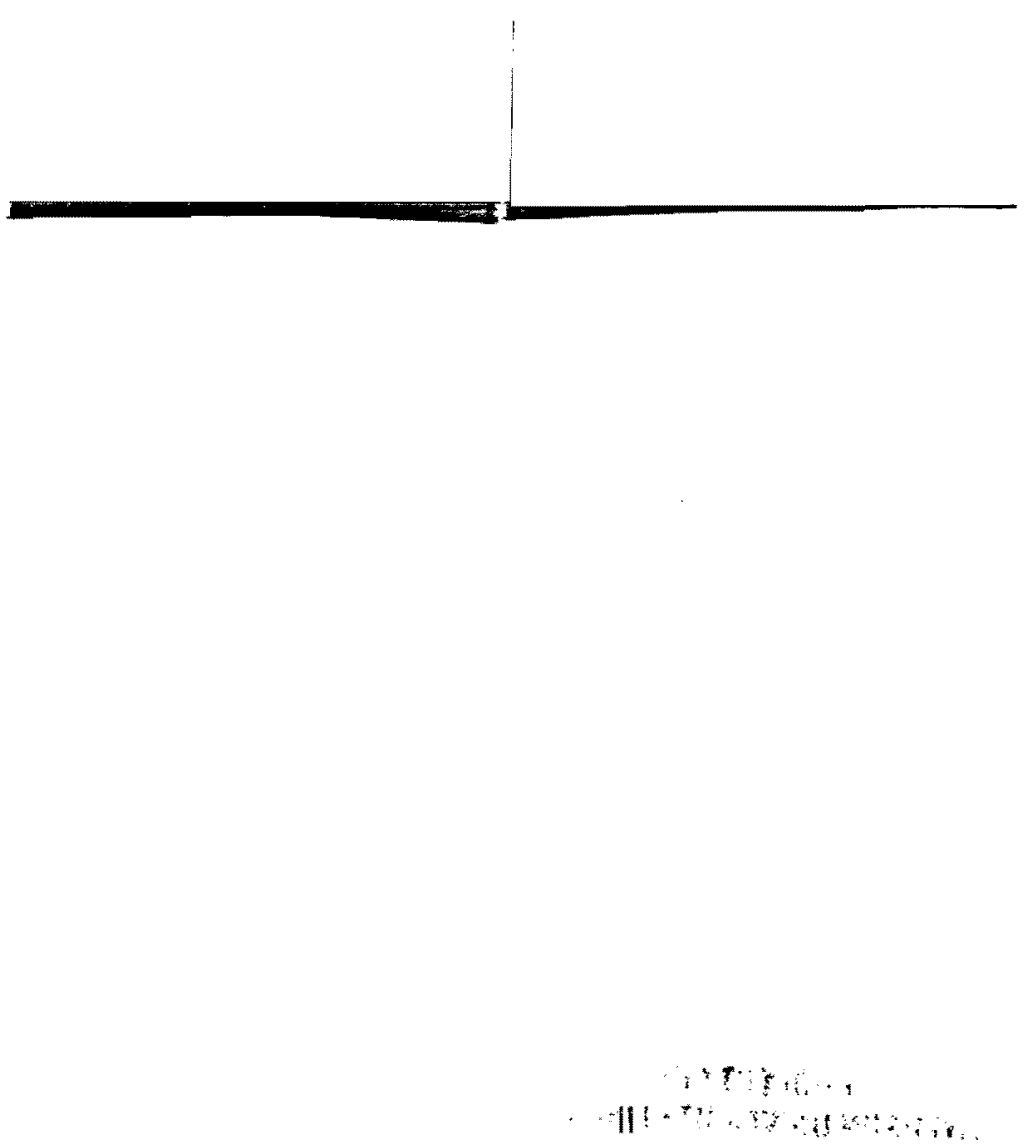


\section{Instructions to Borrowers}

Ryerson University requires the signatures of all persons using or photocopying this thesis. Please sign below, and give address and date. 


\begin{abstract}
The fundamental operation of the switched reluctance motor (SRM) is arguably the simplest and most eloquent of all the universe of rotary electromagnetic machines. Contrast the elementary operation and construction, with the highly non-linear effects that the material properties and geometrical construction of the core add to the design process. A consequence of these complexities, the efficient performance of an SRM requires an insight intensive, multivariable and highly iterative design process.
\end{abstract}

For completeness, a literature survey is offered which presents a detailed review of three key papers that were instrumental in furthering the understanding of concepts, as related to; the fundamental operation, modeling and prediction methods and objective based design for the switched reluctance motor. In addition, two complete sections are reserved to review the fundamental concepts of the magnetic theory and the principles of SRM operation and design.

From this review of theory and the available literature, it is clear that in order to reduce the complexity of the multivariable optimization problems associated with the complex SRM design, a method is required that can identify the significant variables in order to remove the non-significant variables from the objective function; this is commonly referred to parameter screening. This screening process can be facilitated by using factorial design, which is a powerful tool that can be used to test several variables simultaneously in order to determine their significance. The factorial design methodology was applied to a switched reluctance motor, whereby the design parameters were individually screened for their contribution towards the starting torque, aligned/unaligned flux-linkage and the RMS stroke torque. Due to the complexity, sheer number and likely interaction of the critical variables associated with SRM design, a method is described wherein the interaction and criticality of the interactions are sorted through an iterative process; whereby, the least important variables and interactions are weeded out so that the more critical variables and interactions can be studied and rated as to their importance to the outcome of the design process. 


\section{Acknowledgements}

First and foremost I would like to thank my supervisor Dr. K. Raahemifar. Throughout our conversations and regular meetings held during the course of my studies at Ryerson, I have come to appreciate the concern and attention that you direct towards all of your students; something which I have feel that most have forgotten. I for one will not forget and wholeheartedly appreciate the approach of your instruction and your ability to inspire the greatness that is within us all!

To Feisal Hurzook, as my mentor and friend - thank you for all your support over the years, I honestly can't imagine where I'd have been in life if it weren't for meeting you.

To my family: John, Janet and Jessica; thank you for your patience, understanding and guidance - the tuition money has helped too.

To my dearest friend Ana, thank for your patience and your continual loving support, you have been of immense support throughout this 'journey'.

To Robert Davidson; an honourable man, centuries before my time, but years ahead of his own. May his pioneering spirit live on, a truly remarkable and bona fide inventor - if only more of us shared similar principals, the world would most certainly benefit... However, a lesson learned from his legacy; let us not be forgot, make a record of your achievements!

...so, let this be mine. 


\section{Table of Contents}

1 Introduction 1

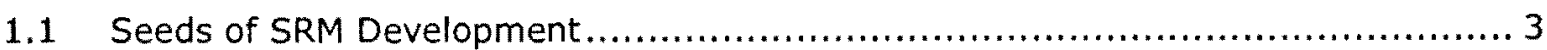

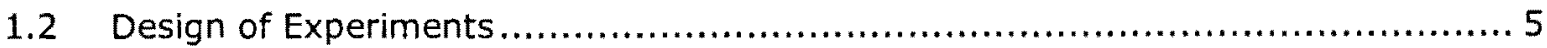

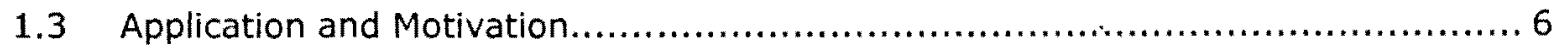

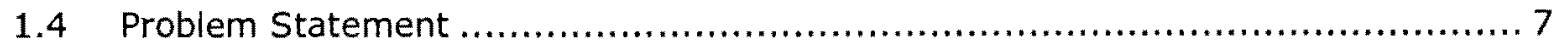

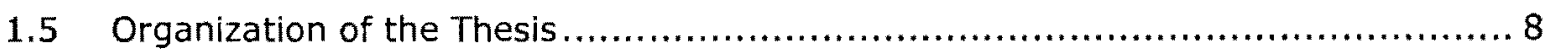

2 Literature Review $\quad 10$

2.1 Static Torque Production in Saturated Doubly-Salient Machines .................... 11

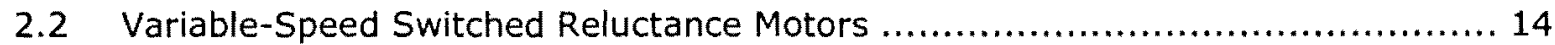

2.3 Design Considerations for the Switched Reluctance Motor ....................... 16

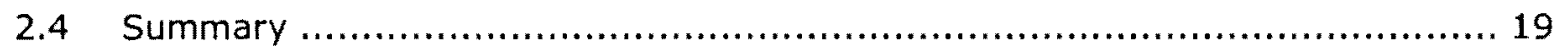

3 Magnetic Circuit Theory $\quad 20$

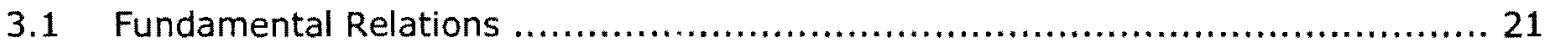

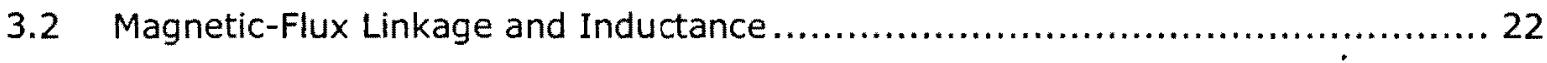

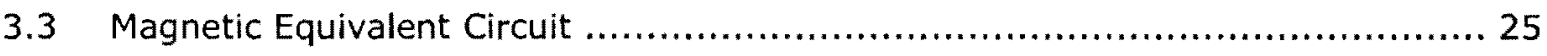

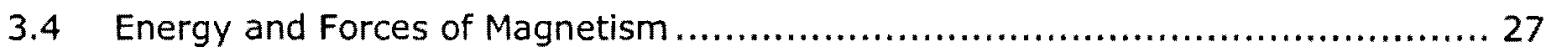

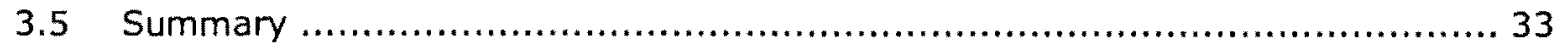

4 The Switched Reluctance Motor: A Case Study 34

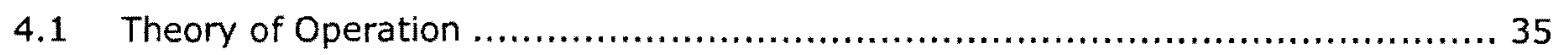

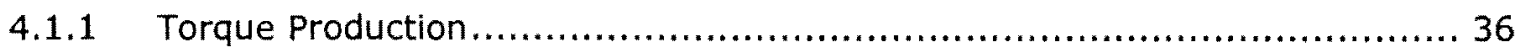

4.1.2 Stroke Angle and Pole Number............................................ 38

4.1.3 Inductance Variation ........................................................... 40

4.1.4 The Feasible Triangle ......................................................... 42

4.1.5 Flux Linkage \& Path Trajectory................................................ 43

4.1.6 A Case (Study) of Saturation ................................................ 44

4.2 Design Consideration for the SRM................................................ 45

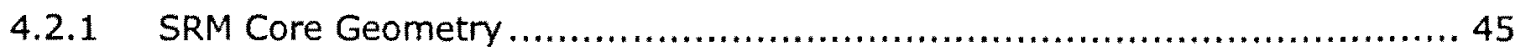

4.2.2 Summary of Empirical Design Relations.................................... 46 


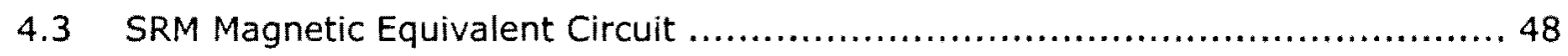

4.3.1 Core Reluctance........................................................ 49

4.3.2 Air Gap Reluctance........................................................... 50

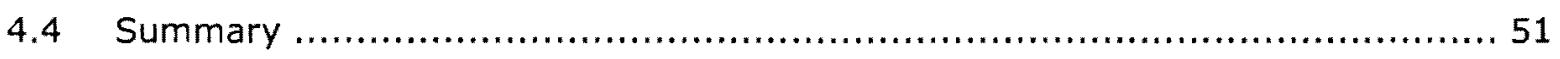

5 Implementation $\quad \mathbf{5 2}$

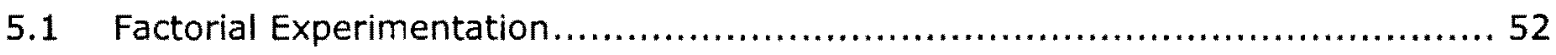

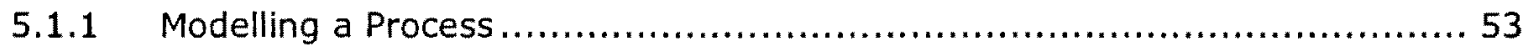

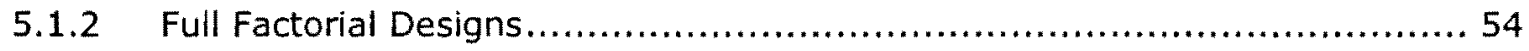

5.1 .3 Fractional Factorial Designs ............................................ 55

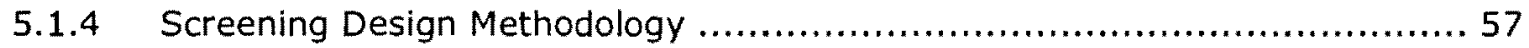

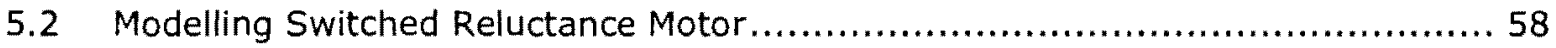

5.2.1 The Modelling Environment ................................................. 60

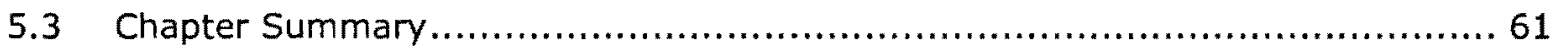

6 Results and Discussions $\quad 62$

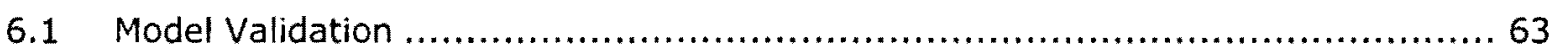

6.2 Parameters Screening: SRM Starting Torque..................................6 66

6.2.1 Six Parameter - Fractional Factorial Experiment ............................. 66

6.2.2 Four Parameter - Full Factorial Experiment ................................ 68

6.2.3 Three Parameter - Full Factorial Experiment................................... 70

6.2.4 Six Parameter - Full Factorial Experiment ................................... 71

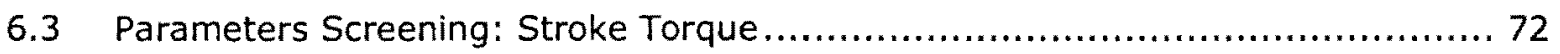

6.4 Parameters Screening: SRM Aligned Flux Linkage ............................... 74

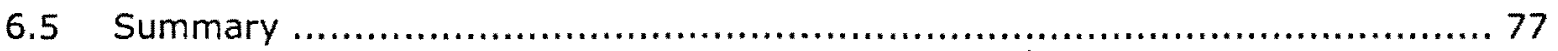

7 Conclusions $\quad \mathbf{8 0}$

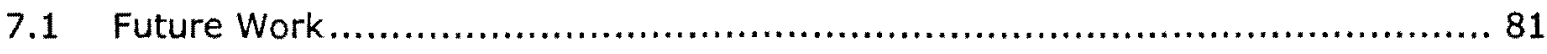

$\begin{array}{ll}\text { References } & 82\end{array}$

$\begin{array}{lr}\text { Appendix A } & 85\end{array}$ 


\section{List of Figures}

Figure 1.1: A brief history of innovation ................................................ 1

Figure 1.2: Robert Davidson's own drawing of his electric locomotive [15] ................ 2

Figure 1.3: David Mackie's drawing of Davidson's motor [15] ............................. 2

Figure 2.1: SRM focused research tree ................................................. 10

Figure 2.2: Tooth flux distribution; (a) aligned, (b) partial, (c) unaligned .................. 12

Figure 2.3: Saturating vs. non-saturating flux linkage trajectories,........................ 17

Figure 3.1: A simple bar magnet and the associated magnetic field ....................... 20

Figure 3.2: A singly excited magnetic circuit ............................................. 21

Figure 3.3: Polarity of induced EMF, (a) ideal coil, (b) practical coil ........................ 23

Figure 3.4: The singly-excited (a) magnetic circuit, (b) equivalent circuit .................. 26

Figure 3.5: The (a) magnetic circuit, (b) offset gap1 tooth, (c) offset gap2 tooth........... 30

Figure 3.6: Relationship between energy and coenergy in a singly excited system......... 32

Figure 4.1: Single-phase 2/2 SRM, (a) unaligned rotor, (b) aligned rotor .................... 35

Figure 4.2: A 6/4 SRM, (a) defined geometry, (b) design parameters ....................... 39

Figure 4.3: Inductance $\&$ torque profile for a single-phase $8 / 8$ SRM $\ldots \ldots \ldots \ldots \ldots \ldots \ldots \ldots \ldots, 40$

Figure 4.4: SRM design, (a) the feasible triangle, (b) inductance profiles ................. 42

Figure 4.5: Example of a SRM flux linkage plot .......................................4 43

Figure 4.6: Design parameters - SRM core geometry ................................... 45

Figure 4.7: 2/2 SRM - aligned rotor, (a) core geometry, (b) equivalent circuit .............48

Figure 4.8: Simplified SRM equivalent circuit.......................................... 48

Figure 4.9: Coordinate system used to define rotor position ................................. 50

Figure 5.1: Process model used for factorial experimentation ........................... 53

Figure 5.2: Full factorial, two-level design in three dimensions .......................... 54

Figure 5.3: Fractional factorial, two-level design in three dimensions........................ 55

Figure 5.4: Geometry of the experimental 6/4 SRM.................................. 58

Figure 5.5: An Assorted Selection of the experimental 6/4 SRM Design Variants............ 59

Figure 6.1: Torque vs. rotor angle M01A - M04A ...................................... 72

Figure 6.2: Torque vs. rotor angle M05A - M08A ...................................... 73

Figure 6.3: Flux linkage vs. coil current M01A - M08A, (a) aligned, (b) unaligned.......... 74 


\section{List of Tables}

Table 1.1: Comparison of predominant machine types for electric vehicle application [17], 6

Table 3.1: Analytical estimations of energy and coenergy for the singly-excited system .. 33

Table 4.1: Design parameters - SRM core geometry.................................. 46

Table 4.2: Summary of empirical mechanical design ratios [9] ............................. 46

Table 4.3: Summary of empirical magnetic design ratios [9] ............................... 47

Table 4.4: Summary of empirical electric design ratios [9] .................................47

Table 5.1: Resolution Level of Fractional Factorial Designs .............................. 56

Table 5.2: Minimum number of simulation runs as a function of the number of factors.... 57

Table 5.3: Experimental 6/4 SRM Design Parameters ....................................... 59

Table 5.4: 6/4 SRM Design Parameters - Complete ....................................... 60

Table 6.1: Experiments performed for Taguchi's L16 design - from [27]..................63

Table 6.2: List of confusions - L16 fractional factorial design - from [27] ..................63

Table 6.3: Contributions obtained by L-16 fractional factorial design - from [27] .......... 64

Table 6.4: Application of MATLAB ANOVA on L16 design - from [27] ........................ 65

Table 6.5: Six parameter L-16 fractional factorial design matrix - starting torque ......... 66

Table 6.6: Experiments performed by application of the L16 design - starting torque ..... 67

Table 6.7: ANOVA on L16 design - starting torque ..................................... 67

Table 6.8: Design matrix - four parameter full factorial - starting torque .................. 68

Table 6.9: Results - four parameter full factorial design - starting torque ...................69

Table 6.10: ANOVA - four parameter full factorial design - starting torque ................. 69

Table 6.11: Design matrix - three parameter full factorial - starting torque ................. 70

Table 6.12: Results - three parameter full factorial design - starting torque ...............70

Table 6.13: ANOVA - three parameter full factorial design - starting torque ................. 71

Table 6.14: ANOVA - six parameter full factorial design - starting torque .................. 71

Table 6.15: Results - three parameter full factorial design - stroke torque .................. 72

Table 6.16: ANOVA - three parameter full factorial design - stroke torque ..................73

Table 6.17: Results - three parameter full factorial design - flux linkage (3A) ............. 75

Table 6.18: ANOVA - three parameter full factorial design - aligned flux linkage (3A) .... 75

Table 6.19: ANOVA - three parameter full factorial design - unaligned flux linkage (3A).. 75 
Table 6.20: Results - three parameter full factorial design - flux linkage (6A) ............. 76

Table 6.21: ANOVA - three parameter full factorial design - aligned flux linkage (6A) .... 76

Table 6.22: ANOVA - three parameter full factorial design - unaligned flux linkage (6A).. 76

Table 6.23: Summary of results - various factorial experiments - starting torque.......... 78

Table 6.24: Cumulative summary of results - starting torque, stroke torque, flux linkage 79

Table A.1: Design matrix - four parameter full factorial - starting torque .................. 85

Table A.2: ANOVA - six parameter full factorial design - starting torque .................. 86 


\section{Nomenclature}

- SRM Switched reluctance motor

- FEM Finite element methods

- FEA Finite element analysis

- DoE Design of experiments

- SRMD Switched reluctance motor drive

- BDCMD Brushless DC motor drive

- SPMMD Synchronous permanent magnet motor drive

- IMD Induction motor drive

- MMF Magnetomotive force

- VRM Variable reluctance machine

- EMF Electromotive force

- VA Volt-ampere

- RMS Root mean square 


\section{List of Symbols}

- $(g)$

- $\left(\alpha_{R}\right)$

- $\left(\alpha_{S}\right)$

- $\left(\beta_{R}\right)$

- $\left(\beta_{S}\right)$

- $\left(K_{L}\right)$

- $\left(N_{R}\right)$

- $\left(N_{S}\right)$

- $(\varepsilon)$

- $(E R)$

- $(\mathcal{F})$

- $(H)$

- $\left(\mathrm{l}_{\mathrm{p}}\right)$

- $(N I)$

- $\quad(I)$

- $(N)$

- $\left(A_{c}\right)$

- $(\phi)$

- $(\lambda)$

- (B)

- $(\mu)$

- $\left(\mu_{r}\right)$
Air gap length

Rotor pole pitch

Stator pole pitch

Rotor pole arc

Stator pole arc

Ratio of inductance overlap

Number of rotor poles

Number of stator poles

Stroke angle

Energy ratio

MMF

Magnetic-field intensity

Mean path length

Ampere-turns

Current

Coil turns

Core cross-sectional area

Magnetic-flux

Magnetic-flux linkage

Magnetic-flux density

Magnetic-permeability

Relative permeability
- $(L)$

- (i)

- $(\varphi)$

- $\left(v_{e}\right)$

- $(R)$

- $\left(v_{L}\right)$

- $\left(v_{t}\right)$

- $(t)$

- (e)

- $\left(V_{t}\right)$

- $(\mathcal{R})$

- $(\mathcal{P})$

- $\left(W_{\text {elec }}\right)$

- $\left(W_{f l d}^{\prime}\right)$

- $\left(W_{f l d}\right)$

- $\left(W_{\text {loss }}\right)$

- $\left(P_{\text {elec }}\right)$

- $\left(f_{f i d}\right)$

- $(x)$

- $(T)$

- $(\theta)$

- $(q)$
Self inductance

time-varying current

time-varying magnetic-flux

time-varying EMF

Resistance

inductor voltage

terminal voltage

time

Euler's number

Fixed terminal voltage

Magnetic reluctance

Magnetic permeance

Electrical energy

Magnetic field coenergy

Magnetic field energy

Energy losses

Electrical power .

Magnetic field force

Plunger position

Developed torque

Rotor angle

Electrical phases 


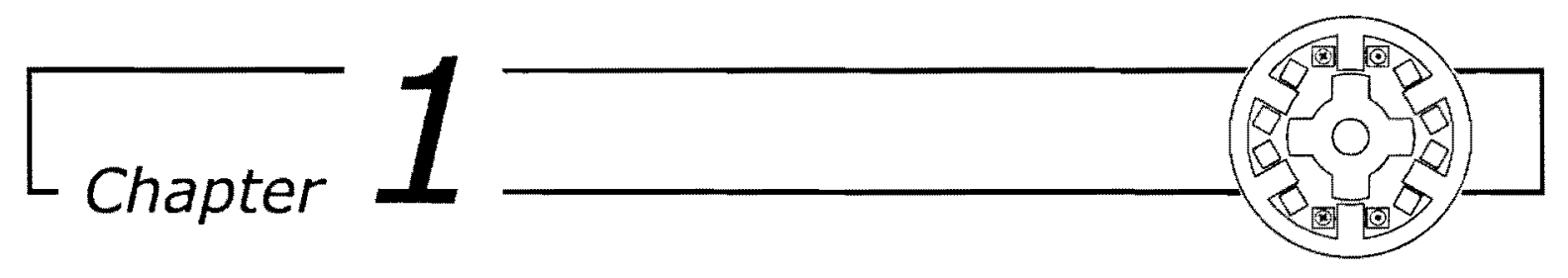

\section{Introduction}

In about 1840, when electric motors were little more than scientific toys and the electric battery only a laboratory device, an obscure Scotsman built an electric locomotive weighing some five tons. Powered only by the most primitive of batteries it carried two people for a mile and a half at speeds upwards of four miles an hour [15].

Harnessing the power of energy conversion machinery has been the pursuit of pioneering engineers and scientists for centuries; from the first purpose-built steam engine, characterized as the 'Engine to Raise Water by Fire', by Captain Thomas Savery [23]; to development of the first 'electricity-powered motor' by Michael Faraday [24]. The first American electric motor patent by Thomas Davenport [20] followed by Nikola Tesla's patent for an Induction-type Motor [21], were both instrumental in pioneering the advancement and developments of our present day electric machinery.

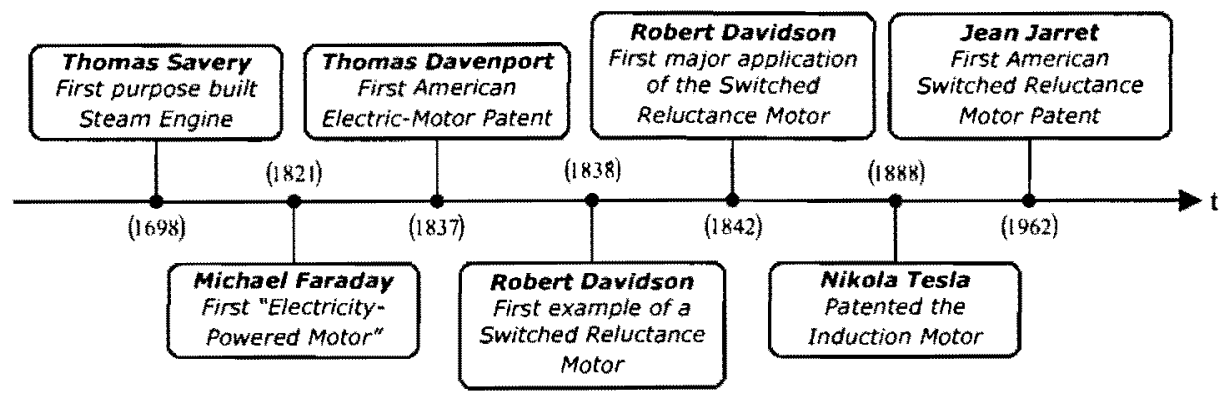

Figure 1.1: A brief history of innovation 
Conducting his development around the same time as Davenport, see Figure 1.1; Robert Davidson, a Scottish yeast manufacturer, with a far-reaching interest in science, built the first example of a Switched Reluctance Motor. Davidson was characterized as a man of high principals who refused to take out patents on several of his inventions stating "the whole of humanity should benefit from his ideas and from the power of electricity" [15]. Consequently, as a result of Davidson's philosophy, there are limited supporting documents that truly detail the breadth of his inventions.

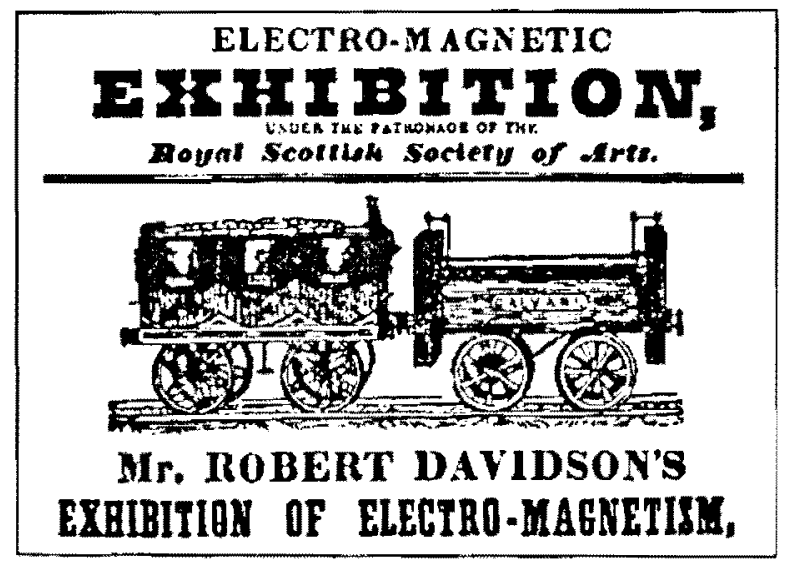

Figure 1.2: Robert Davidson's own drawing of his electric locomotive [15]

Of Davidson's most famous and perhaps his greatest achievement was the construction of a motor large enough to power an electric locomotive at a Royal Scottish Society exhibition in 1842. Arguably, Figure 1.2 is the only surviving record of this event. Davidson, albeit not fully understanding the fundamental operating principles of his machine (see, Figure 1.2), had characterized the operation as: "the destruction of magnetism" [15]. Over a century later, Davidson's motor was reborn; with the machine's fundamental principal now understood, it was appropriately named the Switched Reluctance Motor (SRM).

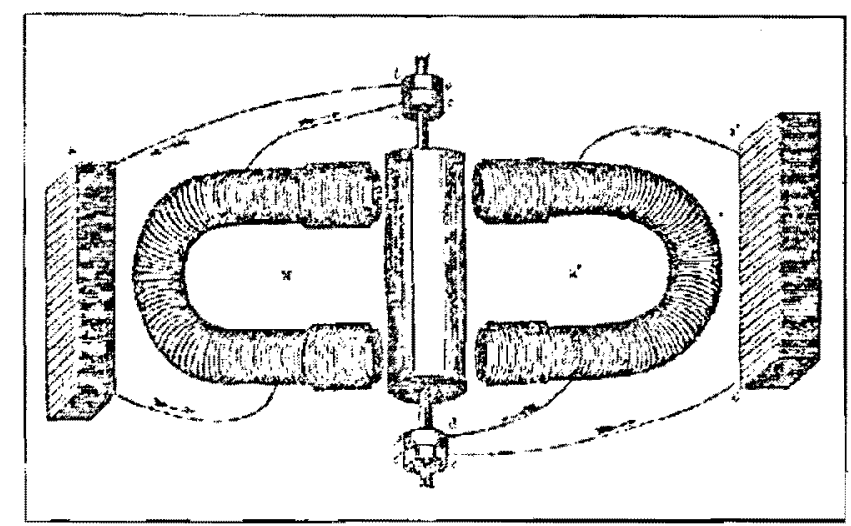

Figure 1.3: David Mackie's drawing of Davidson's motor [15] 
Due to the SRM's inherent complexity in control, it received much less attention than its more famous predecessors; it was essentially forgotten until advancements in semiconductor technology made the difficult control aspects of the SRM more manageable, which resulted in one of the first modern day SRM patents by Jean Jarret, et al. [22]. From the re-birth of the SRM in modern form, the SRM has become widely popular among academics, as evidenced by the areas of diverse research reviewed in this paper, which range from:

i) Fundamental concepts of torque production $[1-5,7,14,18]$,

ii) Application of analytical models to predict flux linkage, inductance \& torque $[1,2,11,13]$,

iii) Application of Finite Element Methods $[3,5,11,13]$,

iv) Development \& application of practical design based methodologies [6-14], and

v) Optimization of the core geometry $[5,7,14,27]$.

\subsection{Seeds of SRM Development}

A reluctance machine is one in which torque is produced by the tendency of its moveable part to move to a position where the inductance of the excited winding is maximized [14].

Vast amounts of research have been conducted on the SRM, from its conception well over $170+$ years ago to the present. Whilst, the machine construction has remained surprisingly consistent, both the fundamental understanding of the operating characteristics and the methods of design have been investigated and refined considerably. To better understand the widespread appeal of the SRM [13], one must consider the simplicity of the machine. The SRM is comprised of salient poles, both on the stator and rotor, coils are then wound around the poles of the stator and the rotor is completely free from windings or permanent magnets. The stator poles are grouped together to form phases and the phase current must be switched on and off when the rotor is at precise positions to create or maintain rotation. The magnitude and timing of the switched-phase currents directly relate to both the operating speed and the developed torque of the SRM. Furthermore, there exists no independent means of excitation; whereby, the inherent excitation of the SRM is provided solely by the voltamperes supplied by the drive - this excitation component can be considered as a fraction of the total voltamperes (equivalently, power) as applied to the coils, with the remainder dividing between the mechanical output power and the losses [14]. 
By definition, torque production in the SRM is developed by the tendency of the rotor poles to align with the magnetic axis of the excited stator poles, which coincidentally adopts a configuration of minimum magnetic-reluctance (or conversely, a configuration of maximum inductance) [1]. Nasar [16] coined the term 'Reluctance Motor simply by referencing the fundamental operating principal of the machine, which later facilitated the revival of academic interest in Davidson's motor. The following events and characteristics, as described in [13] developed during this period has made the modern SRM entirely possible:

i) The advent of high-power semiconductor devices.

ii) An understanding of the improvements to be gained in energy conversion efficiency through exploitation of magnetic saturation.

iii) The realization of energy savings made possible by variable speed drives.

iv) The advent of inexpensive microcomputers.

The SRM itself benefits greatly from its inherently simple construction; however, the performance of the machine is heavily dependent on the characteristics of the non-linear core material and the interdependency between the geometrical proportions of the various core elements, such as: pole width, pole height, rotor diameter, stack length, stator/rotor yoke width and inter-pole gap. For these factors alone, the design process of the SRM tends to be overly complicated. The methods of analysis and the design process associated with the SRM are quite dissimilar from the methods associated with the majority of classical electric machines. As a result the vast wealth of existing design experience derived from classical electric machines has little relevance in SRM design - which lends to the understanding of why the SRM is popular with academics but rarely understood in industry [14].

To analyze and predict SRM performance numerous papers have used a combination of linear and non-linear analytical modelling techniques including finite element analysis (FEA) [1-12]. Early design methodologies used to model and predict performances of the SRM were based on simple linear/non-linear magnetic theory [1]; these methods neglected the intricate saturating effects associated with the various parts of the core. It was later determined that neglecting the subtle effects of saturation would grossly misconstrue the machine's performances; or conversely, an underutilized machine would be developed [2]. As the research and design tools matured, the research shifted towards using FEA tools [3] and/or combinations of analytical/FEA to better predict the performance of the SRM $[11,13,14]$. 
For completeness, the aspects of controlling the SRM can range from the simple, which offer the lowest amount of performance, to highly complicated algorithms that offer very specific performances [13]. The copious amounts of research into the aspects of SRM control has furthered the potential of the machine well beyond the simplified version of yesteryear. As such, these pioneering achievements bring the SRM closer towards market penetration, where Robert Davidson himself had envisioned the rightful place for his simple yet effective machine. The fundamentals of SRM control, although well beyond the scope of this thesis, it is considered as future work.

\subsection{Design of Experiments}

Design of experiments is a series of tests in which purposeful changes are made to the input variables of a system or process and the effects on response variables are measured [25].

In optimization problems, when a large number of input variables are used for a given objective function the complexity of the problem is increased; which in most cases adds additional complication and tends to greatly increase the required computational time of the objective function. A method is required that can identify the significant parameters of optimization and their interactions so that the non-significant parameters can be removed from the objective function.

Design of experiments (DOE) is a method whereby systematic tests are performed on the input variables (factors) of a system or process and the effects on the outputs (responses) are measured [25]. A fundamental component of design of experiments is factorial experimentation, which investigates the effects of several different factors by varying them simultaneously instead of changing only one factor at a time $[25,26,32]$. It has been shown that parameter screening exercises involving factorial experimentation can help to identify the main parameters, and any significant interactions between parameters prior to application of an optimization algorithm [26-31].

Parameter screening has already been shown to be powerful when investigating the SRM core geometry against specific performance metrics, such as the starting torque [27]. The selection of pole width and the air gap ratio can easily be rationalized using parameter screening logic. The techniques of factorial experimentation have been applied to long standing design concepts, and the results have strongly correlated what was already known 
[26-31]. As a result, factorial experimentation has consistently proven a viable tool for the investigation and development of custom electromechanical machine variants.

\subsection{Application and Motivation}

Miller [14] has presented his interpretation regarding the current state of the SRM market. In short, because the SRM and its drive have very little market penetration as compared to induction motors and ac drives, very little infrastructure and tooling exists; which tends to limit the roles of the SRM to niche applications where the high costs associated with the development and support can be absorbed within the budget of a large project. As described, the infrastructure covers all aspects, such as; design, manufacture, sale, commissioning, maintenance and the development of the necessary control algorithms. Therefore, the current market exposure of the SRM resides predominantly within specific applications that capitalize on the characteristics of the SRM.

Some of the most prevalent SRM markets are reviewed and summarized in [13], where the SRM finds diverse application, ranging from; robust and flameproof drives for mining applications, low cost fan applications, miniaturized high speed hard disk drive applications, high powered generator for wind turbines, and the most widely publicized, application of high efficiency and high torque density SRM's for electric vehicle applications.

\begin{tabular}{lccccc}
\hline Performance Criteria & Maximum & BDCMD & SPMMD & SRMD & IMD \\
\hline Power Density & 10 & 9 & 10 & 8 & 7 \\
Overload & 10 & 7 & 7 & 8 & 9 \\
Efficiency & 10 & 9 & 10 & 8 & 7 \\
High Speed Range & 20 & 10 & 16 & 18 & 16 \\
Control & 20 & 15 & 15 & 16 & 16 \\
Noise & 10 & 8 & 8 & 6 & 8 \\
Torque Ripple & 10 & 6 & 8 & 5 & 7 \\
Size and Weight & 10 & 8 & 9 & 7 & 7 \\
Ruggedness & 20 & 14 & 14 & 17 & 16 \\
Maintenance & 10 & 8 & 8 & 9 & 9 \\
Manufacturability & 20 & 14 & 12 & 18 & 16 \\
Cost & 30 & 20 & 18 & 26 & 28 \\
\hline \multicolumn{1}{c}{ Total: } & 180 & 128 & 135 & 146 & 146 \\
\hline
\end{tabular}

Table 1.1: Comparison of predominant machine types for electric vehicle application [17] 
To gauge the relative performance criteria between the most widely used machines for electric vehicle applications; Table 1.1 is repeated from [17], which compares the Switched Reluctance Motor Drive (SRMD), against the Brushless DC Motor Drive (BDCMD), the Synchronous Permanent Magnet Motor Drive (SPMMD) and the Induction Motor Drive (IMD) against the required performance characteristic. By inspection of Table 1.1, it is quite obvious that the SRMD has the necessary performance metrics, and with proper investment into the appropriate infrastructure categories, the SRMD has the potential to become a dominant drive system in the ever increasing electric vehicle market.

\subsection{Problem Statement}

Throughout the years of research, a variety of design methods and modelling approaches have been leveraged by the SRM, as summarized by Vijayakumar el al. [13]. Academia has consistently improved linear and non-linear analytical and FEA modelling techniques to advance the prediction performance of the design methods for the SRM core geometry. While both the analytical and the FEA methods have their advantages and disadvantages, these methods merely provide a tool for analysis. Furthermore, over the years there have been countless papers which have postulated and derived empirical design ratios [5-13], which sets the relative geometries in accordance with singular design objectives; however, these often lead to a single ratio which affects a singular design objective, such as pole width to generated torque.

For example, Arumugam et al. [5], understood that there was a gap in the current research, whereby the primary core dimensions of the SRM were based loosely on the tribal knowledge passed on from the SRM's distant cousin: the stepper motor [1]. To further their understanding, a sensitivity study was performed on the various aspects of core design; namely, the effect of the ratio of pole arc (tooth width) to pole pitch on the average output torque of the SRM. It was observed, that variations in the stator pole arc had a much greater impact on the average torque, over that of the rotor pole arc. However, the mutual compounding affects between the two arcs could not be appreciated.

Costa et al. [27] made an attempt to quantify the design factors of the core geometry using DoE as applied to the starting torque of an SRM, where the significant geometrical factors and their mutual interactions were identified. Although the idea of DoE is quite old and novel [24], its use has not been applied to SRM design in order to both 
validate the existing empirical relationship, nor to test the effect of these relations on the other significant design objectives, such as (among others): average torque, torque density, power output, efficiency, aligned/unaligned flux linkage and inductance.

This thesis proposes to further the study of the experimental SRM presented in [27], whereby specific design objectives are screened in an attempt to further gain insight into the significance of the design factors, as evaluated by their contribution towards identified design objectives. Costa et al. [27] had focused on a limited set of design objectives, specifically the starting torque. The focus of this thesis is to revive the experimental SRM of [27], which listed the following design factors:

i) Outer diameter,

ii) Rotor/Stator; core (yoke) width, pole height, pole arc (width).

The aforementioned design factors are to be the focus of a parameter screening experiment using DoE to identify their mutual contribution upon the design objective. The design objectives have been extended to include:

i) Starting torque

ii) Peak static torque

iii) RMS static torque

iv) Flux linkage in the aligned position (saturated/unsaturated)

v) Flux linkage in the unaligned position (saturated/unsaturated)

\subsection{Organization of the Thesis}

This thesis is organized as follows:

In Chapter 2, a summary literature review is conducted which highlights three of the most significant papers as related to the development of the understanding SRM; the first paper covers the fundamental operating principles, such as torque production, the second covers the general foundation of machine design, the third offers a comprehensive design methodology which summarized the relevant research of the time into a fluid and coherent design synthesis.

Chapter 3 provides a summary review of the fundamentals of Magnetic Circuit analysis in which the basic properties of magnetization are discussed, the fundamental 
properties are highlighted and the necessary formulations are presented. The concepts of magnetic-flux linkage and inductance are discussed; the magnetic equivalent circuit is introduced, which is later used to develop an understanding of the associated energies and forces that are contained within a simple magnetic structure.

In Chapter 4, the useful concepts as related to the switched reluctance motor are presented. The operating principles are discussed, with a focus on key elements, such as; inspection of the magnetic-flux paths, torque production, stroke angle, inductance variation, the magnetic-flux linkage trajectory, modelling by means of the magnetic equivalent circuit, design constraints and general operating points.

In Chapter 5, a summary review of factorial experimentation is detailed and the implementation of the modelling environment is presented. The results of the proposed study are presented in Chapter 6 and the resultant discussions included.

Chapter 7 concludes the thesis, and possible future directions are discussed. 


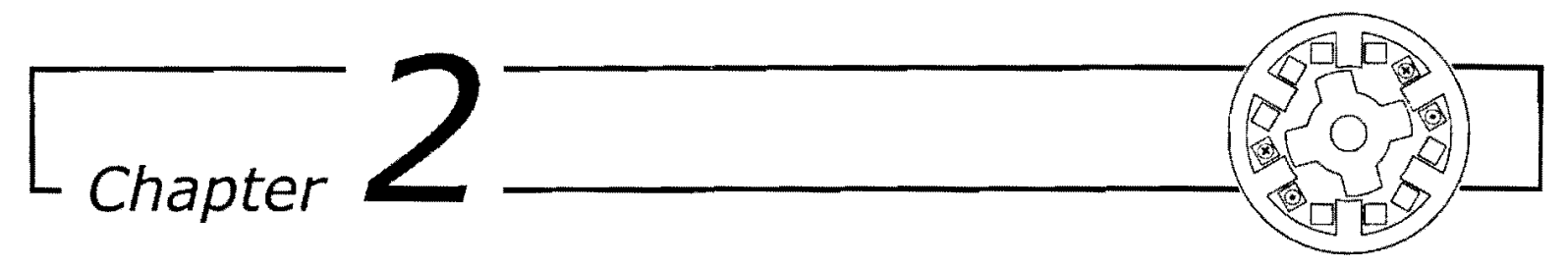

\section{Literature Review}

This section provides a brief cross section of one of the earliest and most predominant research clouds for the switched reluctance motor, as related to the fundamental understanding of torque production, methods of performance estimation, and design optimization of the core geometry.

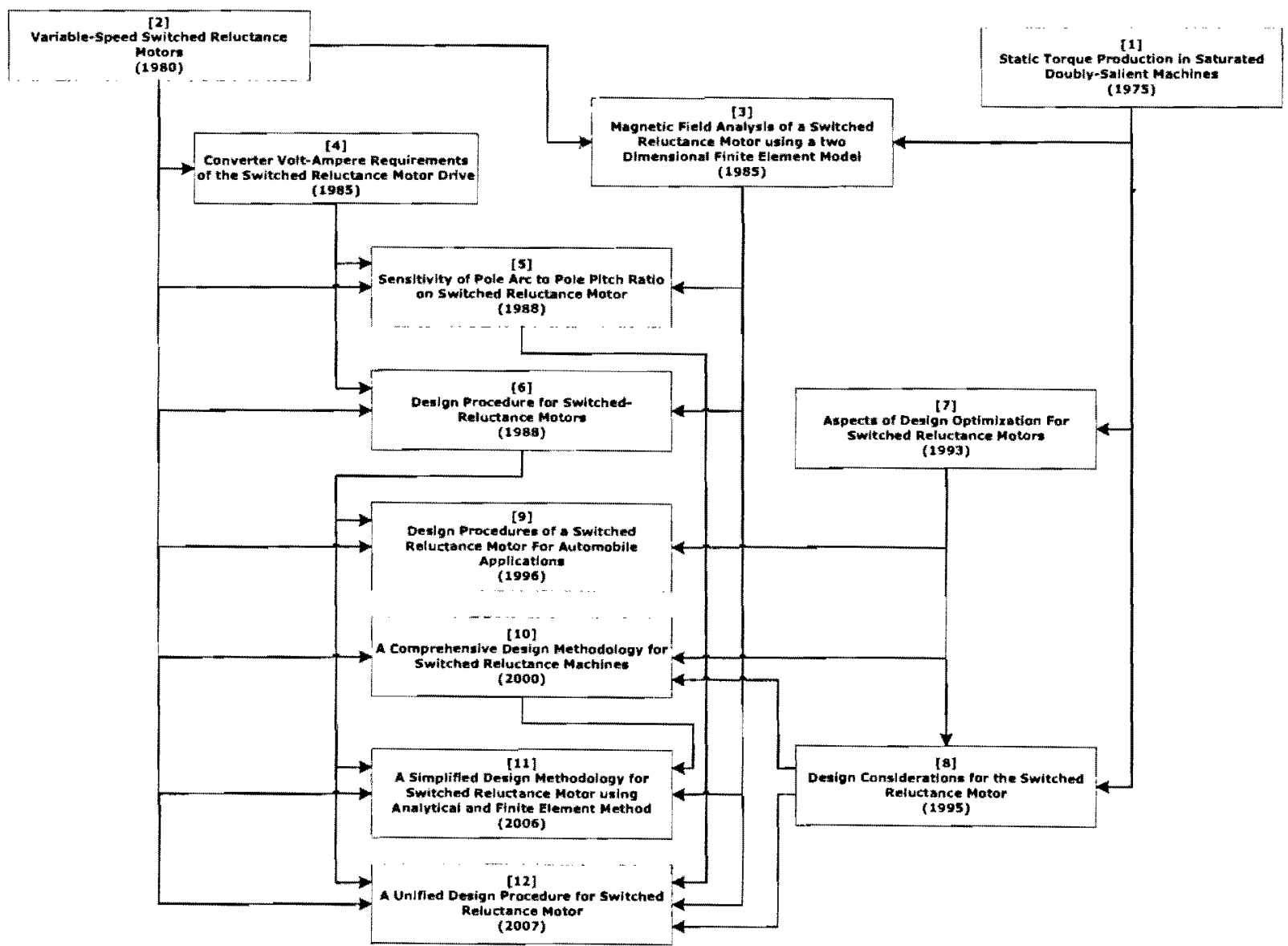

Figure 2.1: SRM focused research tree 
In the case for all rotating electromechanical machines, torque production is created by means of an electromagnetic energy conversion that commonly takes place in the air gap between the stator and the rotor. The fundamental operating principal of the SRM is solely based on the reaction of the induced magnetic-flux within the stator upon the rotor, by means of a magnetomotive force (MMF); whereby, a resultant torque is induced upon the rotor that tends to align with the magnetic axis of the stator. Unlike conventional electromechanical machines, such as; Synchronous, Induction and DC - design of the SRM's core geometry is quite complex and subtle changes in the proportions of the core can have drastic effects on the performance. This section serves as a literature review of some of the most influential papers of the past thirty years; which are specifically focused on the development, design and optimization of the core geometry of the SRM.

\subsection{Static Torque Production in Saturated Doubly-Salient Machines}

During the SRM's infancy, conceptual understanding of the fundamental operating principles of the SRM was limited. Most of the existing knowledge was leveraged from the breadth of research associated with conventional stepping motors. Harris et al. [1] were one of the first to apply a theory of principles surrounding machines of 'doubly-salient' structure; more specifically, a new theory of static torque production in stepping motors was proposed, and the main features of the problem focused on:

i) The limiting value of torque that a rotor of given volume can produce, allowing for the effects of strong magnetic saturation.

ii) The relative proportions of tooth, slot and air gap that permit this limiting value of torque to be achieved.

iii) The nature of the characteristics of torque against MMF and their theoretical prediction.

The authors are credited with pioneering an initial attempt to discover the nature of the limiting torque against the applied MMF, with proper allowance for the effects of magnetic saturation in the core. As a result, this further necessitated the development of accurate prediction methods that were primarily based on the core material and the relative proportions of the gap geometry. 
Referring to Figure 2.2(b), when the teeth of the stator and rotor are in partial overlap, a region of significant magnetic saturation is induced near the surface of the overlapped sections of the tooth; as a result of this local saturation, this presented a challenge in accurately predicting the induced torque by direct application of linear analytical methods. In early attempts at developing an analytical model for the SRM, researchers were unable to adequately account for the nonlinearities associated with the high degree of saturation that was encountered in the core of the SRM. In an attempt to find the optimum air gap geometry, early methods assumed the core material was of infinite permeability; a linear function was presented which leveraged the linear gap permeance functions $\left(\mathcal{P}_{1}, \mathcal{P}_{2}\right)$ per tooth pitch in the aligned and unaligned position respectively. Coincidently, it was stated that maximizing $\left(f_{1}\right)$ would yield optimum gap geometry, where:

$$
f_{1}=\frac{\mathcal{P}_{1}-\mathcal{P}_{2}}{\left(\frac{a}{g}\right)^{2}}
$$

Through rigorous empirical testing it was widely acknowledged that in order to obtain the greatest static torque from a single-phase SRM (with number of stator and rotor teeth equal), the optimum ratio between the tooth width and the tooth pitch $(\beta / \alpha)$ was around $(0.4)$, whilst the optimum ratio of tooth pitch to air gap $(\alpha / g)$ was quite high $(>50)$; implying the necessity for the smallest possible air gap. However, when $\left(f_{1}\right)$ is' maximized the resultant $(\alpha / g)$ was found to be only $(8)$ and since the empirical optimum is $(>50)$, this implied the need for more rigorous treatment of the saturation effects on the permeance functions.

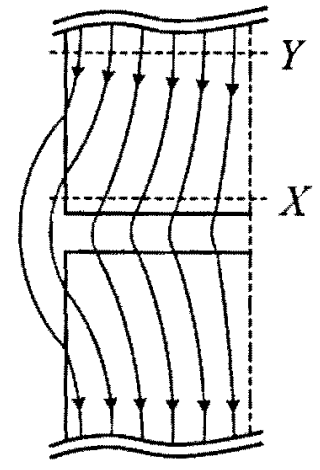

(a)

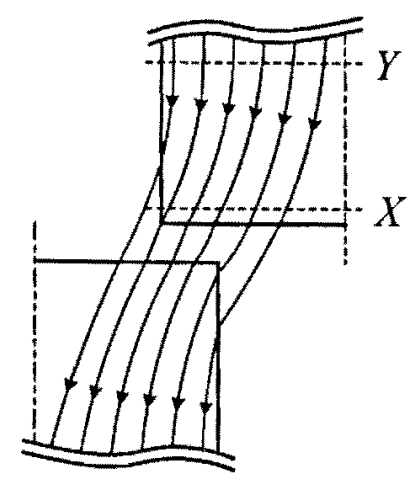

(b)

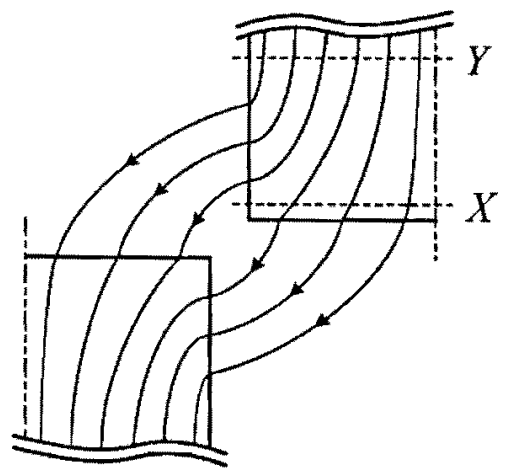

(c)

Figure 2.2: Tooth flux distribution; (a) aligned, (b) partial, (c) unaligned 
Consider the pattern of fluxes for the aligned and unaligned rotor positions of Figure 2.2 (a) and (c) respectively; in both cases one can see that the accumulation of flux in the root of each tooth is from the sides, as-well as the head. Coincidently, for any level of excitation (MMF) the general level of saturation at ' $X X$ ' close to the head versus the level of saturation within the tooth at ' $Y$ ' must be greater; therefore, the tooth surface remains relatively unsaturated near the gap as compared to the tooth body. It was then proposed that the total MMF supplied to the circuit, is divided in the system, between; i) the linear air gap component $\left(\mathcal{F}_{g}\right)$, and ii) the non-linear saturation component $\left(\mathcal{F}_{s}\right)$, such as:

$$
\mathcal{F}=\mathcal{F}_{g}+\mathcal{F}_{s}
$$

Furthermore, it was postulated that the non-linear permeance is a unique function of air gap flux, and is the same for both rotor positions. This model was later shown to conform to a higher degree of accuracy against the measured data from an experimental machine that is strongly saturated.

While pursuing this investigation, it was observed that the shape of the static torque profile vs. rotor position was insensitive to air gap variations when the machine was strongly saturated; coincidently, the developed torque quickly decreases as the air gap increases for the unsaturated case. It was observed that as long as the ratio of tooth pitch to air gap $(\alpha / g)$ is sufficiently high, the limiting torque is not very sensitive to this ratio. Furthermore, the limiting torque was found to be theoretically independent of the number of teeth on the stator and rotor, with the major dominance marked by the magneticpermeance of the air gap in the unaligned and aligned rotor positions. However, the average torque was still found to be dependent on the number of teeth.

Additionally, it was also observed that the effect of tooth taper, in a direction that increases the width at the root, tends to increase the developed torque at high levels of MMF. This statement is of particular interest, as it implies a subtle design improvement could potentially improve the peak output capability of the SRM at extended excitations; such as required for automotive applications.

Harris et al. [1], had effectively proven that a magnetic equivalent circuit model for the SRM could be obtained, simply by applying nonlinear core reluctance, and a linear gap reluctance; which could then be used to reasonably predict the net average output torque as a function of the core geometry and applied MMF, involving only the aligned and 
unaligned rotor positions. This effort highlighted the possibility of making use of the linear data for air gap performance, to predict the operating behaviour when the SRM is operated in saturation.

\subsection{Variable-Speed Switched Reluctance Motors}

Lawrenson et al. [2], recognized that the current research surrounding the stepping motor, could easily be leveraged and applied to development and understanding of the variable reluctance machine (VRM) - which is later termed switched reluctance motor, because mechanical rotation can only be achieved by 'switching' the magnetic-flux between adjacent phases. Credited with laying down the general foundation for the practical design and understanding of the fundamental operation of the SRM; a few of the most notable design formulations are summarized here.

As described; "torque is developed by the tendency for the magnetic circuit to adopt a configuration of minimum reluctance, i.e. for the rotor to move into line with the stator poles and to maximize the inductance of the excited coils" [2]. Considering that torque is only generated during periods of varying inductance; and ideally, the inductance was found to vary solely with rotor position. The necessity of ensuring adequate overlap of the position dependent inductance between phases was considered with the utmost importance. Moreover, the appropriate amount of overlap was said to help minimize the associated torque ripple, whilst ensuring adequate and fully reversible starting toque from any rotor position. For the practical SRM, the rotor pole arc $\left(\beta_{R}\right)$ is normally larger than the stator pole arc $\left(\beta_{S}\right)$; for this special case $\left(\beta_{R}>\beta_{S}\right)$, the ratio of inductance overlap $\left(K_{L}\right)$ was defined as:

$$
K_{L}=1-\frac{2 \pi}{q N_{R} \beta_{S}}
$$

where the inductance overlap is predominantly determined by the number of electrical phases $(q)$, number of stator poles $\left(N_{S}\right)$ and the width of the stator pole $\left(\beta_{S}\right)$ respectively. Furthermore, the number of cycles of inductance variation per revolution is proportional to the number of rotor pole pairs, and the 'length' of the cycle is equal to the rotor pole pitch $\left(\alpha_{R}\right)$. 
Furthering the discussion, a general foundation for the practical design of the SRM was described; which notably resulted in establishing the criterion for the feasible triangle. Later coined the "Lawrenson Criterion", it serves as a set of design principles that correlates the interdependency between the respective stator and rotor tooth widths of the SRM. The following inequalities are presented, that relate the stator and rotor pole arc $\left(\beta_{R}, \beta_{S}\right)$, the number of rotor poles $\left(N_{R}\right)$ and the stroke angle $(\varepsilon)$ in order to guarantee a physically realizable machine, as defined by:

$$
\begin{gathered}
\beta_{R}>\beta_{S}, \\
\beta_{s}>\varepsilon, \\
\frac{2 \pi}{N_{R}}>\left(\beta_{R}+\beta_{S}\right) ;
\end{gathered}
$$

where, Eq. 2.4 guarantees the maximum aligned inductance, Eq. 2.5 achieves adequate starting torque from all rotor positions, and Eq. 2.6 avoids overlap between poles in unaligned conditions.

Additionally, the preferred number of stator $\left(N_{s}\right)$ and rotor $\left(N_{r}\right)$ poles, for fully reversible machines were defined; which are as follows:

- 3-phase motors: $\left(N_{s}=6, N_{r}=4\right)$

- 4-phase motors: $\left(N_{s}=8, N_{r}=6\right)$

- 5-phase motors: $\left(N_{s}=10, N_{r}=4\right)$

Where the abovementioned machine types are bounded by the need for:

i) Zero mutual inductance between phases,

ii) Minimization of the permeance associated with the unaligned inductance,

iii) The requirement for self-starting in either direction from any rotor position, and

iv) The desirability of minimizing the switching frequency.

Similar to power factor for an induction machine, a measure of the 'quality' of performance for the SRM was required. The term 'energy ratio' (ER) was used to relate the useful energy flow as a proportion of the total energy flow; as defined below:

$$
E R=\frac{W_{e l c}-W_{f l d}}{W_{e l c}}
$$


where, $\left(w_{e l c}\right)$ represents the electrical input energy supplied to the terminals of the machine and $\left(W_{f t d}\right)$ represents the magnetic energy stored in the field, which is returned to the supply after every individual alignment cycle. The energy ratio is useful when sizing the volt-ampere (VA) rating of the drive, because it must be designed to handle the circulating energies.

The effects of core saturation have been discussed and were said to be comprised of two main components: i) bulk saturation, and ii) local saturation. Bulk saturation is considered across the entire structure, as the MMF excitation is increased; while, local saturation occurs mainly at the pole tips during periods of partial overlap. The local saturation has the effect of reducing the effective pole arcs (or equivalently, a reduction in the air gap area), which can greatly affect the predicted performance of the machine.

The work presented by Lawrenson et al. [2], highlighted crucial concepts of design. Still to this day numerous publications cite the work presented here most notably, the feasible triangle and the ratio of inductance overlap.

\subsection{Design Considerations for the Switched Reluctance Motor}

Radun [8] recognized that there exists a vast amount of research which specifically deals with the intricate aspects of SRM design and modelling. The most noteworthy approaches vary from detailed FEA modelling to complex non-linear magnetic circuit models. Since the majority of these methods are highly complex and/or strictly numerical in nature, it became quite difficult to gain adequate insight into the specifics surrounding the design and sizing of the SRM. A method of design was presented which reveals an analytical model that includes the effect of iron saturation, whereby the only required input parameters are the core geometry and material properties. The analytical model predictions were evaluated against a pre-existing experimental SRM, which yielded surprisingly accurate results. Additionally, it was shown that there exists a fundamental maximum torque density associated with the SRM, an estimate of this density was obtained as a result of the development of the proposed analytical model.

The paper begins with a discussion about the appropriate choice of air gap, which

gives reference for two machines of exact construction, whereby only the air gaps differ. 
From the area contained in the mutual flux trajectory plots Figure 2.3, it was stated that the saturated machine has the potential to convert more energy, as compared its non-saturated cousin (as it is understood that the area contained within each trajectory, is the energy that is converted to torque)

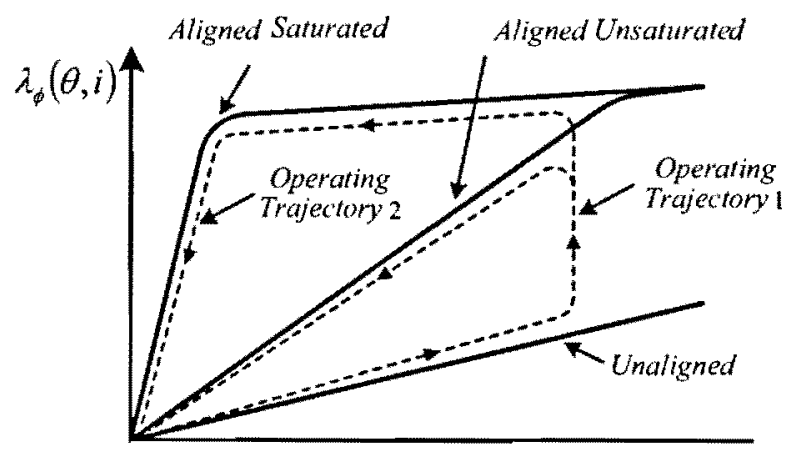

Figure 2.3: Saturating vs. non-saturating flux linkage trajectories

The example above demonstrates that increased saturation greatly improves SRM performance and as such, saturation cannot be ignored in the design and analysis of the machine. As a result, it demonstrated that linear design methods cannot adequately account for the core saturation. It was concluded that the linear analysis method should not be used as the 'sole' basis of design.

Through his analysis, Radun [8] demonstrated that the characteristic flux linkage curves of the SRM, directly reports the maximum energy that can be converted into useful torque. A set of analytical equations were proposed, which estimate the flux linkage at both the aligned and unaligned rotor positions. Furthermore, it was stated, that at the unaligned rotor position, for any practical winding current there is no chance of bulk magnetic saturation; henceforth, only the unaligned inductance need be considered.

A simple 2-D model was constructed, which accurately represented the dimensions of the experimental SRM. By inspection of the FEA for the unaligned rotor position, it was discussed how the flux tends to crowd the facing pole surfaces, such that the tangential field along the iron (the pole surface) was taken to be zero. Therefore, the only field that required solution was the tangential field that directly links the adjacent corners of the stator pole tip to the rotor pole tip. A complex equation to estimate the unaligned inductance was defined. It calculated the flux linkage from the applied MMF divided by the 
distance between the stator and rotor pole tips. The unaligned inductance was identified from this flux linkage expression and is defined as:

$$
L_{u}=8 \mu_{o} N^{2} l_{s t k} \cdot l \sum_{n o d d} \frac{\frac{\sin \left(\frac{n \pi l_{1}}{l}\right)}{l_{L}}+\frac{\sin \left(\frac{n \pi l_{2}}{l}\right)}{l_{2}}}{(n \pi)^{2} \tanh \left(\frac{n \pi h}{l}\right)}
$$

The aforementioned expression, does not include the effects from; i) magnetic saturation of the core, and ii) the contribution to the inductance from the end turns. Furthermore, it was stated: for the unaligned position, the tangential flux that leaves the stator tooth tends to crowd in the corner of the tooth; which effectively produces a dominant high reluctance region that the flux must pass through(while the remainder of the pole volume remained un-saturated). Because of this region of high reluctance, the flux linkage curves at higher excitation tend to mimic a slightly saturated behaviour. It was anticipated that a certain inaccuracy would occur as a result of the local pole saturation and the end winding contribution: a value of $52 \mathrm{uH}$ was calculated from the analytical equation, and 64 uH from 2-D FEA. This $23 \%$ error in the analytical method was assumed a result of the local saturation of the poles and the leakage flux into the rotor yoke; the effects of which are not accounted for in Eq. 2.8.

To estimate the flux linkage as the poles begin to overlap, a different analytical model was described. The proposed model assumes two separate magnetic paths, which are driven by the same MMF; in each of these branches there is an air gap in series with saturating iron. Two flux paths are defined; i) the main flux path, which directly contributes to torque production; and ii) the fringing flux path(s), which indirectly increases the unaligned inductance. This variable fringing flux closely models the physical situation, which accounts for a portion the fringing flux from the stator that links to the rotor yoke and the remaining flux that links to the rotor pole. The fringing flux linking to the yoke dominates at small pole overlap, while the fringing flux linking to the rotor pole dominates at large pole overlaps. Therefore, the total flux linked by the phase is the sum of the main flux and the fringing flux. The simplified analytical equation which estimates the flux linkage as a function of rotor position and current is repeated below:

$$
\lambda_{f}(\theta, I)=\lambda_{o} \frac{p w-R_{g} \theta}{g_{f}}\left[N I\left(\frac{1}{2}+\frac{g_{f}}{l_{s}}\right)+\frac{l_{m} B_{s a t}}{2 \mu}-\sqrt{\frac{l_{f}^{2} B_{s a t}^{2}}{4 \mu^{2}}+N I \frac{B_{s a t}}{\mu}\left(l_{s}-\frac{l_{f}}{2}\right)+\frac{(N I)^{2}}{4}}\right] ;
$$

see [8] for nomenclature description. 
Although the developed analytical equations are complex, they predict the SRM's performance curves related to flux linkage, MMF and the static torque with reasonable accuracy. The presented model is well suited for rapidly screening preliminary machine designs and evaluating performances of prototype machines - especially in the area of core sizing. Using the presented analytical equation, it is possible to evaluate unaligned inductance as a function of rotor height. It has been determined that the rotor pole height does not need to be greater than 1.5 to 2.0 times greater than the slot height. Radun [8] successfully developed two separate analytical equations that calculate the flux linkage as a function of rotor position and material saturation. Since these functions are completely described, the static torque can be calculated by first integrating the flux linkage with respect to current to obtain the coenergy and then differentiating the coenergy with respect to rotor position to obtain the torque. The results of the analytical estimations were evaluated against an actual SRM, whereby the resultant predictions were within acceptable engineering tolerances.

\subsection{Summary}

Three of the most influential papers of the identified research tree have been presented: The first covered the fundamental principles behind torque production; the second laid the general foundation for practical understanding of the operating characteristics of the SRM and the third; reported a comprehensive design methodology based on an analytical model which included the necessary effects of magnetic-saturation. 


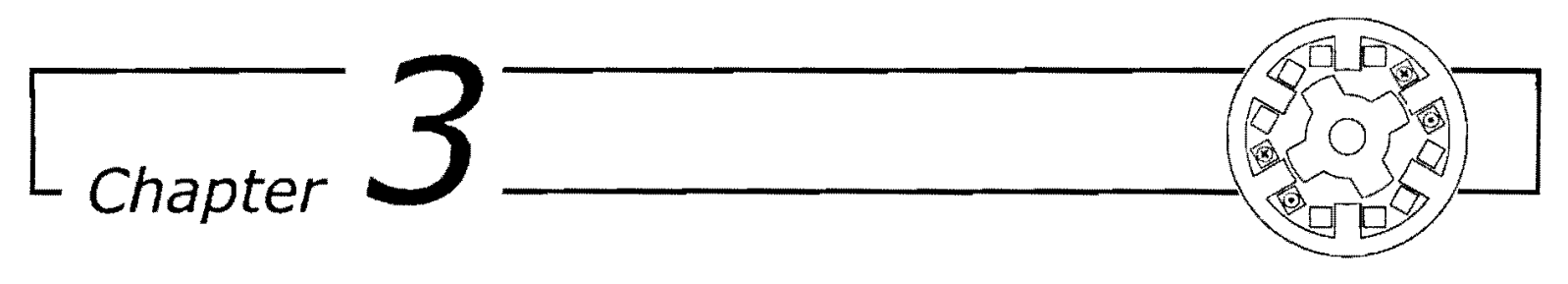

\section{Magnetic Circuit Theory}

This section develops the fundamental equations surrounding the generalized magnetic theory which serves to familiarize the reader with the concepts presented throughout the remainder of this thesis. The discussion begins by considering the standard bar magnet. Since it is impossible to isolate magnetic poles [19], a single bar magnet is comprised of a North and a South pole. By properties inherent to the magnetic-material, a persistent magnetization exists from within and this remnant magnetization produces a proportional flux. A flux, more formally known as a magnetic-flux $(\phi)$ is generated from within the material. This continuous magnetic-flux follows the contour as depicted in Figure 3.1, and emanates from North pole, and converges to the South pole of the magnet.

Properties of magnetic-flux

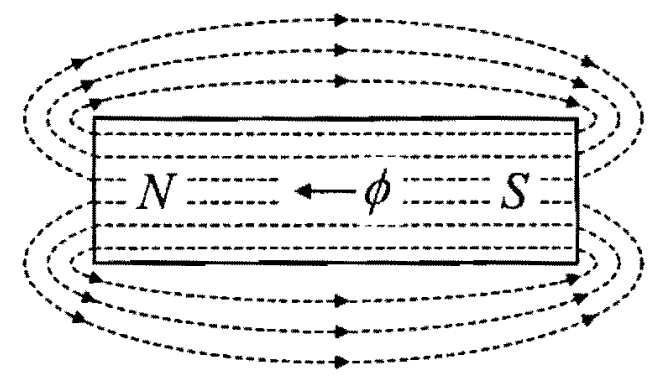

Figure 3.1: A simple bar magnet and the associated magnetic field i) Flux forms closed loops, and tend to be as short as possible

ii) Flux lines never cross one another

iii) Parallel flux lines try to separate as much as possible

iv) Flux does not 'flow', or does it?

The magnetic-flux produces a magnetic-field which surrounds the bar magnet. The density of the magnetic-flux is proportionally related to the intensity of the magnetic-field through the magnetic-permeability of the medium. Although there is a divide in the scientific community as to whether or not magnetic-flux flows [19], as considered here, the 
magnetic-flux flows as previously described. Each flux line is considered closed, as it has no beginning, nor end. The magnetic-flux is considered to be polarized; therefore, the resultant magnetic-field is also polarized. As a result of the magnetic polarization, physically the magnet is either:

i) attracted by opposite polarity magnetic-fields, or

ii) repelled by like polarity magnetic-fields.

\subsection{Fundamental Relations}

By properties of Maxwell's equations, it can be shown that the magnetic-field quantities can be determined solely from the instantaneous values of the source currents $[18,19]$. Eq. 3.1 shows that the $\operatorname{MMF}(\mathcal{F})$, which is the source of the magnetic-field, is proportional to the scalar product of the magnetic-field intensity $(H)$ and the mean path length $\left(l_{p}\right)$ of the medium under consideration. Or equivalently, the MMF is equivalent to the product of the applied ampere-turns (NI); where $(I)$ is the current through the coil, and $(N)$ is the number of turns contained within the coil, as defined by:

$$
\mathcal{F}=H l_{p}=N I
$$

Application of Eq. 3.1 can be applied to the magnetic circuit shown in Figure 3.2. If a coil of wire is wound around a high-permeability steel core, the high-permeability of the steel core tends to confine the magnetic-flux within - similar to the way currents are confined to the conductors of an electrical circuit. The total MMF $(\mathcal{F})$ acting upon the circuit is determined by the ampere-turn product $(N I)$ applied. The resultant magnetic-field intensity $(H)$ within the core is then directly related to the mean path length of the core material $\left(l_{c}\right)$; or equivalently the magnetic circuit length.

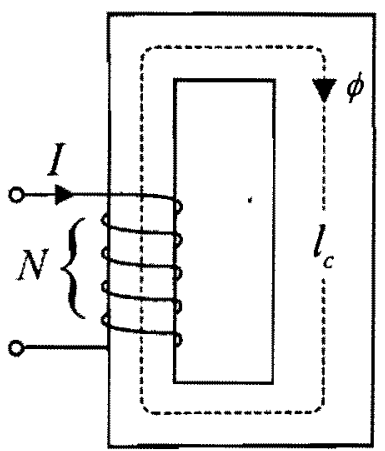

Figure 3.2: A singly excited magnetic circuit 
The resultant magnetic-flux induced in the core of the circuit can be considered uniform across the cross-sectional area $\left(A_{c}\right)$ of the core; such that, the relationship between the magnetic-flux $(\phi)$ and the magnetic-flux density $(B)$ is linear, as shown by:

$$
\phi=B A_{c}
$$

Furthermore, the magnetic-permeability $(\mu)$ relates the magnetic-flux density and the magnetic-field intensity; Eq. 3.3 defines their relationship when the magnetic-permeability of the material is assumed linear, where:

$$
B=\mu H .
$$

Typically, when the material is assumed linear, the permeability can be considered to be comprised of two independent terms, the permeability of free space $\left(\mu_{o}=4 \pi \times 10^{-7}\right)$, multiplied by the relative permeability $\left(\mu_{r}\right)$ of the material (both of which are assumed constant and/or linear), where:

$$
\mu=\mu_{o} \mu_{r}
$$

Moreover, the permeability of certain materials can be highly nonlinear, and the magneticflux density tends to be a multivalued function of the magnetic-field intensity $[18,19]$. For most practical applications where the core material is non-saturating the magneticpermeability of the material can be assumed linear. Furthermore, even highly nonlinear materials can exhibit linear characteristics well below their point of saturation.

\subsection{Magnetic-Flux Linkage and Inductance}

Referring to Figure 3.2; as current is applied to the coil of ' $N$ ' turns, a proportional magnetic-flux is developed within the high-permeability steel core. The quantity of magnetic-flux that passes though each turn of the coil is then defined as the magnetic-flux linkage $(\lambda)$ - in general: The flux linkage of a coil is equal to the surface integral of the normal component of the magnetic-flux density integrated over any surface spanned by that coil [19], it follows:

$$
\lambda=N \phi
$$


If we consider the core material is of constant magnetic-permeability, the flux linkage varies proportionally to the current (i) producing it; whereby, $(\lambda \propto i)$. The inductance $(L)$ of a coil is the term used to describe the ratio of the flux linkage to the current producing it $[18,19]$, where:

$$
L=\frac{\lambda}{i}
$$

is defined as the 'self-inductance' of the coil, since the flux linkage is produced by the coil itself. If more than one coil is coupled to the same core, the resulting 'mutual-inductance' between the coils must be considered. Moreover, not only do the coils need to be coupled to the same magnetic core, the core must be configured such that, the magnetic-flux paths from the neighbouring coils effectively ' $/ i n k^{\prime}$ each-other. For a more comprehensive treatment of mutual inductance, the reader is referred to [18].

To further develop the concept of inductance, let us consider when a time-varying current $(i)$ is applied to the ideal coil of Figure 3.3(a); a proportional time-varying magneticflux $(\varphi)$ is induced within the high permeability steel core. As this time-varying magneticflux links the coil of ' $N$ ' turns, an electromotive force (EMF) is developed across the coil. This induced EMF is analogous to an impressed voltage, and is defined as such $\left(v_{e}\right)$.

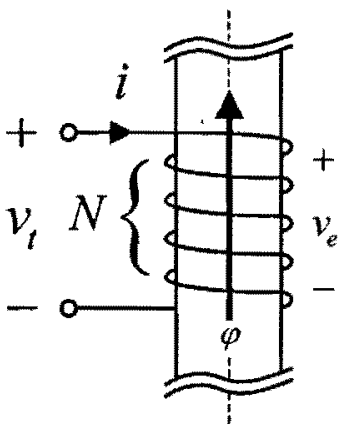

(a)

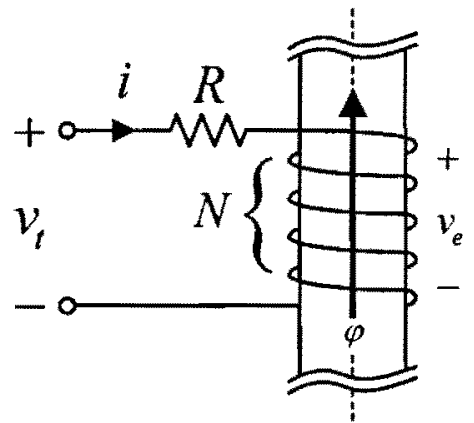

(b)

Figure 3.3: Polarity of induced EMF, (a) ideal coil, (b) practical coil

Figure 3.3(a) defines the polarity of the induced EMF is such that the EMF tends to establish a current in the coil that produces a magnetic-flux that opposes any change in the original magnetic-flux [18]. Therefore, the EMF is simply an induced voltage that appears across the coil which strictly opposes any change in current as time-varying current is applied to the coil; as defined by Eq. 3.7. For completeness; as the magnetic-flux through 
the coil approaches a constant value, the EMF induced across the coil approaches zero which effectively reduces the coil to nothing more than a plece of wire; current limiting is then determined solely by the electrical-resistance $(R)$ of the wire. Likewise, with an increase in inductance, there exists a proportionately larger opposition to time-rate changing current within the coil.

$$
v_{e}=N \frac{d \varphi}{d t}=\frac{d \lambda}{d t}
$$

Assuming a constant inductance, we can then combine Eq. 3.6 with Eq. 3.7; which results in the familiar inductor volt-second equation. If the resistance of the coil is neglected, the EMF induced across the coil equals the voltage applied to the inductor $\left(v_{2}\right)$, where:

$$
v_{L}=v_{e}=L \frac{d i}{d t}
$$

the EMF induced across the coil is directly related to the magnitude of the inductance and the time-derivative of the current through the coil. For the case of a time-varying inductance; Eq. 3.8 must be written as:

$$
v_{L}=v_{e}=L \frac{d i}{d t}+i \frac{d L}{d t}
$$

Consider the practical coil of Figure 3.3(b); the resistance of the coil has been lumped together into a single resistive element, and the EMF associated with the coil is as before; the system must balance the applied terminal voltage $\left(v_{t}\right)$, where:

$$
v_{t}=R i+\frac{d \lambda}{d t}
$$

or equivalently in terms of the coil inductance:

$$
v_{t}=R i+L \frac{d i}{d t}
$$

For the case of a fixed terminal voltage $\left(V_{t}\right)$; the time-rate $(t)$ changing current $(i)$ into the coil must follow:

$$
i=\frac{V_{r}}{R}\left(1-e^{-t /(L ; H)}\right)
$$


Moreover, as the time-rate change in current approaches zero, the EMF induced across the coil approaches zero; therefore, the coil current is then limited solely by the coil resistance, leaving the terminal voltage proportional to:

$$
V_{t}=R I
$$

In summary, for a given circuit, the inductance is constant and the EMF induced upon the coil is strictly as a result of the time-varying flux linkage through the coil. This induced EMF tends to limit the current through the coil and the magnitude of the inductance can be considered to merely multiply the magnitude of the EMF term.

\subsection{Magnetic Equivalent Circuit}

Similar to electrical resistance, the magnetic reluctance $(\mathcal{R})$ is the property of the material which resists magnetic-flux. If all the magnetic-flux is confined to a path of constant cross-sectional area, the reluctance reduces to the physical geometry of the magnetic circuit and is simply the ratio of path length $\left(l_{p}\right)$ over cross-sectional area of the path $\left(A_{p}\right)$ divided by the magnetic permeance $(\mu)$ of the material, where:

$$
\mathcal{R}=\frac{l_{p}}{\mu A_{p}}
$$

it follows that the reciprocal of reluctance is magnetic permeance $(\mathcal{P})$ :

$$
\mathcal{P}=\frac{1}{\mathcal{R}}
$$

Consider the following magnetic circuit shown in Figure 3.4(a); here we see that the system is composed of a single air gap connected in series with a high-permeability steel core, with a single coil (Coil1). Although ferromagnetic materials are nonlinear, a relative permeability is sometimes assumed, which tends to 'linearize' the material; with this assumption a representative electrical equivalent circuit can be constructed, as detailed in Figure $3.4(b)$. The air gap is represented by a single magnetic reluctance $\left(\mathcal{R}_{g}\right)$, whilst the core itself is represented by a single reluctance $\left(\mathcal{R}_{c}\right)$. Strictly speaking, if the air gap length 
becomes excessively large, the flux tends to leak out the sides of the air gap, therefore the analogy of the magnetic circuit is no longer applicable.

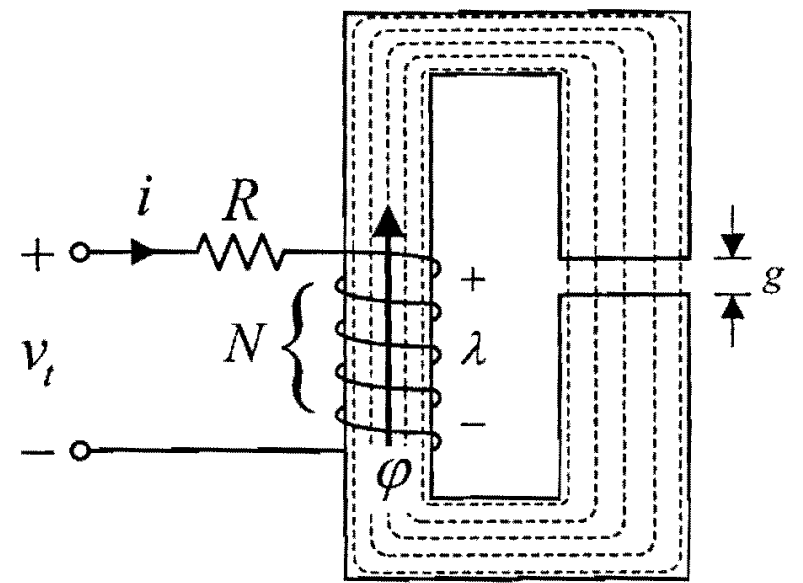

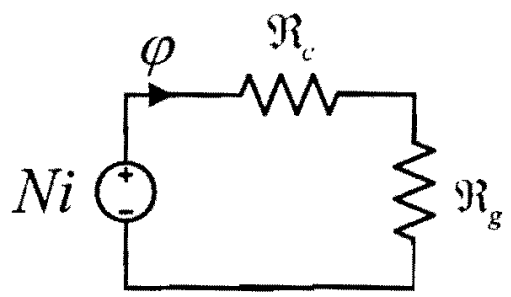

(b)

(a)

Figure 3.4: The singly-excited (a) magnetic circuit, (b) equivalent circuit

By analogy of the magnetic equivalent of Ohm's Law: the MMF $(\mathcal{F})$ is equal to the impressed electrical voltage, the reluctance $(\mathcal{R})$ is equal to the electrical resistance and, the magnetic-flux $(\varphi)$ is the equivalent to the electrical current; where:

$$
\mathcal{F}=\varphi \mathcal{R}
$$

Combining Eq. 3.1, Eq. 3.5 and Eq. 3.16, we may write:

$$
\lambda=N \varphi=\frac{N^{2} i}{\left(\mathcal{R}_{g}+\mathcal{R}_{c}\right)} .
$$

Coincidentally, by inspection of Eq. 3.17, it can also be shown (assuming constant permeability) that the inductance of the coil is related to the number of turns over the total reluctance of the path in-which the magnetic-flux must traverse, where:

$$
L=N^{2} \frac{1}{\left(\mathcal{R}_{g}+\mathcal{R}_{c}\right)} .
$$




\subsection{Energy and Forces of Magnetism}

When the principles of Energy are discussed, the true definition is something along the lines of: "Energy is the capacity of a system to perform work" and by work, a displacement or an increase in 'stored' energy is expected [18]. By the principal of the conservation of energy; 'energy is neither created nor destroyed', we then must assume that energy is simply transformed from one form or another - this concept is further developed when the energy balance of an electromechanical system is considered.

Consider the magnetic circuit of Figure 3.4(a), where a single coil element is wound around a high permeability steel core, with a fixed air gap length $(g)$. The coil contains the lumped winding resistance and an ideal winding of $(N)$ turns. Figure $3.4(\mathrm{~b})$ details the magnetic-equivalent circuit, where the polarity of the impressed time-varying MMF (Ni) defines the direction of the magnetic-flux $(\varphi)$; and the core reluctance $\left(\mathcal{R}_{c}\right)$ has been separated from the air gap reluctance $\left(\mathcal{R}_{g}\right)$.

Considering that the circuit is an electromechanical energy conversion device, one may question how such a conversion take place. The basic energy conversion process involves a reaction between the electric and mechanical subsystems through a coupling magnetic field [18]. As electrical energy is provided to the system, the energy is divided into various lumped terms. Eq. 3.19 defines the energy balance equation for a conventional electromechanical energy conversion device:

$$
W_{\text {elec }}=W_{f l d}+W_{\text {mech }}+W_{\text {loss }}
$$

where, the input electrical energy $\left(W_{\text {elec }}\right)$ must equal the sum of the energy stored in the magnetic field $\left(W_{f l d}\right)$, the mechanical output energy $\left(W_{\text {mech }}\right)$, and the associated energy losses ( $W_{\text {loss}}$ ). It should be understood that this lost energy is usually associated with 'wasted' energy; or simply, energy that is converted to heat.

Consider the input terminals of the device, where the applied electrical power $\left(P_{e t e c}\right)$ is solely determined by the product of the applied terminal voltage $\left(v_{t}\right)$ and the resultant coil current ( $b$ ); as defined by:

$$
P_{\text {elec }}=i v_{t}
$$


For the coil with finite resistance; the EMF, together with the voltage drop across the coil resistance must balance the applied terminal voltage:

$$
v_{t}=R i+v_{e}=R i+\frac{d \lambda}{d t}
$$

Consider the ideal coil, where the resistance is negligible, the applied electrical power is then simply, the product of the coil EMF and the coil current:

$$
P_{e l e c}=i v_{e}=i \frac{d \lambda}{d t}
$$

Moreover, the time-rate change of energy into the system can be found by integrating the electrical input power, where:

$$
d W_{\text {elec }}=\int_{t_{0}}^{t_{1}} P_{e l e c} d t=\int_{\lambda_{0}}^{\lambda_{1}} i d \lambda
$$

For the lossless system, the coil losses and the core losses are neglected. As a result, part of the electrical energy is transformed by the system into a mechanical force and the remaining energy is stored in the magnetic-field, it follows:

$$
d W_{\text {elec }}=d W_{f l d}+d W_{\text {mech }}
$$

where the change in electrical energy ( $d W_{\text {elec }}$ ) equals the summation of the change in stored magnetic $\left(d W_{f l d}\right)$ energy, and the change in mechanical energy ( $d W_{\text {mech }}$ ). Recall the definition of 'work'; where motion must occur in the direction of the applied force, where:

$$
d W_{\text {mech }}=f_{f l d} d g
$$

Considering the magnetic structure of Figure $3.4(a)$ is fixed, the magnetic field creates a force of attraction between the overlapping faces of the air gap, and this force albeit is of significance, there is no displacement of the air gap $(d g)$; therefore, no work is performed. The energy balance equation for this ideal system is simply, the changing electrical energy is equal to the change in the magnetic field energy, where:

$$
d W_{e l e c}=d W_{f l d}
$$


If the length of the air gap $(g)$ were constructed to vary along the direction of decreasing gap length, and if the reluctance of the core $\left(\mathcal{R}_{c}\right)$ were neglected; the reluctance of the magnetic circuit would be variable, and a strict function of air gap length $(g)$, where:

$$
\mathcal{R}(g)=\frac{g}{\mu_{0} A_{g}} .
$$

We then can consider the self inductance of the magnetic circuit, strictly as a function of the geometry of the circuit; in this case the length of the air gap:

$$
L(g)=N^{2} \frac{1}{\mathcal{R}(g)}
$$

A force is developed by the magnetic field, which acts in such a way as to minimize the length of the air gap $(g)$. This magnetic field force $\left(f_{f l d}\right)$ is directly related to the reluctance of the air gap, as defined by:

$$
f_{f l d}=(N i)^{2} \frac{\partial}{\partial x}\left(\frac{1}{\mathcal{R}(g)}\right)=\frac{(N i)^{2} \mu_{0} A_{g}}{g^{2}}
$$

By inspection of Eq. 3.29, the induced force on the magnetic core that tends to pull in the direction of decreasing reluctance. For the ideal case, this force tends towards infinity as the gap length tends towards zero. However, for the practical system the core reluctance tends to limit the maximum force.

To perform useful work, a physical displacement must occur as the force is applied. For the lossless electromechanical system of Figure 3.5(a), which illustrates a single coil magnetic circuit with a moveable plunger; the plunger is restricted to movement along the ' $x$ ' direction only. We consider the case when the resistance of the coil has been neglected and the permeability of the material is considered linear. As current $(I)$ is applied to the coil, the magnetic-flux linkage $(\lambda)$ impresses upon the coil and is proportional to the number of coil turns $(N)$, a magnetic-flux $(\phi)$ is then introduced within the magnetic structure. Considering the fundamental properties of magnetic-flux (that the magnetic-flux lines are always parallel, never cross, and magnetic-flux lines maximize their mutual spacing from one another, while ensuring their respective loops are as short as possible), it can be assumed that the magnetic-flux exists perpendicular to the pole face and travels the shortest distance to the overlapping pole face - whereby non-overlapping faces neither emanate, or receive any flux. 


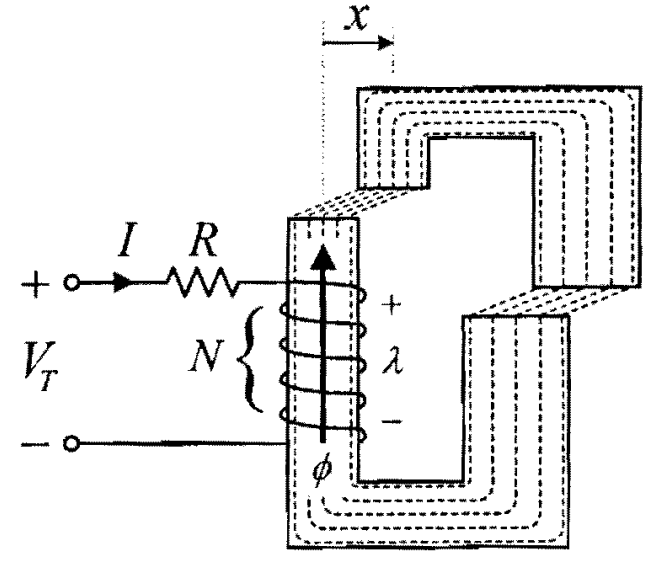

(a)

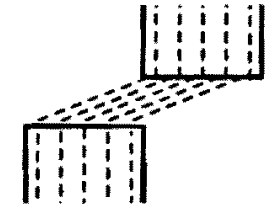

(b)

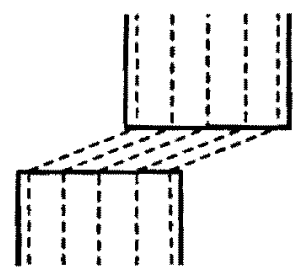

(c)

Figure 3.5: The (a) magnetic circuit, (b) offset gap1 tooth, (c) offset gap2 tooth

Based on this we consider the detailed view of Figure 3.5(b); where the air gap1 is just at the position of minimum overlap. It is this position where the reluctance of air gap 1 $\left(\mathcal{R}_{g 1}\right)$ approaches maximum and the total reluctance $\left(\mathcal{R}_{T}\right)$ is described by the mean path lengths of the core sections $\left(l_{1}, l_{2}\right)$ and the stretched mean path length of the combined air gap $\left(g_{1}, g_{2}\right)$. For a fixed value of $\operatorname{MMF}(\mathcal{F})$, the induced magnetic-flux at this position is at a minimum.

Using Engineering approximations, it can be considered that if the plunger were moved further out of alignment with the stator, the reluctance tends towards infinity and the magnetic-flux tends towards zero. One may question the impact of air gap2 on the circuit. It should be noted that when air gap1 is fully unaligned, air gap2 still overlaps the stator, but since the air gap reluctances are in series, air gap1 dominates the circuit and gap2' impact is inconsequential.

Typically, a force is induced on the plunger by the magnetic-flux which tends to pull the plunger inward, effectively minimizing the air gap. Since the plunger can only be translated in the $(x)$ direction, the force acting on the plunger experiences a component along $(x)$. Therefore the induced force tends to slide the plunger into alignment with the stator.

For the lossless case, we may rewrite the energy balance equation where the Electrical power input is equal to the time rate change of the stored energy in the field, plus the mechanical power output, of the form in Eq. 3.30 as disused in [18]. Considering the 
lossless electromechanical system, defined by Eq. 3.30; the time rate change of the stored energy in the magnetic field is equal to the electrical power input minus the mechanical power output:

$$
\frac{d W_{\text {mech }}}{d t}=\frac{d W_{\text {elec }}}{d t}+\frac{d W_{\text {fld }}}{d t}
$$

When a coil of wire is wound around a steel core, the inductance of the circuit is usually the primary variable of interest. Considering the ideal case where the core material is linear, or non-saturating, the inductance of the magnetic circuit is predominantly determined by the core geometry and its permeability [18]. As the plunger moves along $(x)$ the air gap area of the overlapping pole faces varies with $(x)$; therefore the air gap reluctance also varies with $(x)$, as defined by:

$$
\mathcal{R}_{g}(x)=\frac{g}{\mu_{0} A_{g}(x)}
$$

Consider the self inductance of the magnetic circuit, which is strictly a function of the geometry of the circuit (in this case the linear displacement of the plunger), as shown in Figure 3.5(a), where:

$$
L(x)=N^{2} \frac{1}{\mathcal{R}(x)}
$$

Rewriting Eq. 3.30:

$$
\frac{d W_{f l d}}{d t}=\frac{d W_{e l e c}}{d t}-\frac{d W_{\text {mech }}}{d t}=v_{e} i-f_{f l d} \frac{d x}{d t}
$$

Since the lossless magnetic storage system is considered, the value of the magnetic field energy $\left(W_{f l d}\right)$ varies linearly with the coil flux linkage and the plunger position. By combining Eq. 3.7 and Eq. 3.33, we can define the time-rate change of field energy ( $d w_{f l d}$ ) in explicit terms of flux linkage $(\lambda)$ and plunger position $(x)$ :

$$
d W_{f l d}(\lambda, x)=i \dot{d} \lambda-f_{f l d} d x
$$

Recall the general form of the partial differential equation with two state variables, of the form:

$$
d W_{f l d}(\lambda, x)=\left.\frac{\partial W_{f l d}}{\partial \lambda}\right|_{x} d \lambda+\left.\frac{\partial W_{f l d}}{\partial x}\right|_{\lambda} d x
$$


matching terms in Eq. 3.34 with Eq. 3.35, we may write the current in terms of:

$$
i=\left.\frac{\partial W_{f l d}(\lambda, x)}{\partial \lambda}\right|_{x}
$$

and the magnetic field force as:

$$
f_{f l d}=-\left.\frac{\partial W_{f l d}(\lambda, x)}{\partial x}\right|_{\lambda}
$$

where, the magnitude of the generated force is strictly a function of the magnetic-field energy as a function of the linear displacement of the plunger (while the flux linkage is held constant). Consider the field energy from Eq. 3.23, we may write:

$$
W_{f l d}(\lambda, x)=\int_{0}^{\lambda} i\left(\lambda^{\prime}, x\right) d \lambda^{\prime}=\int_{0}^{\lambda} \frac{\lambda^{\prime}}{L(x)} d \lambda^{\prime}=\frac{1}{2} \frac{\lambda^{2}}{L(x)}
$$

Since flux linkage itself has an indirect relationship to the system input variables, namely voltage and current, we look to define the output force as a function of the input current. The coenergy $\left(W_{f l d}^{\prime}\right)$ is a function of $(i)$ and $(x)$; and for the singly excited system, the energy and coenergy must satisfy the following relationship:

$$
W_{f l d}(\lambda, x)+W_{f l d}^{\prime}(i, x)=i \lambda
$$

To better understand the relationship between energy and coenergy, we consider the $(i-\lambda)$ curve of Figure 3.6, which must satisfy Eq. 3.39.

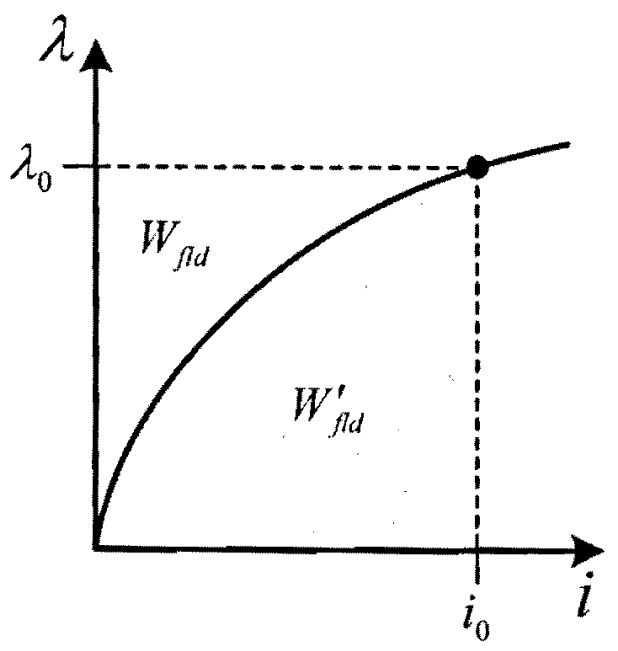

Figure 3.6: Relationship between energy and coenergy in a singly excited system 
The coenergy can be used to determine the magnetic force, strictly as a function of coil current and plunger position. Following a similar derivation the relationship between energy and coenergy is summarized in Table 3.1.

\begin{tabular}{ccc}
\hline \multicolumn{2}{c}{ Magnetic Field Energy } & Magnetic Field Coenergy \\
\hline$d W_{f l d}(\lambda, x)=i d \lambda-f_{f l d} d x$ & $(3.31)$ & $d W_{f l d}^{\prime}(i, x)=\lambda d i+f_{f l d} d x$ \\
$W_{f l d}(\lambda, x)=\frac{1}{2} \frac{\lambda^{2}}{L(x)}$ & $(3.32)$ & $W_{f l d}^{\prime}(i, x)=\frac{1}{2} L(x) i^{2}$ \\
$i=\left.\frac{\partial W_{f l d}(\lambda, x)}{\partial \lambda}\right|_{x}$ & $(3.34)$ & $\lambda=\left.\frac{\partial W_{f l d}^{\prime}(i, x)}{\partial i}\right|_{x}$ \\
$f_{f l d}=-\left.\frac{\partial W_{f l d}(\lambda, x)}{\partial x}\right|_{\lambda}$ & $(3.35)$ & $f_{f l d}=\left.\frac{\partial W_{f l d}^{\prime}(i, x)}{\partial x}\right|_{i}$
\end{tabular}

Table 3.1: Analytical estimations of energy and coenergy for the singly-excited system

\subsection{Summary}

This section introduced the fundamental concepts of Ohm's law as applied to magnetic circuits; the fundamental principles of magnetic-flux, flux linkage, inductance, force, energy and coenergy have been discussed. The concepts were presented, mainly to assist with furthering the understanding of the physical operation of the SRM, which follows in Chapter 4. 


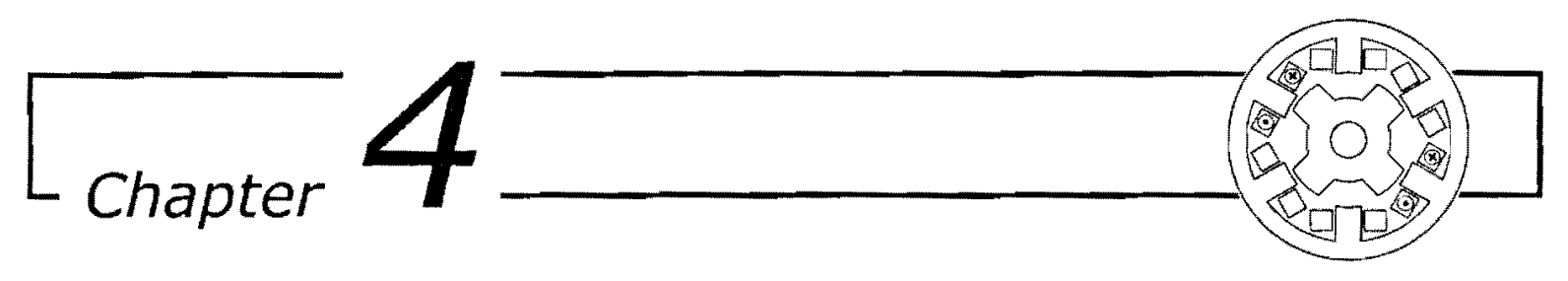

\section{The Switched Reluctance Motor: A Case Study}

The switched reluctance motor turns many of the tenets of classical electric machines technology upside down. This possibly explains why it is popular with academics but rare in the factory [13].

In Chapter 3 the fundamentals of magnetic theory were reviewed, the properties of magnetic-flux, flux linkage and concepts of energy and torque were discussed. The material presented here is to provide the reader with a general level of understanding of the operation, design and fundamental characteristics of the SRM.

In conventional motors, the poles of the machine do not necessarily contribute towards the torque production; their purpose is simply to minimize the air gap between the rotor and stator, while reserving enough space for the windings [7] - moreover, the exacting shape of the poles are of even less significance. Conversely when considering the elements of torque production in SRM, the geometry of the poles on both the rotor and stator are arguably the most important factor when designing the SRM. Furthermore, the magnetic properties of the iron, the number of phases and the number of poles per phase all have a non-linear effect of the SRM's performance. These effects along with the sizing of the machine envelope and internal dimensions make the machine design an insight intensive effort.

Being the simplest of electrical machines the Switched Reluctance Motor (SRM) usually consists of a stator with excitation windings and a Ferromagnetic rotor with saliency [18]. Due to their relatively simple construction SRM's offer high power density and efficiency, with excellent fault tolerance at a fraction of the cost of comparable electrical 
machines [13]. Although not perfect, the SRM has less power density as compared to machines that utilize permanent magnets on their rotors, however machines of this type may not have the thermal overloading performance as compared to the SRM; this is mainly because they risk demagnetization at high levels of excitation. Moreover, the SRM's simple rotor structure allows for the development of machines for very high speed applications [10].

\subsection{Theory of Operation}

Definition: Torque is developed by the tendency for the magnetic circuit to adopt a configuration of minimum reluctance, i.e. for the rotor to move into line with the stator poles and to maximise the inductance of the excited coils [2].

To illustrate the basic operation of the switched reluctance motor, we consider the simplest type of configuration; the single-phase 2/2 SRM, as detailed in Figure 4.1. This single-phase 2/2 SRM is comprised of a single pair of salient poles, on both the stator and the rotor - where $\left(N_{S}=2\right)$ and $\left(N_{R}=2\right)$. For this simplified configuration, the stator and rotor poles pairs are placed diametrically opposite from one-another and each stator pole carries a coil. The coils can be connected in either series or parallel configuration depending on the application. Furthermore, each coil is wound in such a way, that the polarity of the induced magnetic-flux from each coil is the same when current is applied to the coils.

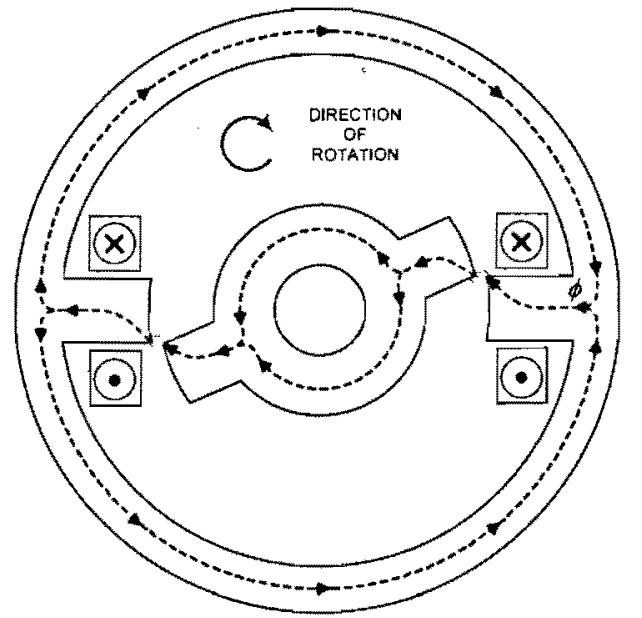

(a)

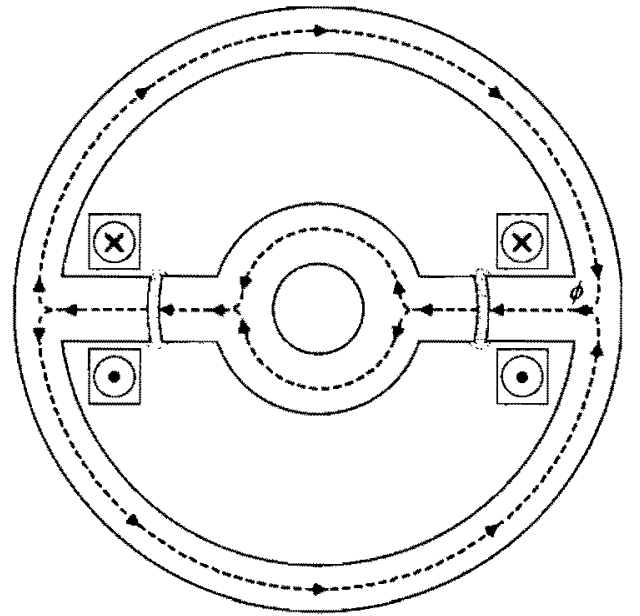

(b)

Figure 4.1: Single-phase 2/2 SRM, (a) unaligned rotor, (b) aligned rotor

By inspection of Figure 4.1(a), we consider that when current is applied to the stator coils the resultant MMF impresses upon the core producing an induced magnetic-flux within the 
core. As this magnetic-flux leaves the stator pole tip, it concentrates at the edges of the pole before it crosses the air gap. As the magnetic-flux crosses the air gap it effectively 'links' with the rotor pole tips, which induces a torque upon the rotor. This induced torque acts upon the rotor, which tends to align the poles of the rotor with the stator poles and thus effectively maximizes the stator flux linkage - or coincidentally, minimizing the reluctance of the air gap. Moreover, when the reluctance is minimized the inductance is maximized.

At the fully aligned position (see, Figure 4.1(b)), the system reluctance has been minimized, which represents a stable minimum. Consequently, in the fully aligned position the developed torque is zero. Furthermore, it can be observed that the induced torque on the rotor is independent on the direction of the current in the coil, which is considered as an advantage, because only unidirectional currents are required to achieve bidirectional operation, unlike most other machines.

\subsubsection{Torque Production}

To better understand the mechanisms of the magnetically induced torque we consider when the rotor and the stator poles are on the edge of overlap, as shown in Figure 4.1(a). To summarize what Jarvis [15], so eloquently described; as the rotor pole approaches the edge of the stator pole face, two physical forces are exerted on the rotor. The first is a tangential component, which contributes towards the turning moment, or more formally the torque; the second, is a radial force, which acts in a direction to collapse the rotor upon the stator. As the tangential force draws the rotor into alignment, the maximum developed torque occurs at about the mid-way point of overlap between the stator and rotor poles. Moreover, as the rotor approaches alignment, this torque tends towards zero. Simultaneously, as the rotor approaches alignment the radial force increases drastically, eventually reaching maximum at alignment. As literature suggests [10,13-15], the radial force can be several times greater than the maximum tangential force. This radial force causes high unbalanced stress loads on the bearings, lends to case deformation and is the prime contributor to unwanted noise and vibrations.

Following the discussions in Chapter 3 , the induced torque upon the rotor is a function of coil current and rotor position. Recall Eq. 3.43 which relates the torque to the 
partial derivative of the coenergy $\left(W_{f t d}^{\prime}\right)$ with respect to plunger position $(x)$, we may rewrite in terms of rotor angle $(\theta)$, where:

$$
T(i, \theta)=\left.\frac{\partial W_{f l d}^{\prime}(i, \theta)}{\partial \theta}\right|_{i}
$$

similarly from Eq. 3.41, the coenergy as a function of coil current and rotor position can be determined from:

$$
W_{f l d}^{\prime}(i, \theta)=\frac{1}{2} L(\theta) i^{2}
$$

Combining Eq. 4.1 and Eq. 4.2, results in an equation for the induced torque, where Eq. 4.3 defines the developed torque $(T)$ as a function of coil current and rotor position:

$$
T(i, \theta)=\frac{i^{2}}{2} \frac{d L(\theta)}{d \theta}
$$

Recall Eq. 3.32 which defines the position dependant inductance as a function of the position dependant reluctance, we may rewrite in terms of rotor position:

$$
L(\theta)=N^{2} \frac{1}{\mathcal{R}(\theta)}
$$

combining Eq. 4.3 with Eq. 4.4, the torque can be determined from the position dependant reluctance, or equivalently the position dependant permeance, where:

$$
T(i, \theta)=\frac{(N i)^{2}}{2} \frac{d}{d \theta}\left(\frac{1}{\mathcal{R}(\theta)}\right)=\frac{(N i)^{2}}{2} \frac{d \mathcal{P}(\theta)}{d \theta}
$$

Conversely, Eq. 4.3 and Eq. 4.5 predict the ideal torque and are only valid if the following assumptions have been made:

i) The permeability of the core is negligible, or linear,

ii) Leakage fields are neglected, and,

iii) Air gap fringing is neglected.

After application of the above assumptions, the SRM model has effectively been linearized. For this ideal case, the coil inductance is strictly a function of rotor position, which varies linearly with respect to rotor position and the induced torque is constant during the periods of changing inductance. 
With appropriate estimations for the core permeance, Eq. 4.4 is useful for predicting the maximum inductance in the fully aligned position. However, as the rotor rotates and the overlap of the poles decreases, the fringing fields begin to dominate, which Eq. 4.4 does not account for. Furthermore, Eq. 4.4 can be adapted to include the higher order affects (such as leakage, core saturation and fringing), but in doing so, the analytical equations become much more complex [1-3,8]. Whereby, a different estimation method may be required, such as 2-D FEA, or a combination thereof.

\subsubsection{Stroke Angle and Pole Number}

With such a wide range of operating characteristics, numerous varieties of SRM's can be constructed and are classified into one of three main categories. The construction can be either:

i) Single-phase,

ii) Multiple-phase, or

iii) Multiple-phase, with pole repetitions.

Typically a conventional single-phase SRM cannot start itself from any rotor position, and usually sophisticated mechanisms are introduced to achieve a self-starting, singlephase design [13]. For applications where self-starting is not required (for example, in industrial fan applications), the single-phase SRM's offer a cost effective alternative. Other applications, such as a series hybrid electric vehicle, may require a reversible self-starting SRM $[9,13,17]$. To facilitate the necessary conditions for a self-starting SRM, we must consider the stroke angle $(\varepsilon)$. By definition, the stroke angle defines the angle by which the rotor is rotated through after each successive alignment with the stator poles of neighbouring phases, written as:

$$
\varepsilon=\frac{\alpha_{R}}{q}
$$

where, the stroke angle is defined as a function of the rotor pole pitch $\left(\alpha_{R}\right)$, over the number of phases ( $q$ ) of the machine. For completeness, the rotor pole pitch $\left(\alpha_{R}\right)$, is defined by:

$$
\alpha_{R}=\frac{2 \pi}{N_{R}}=\frac{360^{\circ}}{N_{R}}
$$


similarly, the stator pole pitch $\left(\alpha_{s}\right)$, as defined by:

$$
\alpha_{S}=\frac{2 \pi}{N_{S}}=\frac{360^{\circ}}{N_{S}}
$$

Consider the 6/4 three-phase SRM of Figure 4.2(a), whereby the following geometries have been defined. Here we can see that the rotor displaces approximately 30 degrees as the individual phases are energized. For the rotor to complete one rotation, it follows, that each phase must be 'fired' twice. Therefore is takes $\left(360^{\circ} / \varepsilon=12\right) 12$-steps per successive rotation.

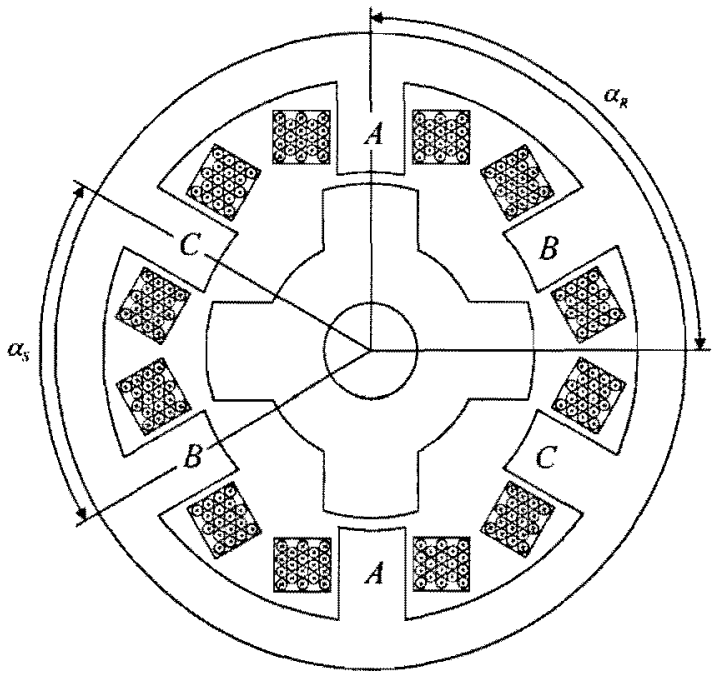

\section{Design Parameters}

(a)

Figure 4.2: A 6/4 SRM, (a) defined geometry, (b) design parameters

Following a detailed discussion by Anwar et al. [10], a few key points are summarized: It was observed that doubling the number of poles per phase has shown marked improvement to the performance of the experimental SRM. For a machine with the same active volume and copper loss, the optimized pole width can be approximately $70 \%$ that of the single-repetition machine - which effectively produces approximately $40 \%$ more thermally limited torque. Furthermore, when considering the higher pole repetition machines, the flux paths are shorter, which effectively reduces the core losses and the absorption of MMF in the stator yoke (recall that if the pole width is decreased, the stator yoke can also be proportionally decreased).

In summary as an additional level of design complexity, the careful consideration of the number of poles on both the stator and rotor must be balanced. Having a higher 
number of rotor poles lends towards a smaller stroke angle, which effectively reduces the torque ripple; however, this is achieved at the cost of a reduced saliency ratio (ratio between minimum and maximum inductances). The reduction of the saliency ratio tends to decrease the torque output, while increasing the required converter volt-amperes. Consequently, increasing the number of phases reduces the stroke angle, and therefore tends to reduce the torque ripple, with a smaller penalty in saliency ratio - however, with an increase in phases, a proportional increase in switching frequency results, which tends to reduce the overall efficiency of the system.

\subsubsection{Inductance Variation}

As the torque at any point is proportional to the slope of the inductance, it follows that, to increase torque, the permeance corresponding to $L_{\min }$ should be made as small as possible [2].

From previous sections, development linear theory had defined that torque is only developed during periods of 'changing' inductance. This inductance is considered to vary only when the 'relative overlap' between the stator and rotor poles is increasing, or conversely decreasing. Once there is complete overlap between the poles, the relative change in inductance tends towards zero; in this state first-order approximations.imply that zero torque is induced on the rotor. However, there are higher-order interactions, which are mainly caused by the 'fringing' fields, continue pull the rotor into PERFECT alignment.

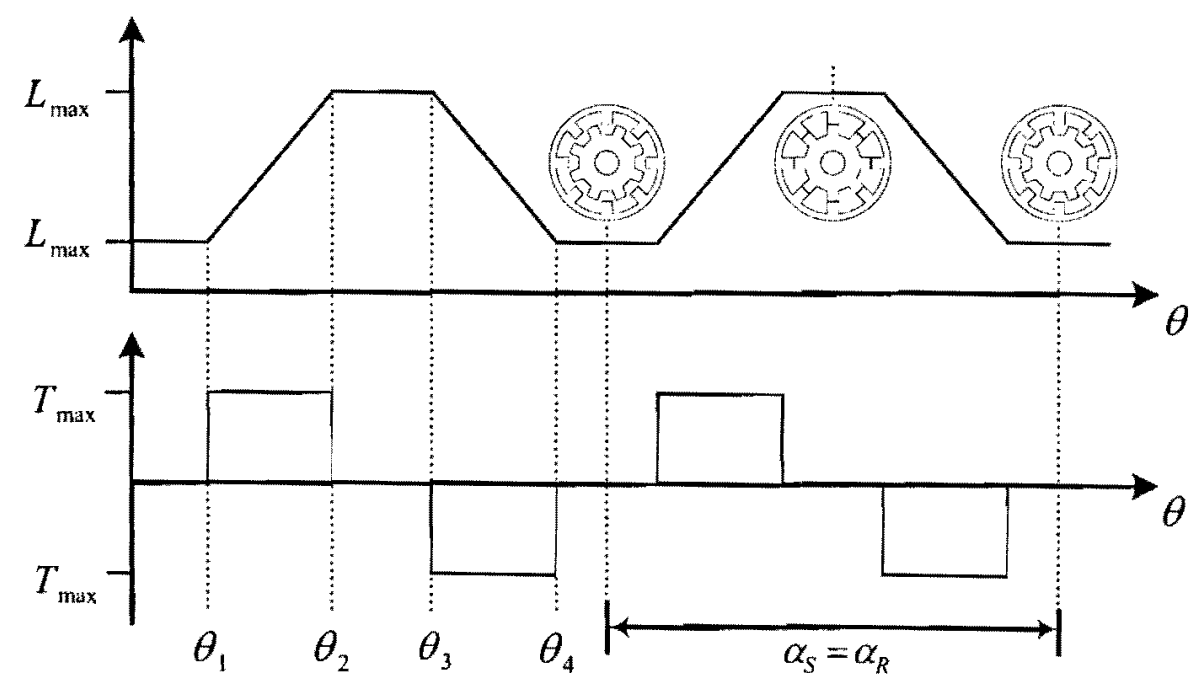

Figure 4.3: Inductance \& torque profile for a single-phase 8/8 SRM 
By inspection of Figure 4.3, the inductance has been shown to vary linearly with rotor position. Consequently, in the practical machine, a certain amount of magnetic-flux fringing is encountered, which tends to influence the effectiveness of the overlapping area of the poles. It can be expected that certain amount of 'rounding' occurs in the actual inductance profile - furthermore, the SRM is capable of producing bi-directional torque, as detailed. The following operating regions are described [2]:

i) Region 1: at $\left(\theta_{1}\right)$ the 'leading' edges of rotor poles meet the edges of stator poles and the inductance starts a linear increase with rotation, continuing until the poles are fully overlapped at $\left(\theta_{2}\right)$, when the inductance reaches its maximum value $\left(L_{\max }\right)$.

ii) Region 2: from $\left(\theta_{2}\right)$ to $\left(\theta_{3}\right)$ the inductance remains constant at $\left(L_{\text {max }}\right)$, through the region of complete overlap. This region is generally known as the 'dead zone', as no significant torque is produced.

iii) Region 3: from $\left(\theta_{3}\right)$ to $\left(\theta_{4}\right)$ the inductance decreases linearly' to the minimum value, $\left(L_{\min }\right)$.

iv) Region 4: from $\left(\theta_{4}\right)$ onward, the stator and rotor poles are not overlapped and the inductance remains constant at $\left(L_{\min }\right)$.

As previously mentioned, it is necessary to ensure that there is adequate overlap of the position dependent inductance between phases. The appropriate amount of overlap was said to help minimize the associated torque ripple, whilst ensuring adequate and fully reversible starting toque from any rotor position [2]. For the practical SRM, the rotor pole width $\left(\beta_{R}\right)$ is normally larger than the stator pole width $\left(\beta_{S}\right)$. For this special case $\left(\beta_{R}>\beta_{S}\right)$, the ratio of inductance overlap $\left(K_{L}\right)$ was defined as:

$$
K_{L}=1-\frac{2 \pi}{q N_{R} \beta_{S}}
$$

When the rotor is aligned with the stator, the coil inductance is said to be maximum. Since the developed torque is strictly determined by the saliency-ratio of the machine, the designer can choose to maximize the aligned inductance, or conversely, minimize the unaligned inductance. Careful consideration must be applied, when increasing the magnitude of aligned inductance, since an increase in inductance, proportionally increases the time required to move current in and out of the coils. From Figure 4.3 , it is shown that if current remains in the coil at the onset of region 3 , a negative torque is induced upon the rotor, which effectively decreases the average motoring torque. 


\subsubsection{The Feasible Triangle}

The design goal of SRM is to guarantee generation of a unidirectional torque throughout the required stroke angle. The feasible triangle [2] is used to describe the relation between the stator pole arc $\left(\beta_{S}\right)$ and the rotor pole arc $\left(\beta_{R}\right)$.

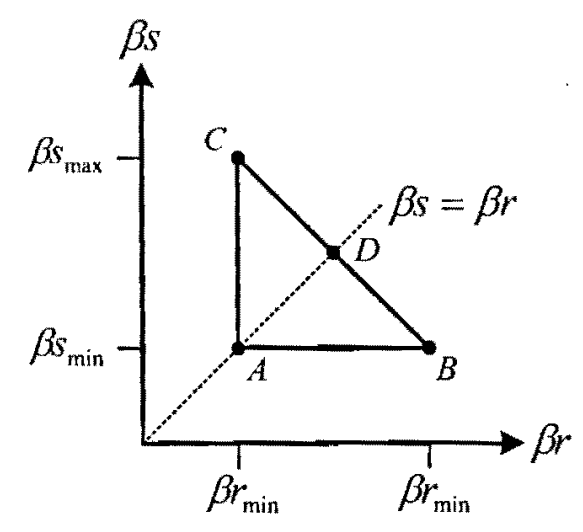

(a)
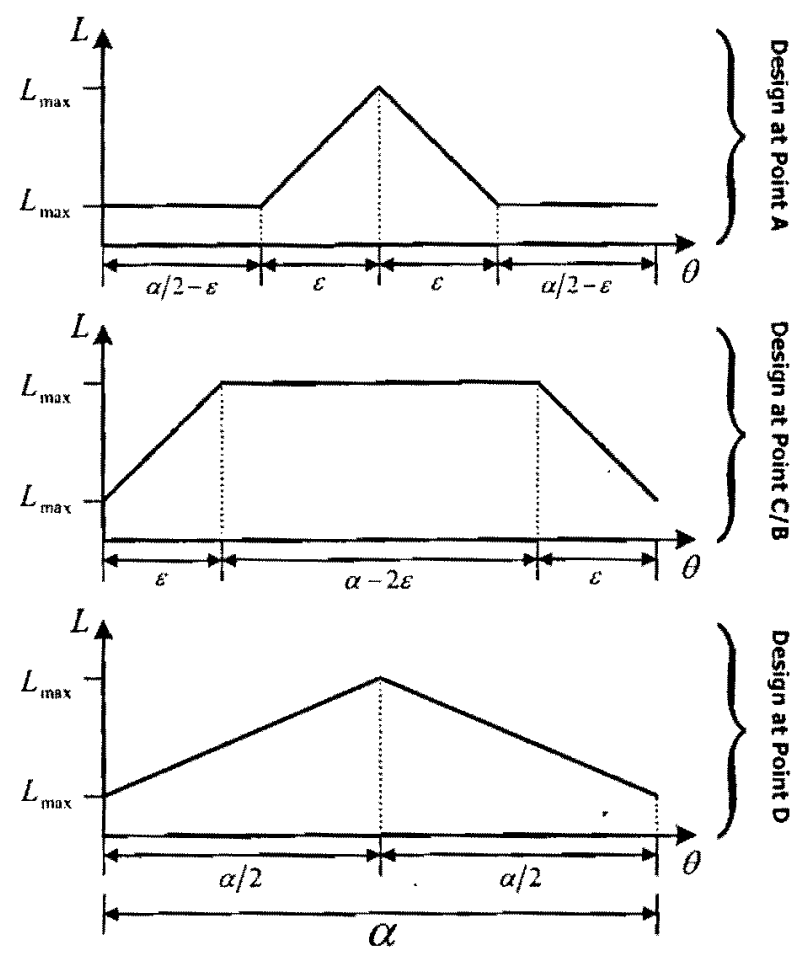

(b)

Figure 4.4: SRM design, (a) the feasible triangle, (b) inductance profiles

As discussed in Chapter 2, the feasible triangle correlates the interdependency between the respective stator and rotor tooth widths of the SRM. The following inequalities are presented, which relate the stator and rotor pole widths $\left(\beta_{R}, \beta_{S}\right)$, the number of rotor poles $\left(N_{R}\right)$ and the stroke angle $(\varepsilon)$, which guarantees a physically realizable machine, where:

$$
\begin{gathered}
\beta_{R}>\beta_{S}, \\
\beta_{s}>\varepsilon, \\
\frac{2 \pi}{N_{R}}>\left(\beta_{R}+\beta_{S}\right) .
\end{gathered}
$$


As discussed in detail by Lawrenson et al. [2], an attempt is made here to summarize the key points discussed. By inspection of Figure 4.4(a), the limits of all the possible combinations of $\left(\beta_{R}, \beta_{S}\right)$ are contained within the triangle of 'ABC'. Consider point ' $A$ ' in Figure $4.4(\mathrm{~b})$, the inductance associated with this point would contain no dead-zone and moreover, the volume of the core iron would minimum. Designing the inductance profile at points ' $\mathrm{B}$ ' or ' $\mathrm{C}$ ' would result in a machine with a significant dead-zone and the period of minimum inductance is almost non-existent. A machine constructed at ' $B$ ' would have maximum winding space, but maximum rotor inertia. A machine constructed at ' $C$ ' would have zero winding space, but minimum rotor inertia. The special case at ' $D$ ' was also discussed, which equally shares the characteristics of both points ' $B$ ' and ' $C$ ', where there exists no dead-zone and the period in minimum inductance is negligible.

\subsubsection{Flux Linkage \& Path Trajectory}

To adequately understand the operating characteristics for a particular SRM all that is required is a plot of the flux linkage vs. coil current for a few selected rotor positions. The flux linkage curve lends various insights to the designer, such as; the developed torque, aligned and unaligned inductances and the influence of saturation on the performance. Referring to Figure 2.3, the area enclosed by the trajectory path as the rotor moves from the unaligned to aligned position as a function of the applied current is proportional to the developed torque.

\section{Flux Linkage vs. Current vs. Rotor Position}

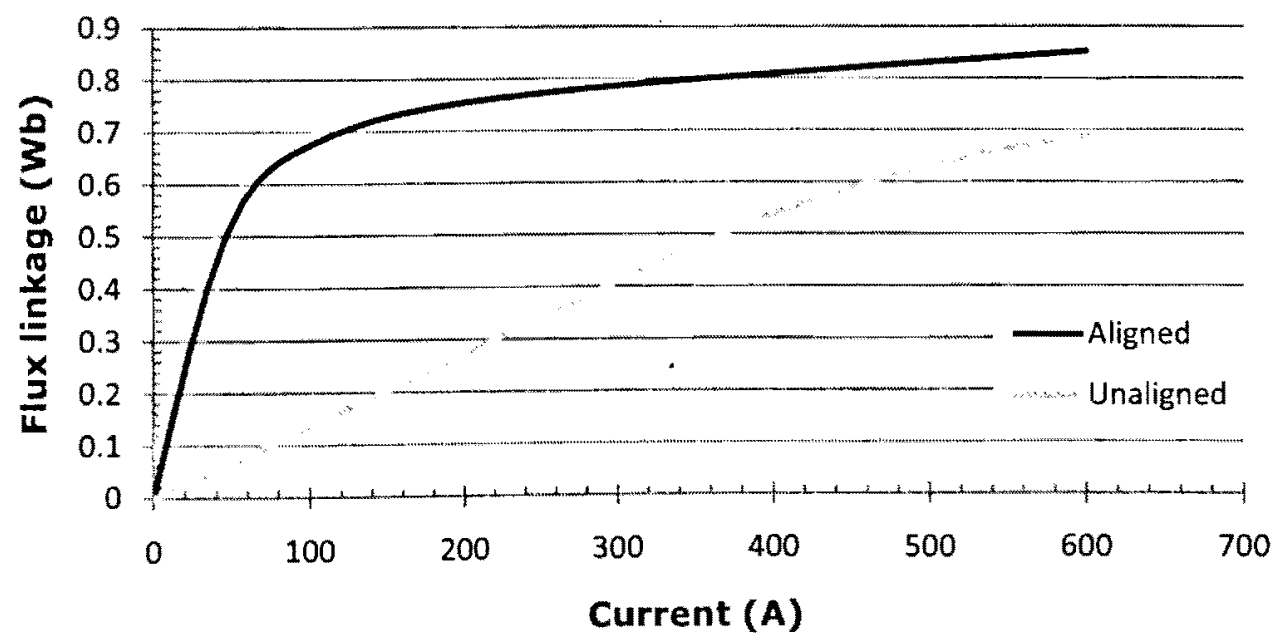

Figure 4.5: Example of a SRM flux linkage plot 


\subsubsection{A Case (Study) of Saturation}

During early attempts at developing an analytical model for the SRM, researchers were unable to adequately account for the nonlinearities associated with the high degree of saturation that was usually encountered in the core of the SRM [1-3]. As summarized in Chapter 2, Lawrenson et al. [2], outlined the effects of core saturation and classified the effects as two main components:

i) Bulk saturation, and

ii) Local saturation.

Bulk saturation is considered across the entire structure, as the MMF excitation is increased. Local saturation occurs mainly at the pole tips during periods of partial overlap. The local saturation has the outcome of reducing the effective pole arcs (or equivalently, a reduction in the air gap area), which can greatly affect the predicted performance of the machine. Even for the non-saturating design, when the poles of the stator and rotor are in partial overlap, the magnetic-flux density drastically increases within the overlapping pole tips. This effectively saturates the poles. On the other hand, neither the fully aligned, nor the fully unaligned positions encounter such saturation.

Harris et al. [1], proposed that the analytical method could be applied strictly to the aligned and unaligned positions in an effort to predict the average torque as the rotor is swept from unaligned to aligned (while neglecting the region of partial overlap). This effort highlighted the possibility of making use of the linear data for air gap performance, to predict the operating behaviour when the SRM is operated in saturation.

Furthermore, Harris et al. [1] postulated that as long as the current is high enough to drive the machine close to saturation in the fully unaligned position, then the average toque approaches the maximum limiting torque - effectively maximizing the power density of the SRM, but at the price of the increased loss in conversion efficiency, predominantly due to a significant increase in core loss. While pursuing this investigation [1], it was observed that the shape of the static torque profile vs. rotor position was insensitive to air gap variations when the machine was strongly saturated. Coincidently, the developed torque quickly decreases as the air gap increases for the unsaturated case [7]. It was reported as much as a $16 \%$ reduction in the average output torque when the air gap was increased from $(0.254 \mathrm{~mm})$ to $(0.508 \mathrm{~mm})$, which is quite significant! 


\subsection{Design Consideration for the SRM}

This section details the geometry of the SRM core and summarizes a majority of the design ratios that have been developed over the years of research $[6,8-10]$.

\subsubsection{SRM Core Geometry}

Figure 4.6, defines the significant design parameters of the core geometry for the generalized SRM. Table 4.1 lists the design parameters.

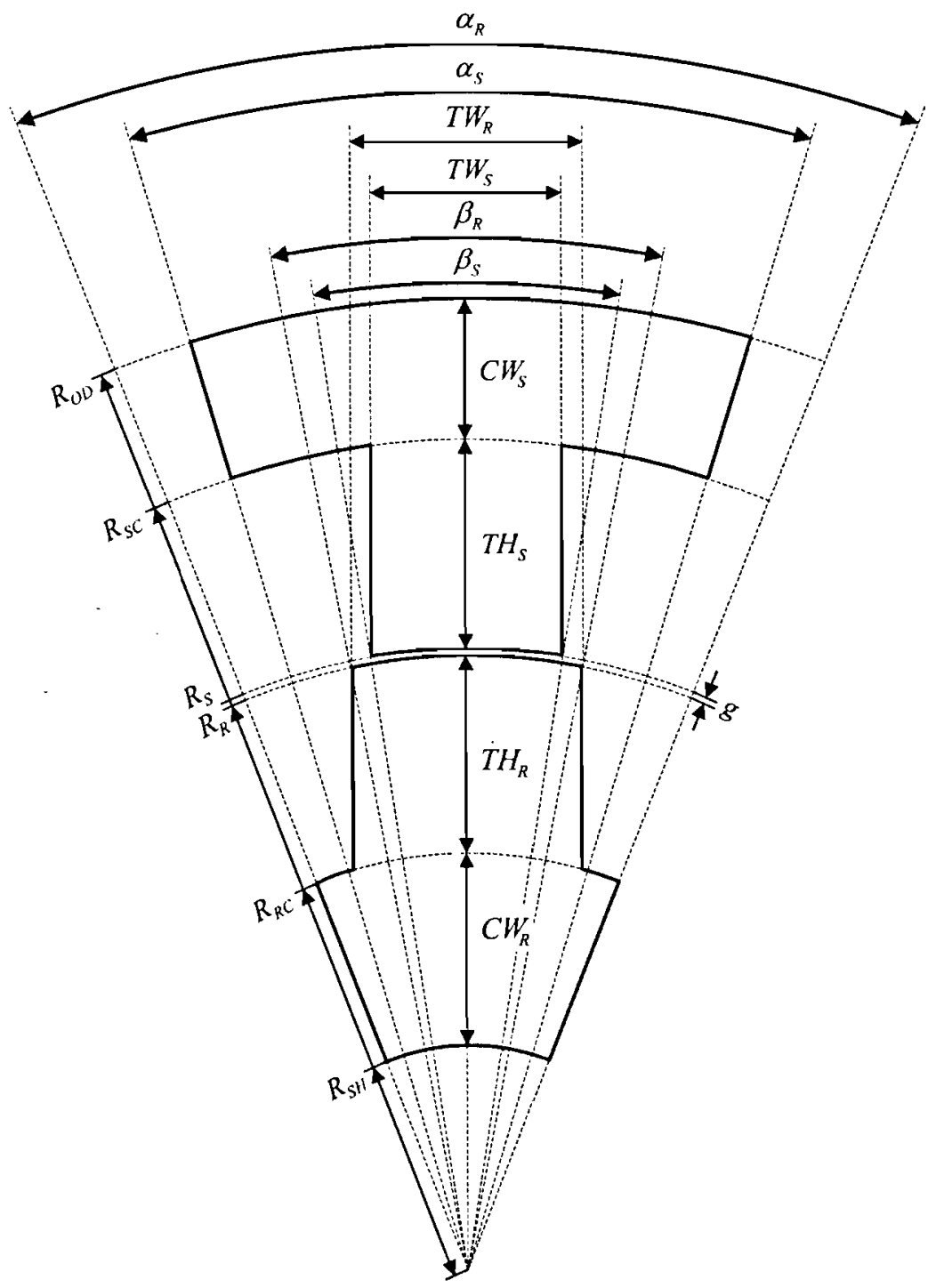

Figure 4.6: Design parameters - SRM core geometry 


\begin{tabular}{clcl}
\hline & Stator Parameters & & Rotor Parameters \\
\hline$\left(R_{O D}\right)$ & Outer Radius & $\left(R_{R}\right)$ & Rotor Radius \\
$\left(R_{S C}\right)$ & Stator Core Radius & $\left(R_{R C}\right)$ & Rotor Core Radius \\
$\left(R_{S}\right)$ & Stator Radius & $\left(R_{S H}\right)$ & Drive Shaft Radius \\
$\left(C W_{S}\right)$ & Stator Core Width & $\left(C W_{R}\right)$ & Rotor Core Width \\
$\left(T H_{S}\right)$ & Stator Tooth Height & $\left(T H_{R}\right)$ & Rotor Tooth Height \\
$\left(T W_{S}\right)$ & Stator Tooth Width & $\left(T W_{R}\right)$ & Rotor Tooth Width \\
$\left(\alpha_{S}\right)$ & Stator Pole Pitch & $\left(\alpha_{R}\right)$ & Rotor Pole Pitch \\
$\left(\beta_{S}\right)$ & Stator Pole Angle & $\left(\beta_{R}\right)$ & Rotor Pole Angle \\
\hline
\end{tabular}

(g) Air Gap

$\left(S_{L}\right)$ Core Stack Length

$\left(S_{F}\right)$ Core Stacking Factor

Table 4.1: Design parameters - SRM core geometry

\subsubsection{Summary of Empirical Design Relations}

Table 4.2 summarizes the empirical mechanical design ratios for the SRM.

\begin{tabular}{|c|c|c|}
\hline \multicolumn{2}{|c|}{ Empirical Relations (Mechanical) } & Description \\
\hline$K_{1 R}=\frac{C W_{R}}{\frac{1}{2}\left(T H_{R}\right)}$ & $(4.13)$ & $\begin{array}{l}\text { Ratio of the rotor yoke thickness }\left(C W_{R}\right) \text { to half rotor } \\
\text { pole height }\left(T H_{R}\right) \text { : Usually between } 1.1 \text { and } 1.3\end{array}$ \\
\hline$K_{1 S}=\frac{C W_{S}}{\frac{1}{2}\left(T H_{S}\right)}$ & $(4.14)$ & $\begin{array}{l}\text { Ratio of the stator yoke thickness }\left(C W_{S}\right) \text { to half stator } \\
\text { pole height }\left(T H_{S}\right) \text { : Usually between } 1.1 \text { and } 1.3\end{array}$ \\
\hline$K_{2}=\frac{\beta_{R}}{\alpha_{R}}$ & $(4.15)$ & $\begin{array}{l}\text { Ratio of rotor pole angle }\left(\beta_{R}\right) \text { to the rotor pole pitch } \\
\left(\alpha_{R}\right): \text { Usually between } 0.36 \text { and } 0.43\end{array}$ \\
\hline$K_{3}=\frac{\beta_{S}}{\beta_{R}}$ & $(4.16)$ & $\begin{array}{l}\text { Ratio of stator pole angle }\left(\beta_{S}\right) \text { to the rotor pole angle } \\
\left(\beta_{R}\right) \text { : Usually between } 0.67 \text { and } 1.0\end{array}$ \\
\hline$K_{4}=\frac{T H_{R}}{R_{O D}\left(\alpha_{R}-\beta_{R}\right)}$ & $(4.17)$ & $\begin{array}{l}\text { Ratio of the rotor pole height }\left(T H_{R}\right) \text { to the rotor inter- } \\
\text { pole gap: Usually between } 0.55 \text { to } 0.75\end{array}$ \\
\hline$K_{L}=\frac{S_{L}}{2\left(R_{O D}\right)}$ & $(4.18)$ & $\begin{array}{l}\text { Ratio of the stack length }\left(S_{L}\right) \text { to the rotor bore (rotor } \\
\text { diameter): Usually between } 0.4 \text { to } 3.0\end{array}$ \\
\hline$K_{g}=\frac{\alpha_{R}}{g}$ & $(4.19)$ & $\begin{array}{l}\text { Ratio of rotor pole pitch }\left(\alpha_{R}\right) \text { to the air gap thickness } \\
(g) \text { : Usually between } 50 \text { to } 120\end{array}$ \\
\hline$K_{s f}$ & $(4.20)$ & $\begin{array}{l}\text { Fill factor of the stator slot by the windings: Usually } \\
\text { between } 0.6 \text { to } 0.6\end{array}$ \\
\hline
\end{tabular}

Table 4.2: Summary of empirical mechanical design ratios [9] 
Table 4.3 summarizes the empirical magnetic design ratios for the SRM.

\begin{tabular}{|c|c|c|}
\hline \multicolumn{2}{|c|}{ Empirical Relations (Magnetic) } & Description \\
\hline$K_{s}$ & $(4.21)$ & $\begin{array}{l}\text { Ratio of the actual converted energy }\left(W_{\text {mech }}\right) \text { to the } \\
\text { energy between the aligned and unaligned position } \\
\left(W_{f l d}\right) \text { : Usually between } 0.8 \text { to } 1.1\end{array}$ \\
\hline$K_{x}$ & $(4.22)$ & $\begin{array}{l}\text { Ratio of the energy }\left(W_{f l d}\right) \text { between the aligned and } \\
\text { unaligned rotor positions to the product }\left(\phi_{\max } \times l_{\max }\right) \text { : } \\
\text { Usually designed to } 1.27\end{array}$ \\
\hline$K_{\phi}$ & $(4.23)$ & $\begin{array}{l}\text { Ratio of the maximum flux linkage }\left(\lambda_{\max }\right) \text { and the } \\
\text { average flux linkage per phase }\left(\lambda_{p h}\right) \text { : Usually designed } \\
\text { to } 2.77\end{array}$ \\
\hline$B_{s}$ & $(4.24)$ & Mean magnetic loading: Usually between 30 to 55 \\
\hline$B_{m}$ & $(4.25)$ & $\begin{array}{l}\text { Maximum flux density at alignment: Usually between } \\
1.35 \text { to } 1.8 \text { (Teslas) }\end{array}$ \\
\hline
\end{tabular}

Table 4.3: Summary of empirical magnetic design ratios [9]

Table 4.4 summarizes the empirical electrical design ratios for the SRM.

\begin{tabular}{lll}
\hline Empirical Relations (Electric) & \multicolumn{1}{c}{ Description } \\
\hline$A$ & $(4.26)$ & $\begin{array}{l}\text { Electrical loading }(A): \text { Usually between } 30 \text { to } 55 \\
(\text { Amperes } / \mathrm{mm})\end{array}$ \\
$J$ & $(4.27)$ & $\begin{array}{l}\text { Current density }(J) \text { of the of the stator winding: } \\
\text { Usually between } 3.0 \text { to } 5.5\left(A m p e r e s / \mathrm{mm}^{2}\right)\end{array}$ \\
\hline
\end{tabular}

Table 4.4: Summary of empirical electric design ratios [9] 


\subsection{SRM Magnetic Equivalent Circuit}

The SRM equivalent magnetic circuit is a useful analytical model that can be used to estimate the maximum inductance when the rotor is in the aligned position. Consider the $2 / 2$ single-phase SRM as defined in Figure 4.7(a); when the rotor is said to be aligned, the rotor poles exactly overlap the stator poles, and maximum magnetic coupling between the poles is experienced, whereby the associated air gap reluctance has been minimized. Furthermore, in the aligned position the effects of magnetic-flux fringing can be considered minimal and can be neglected from the analysis. Figure $4.7(\mathrm{~b})$ defines the magnetic equivalent circuit or the SRM for the aligned rotor position.

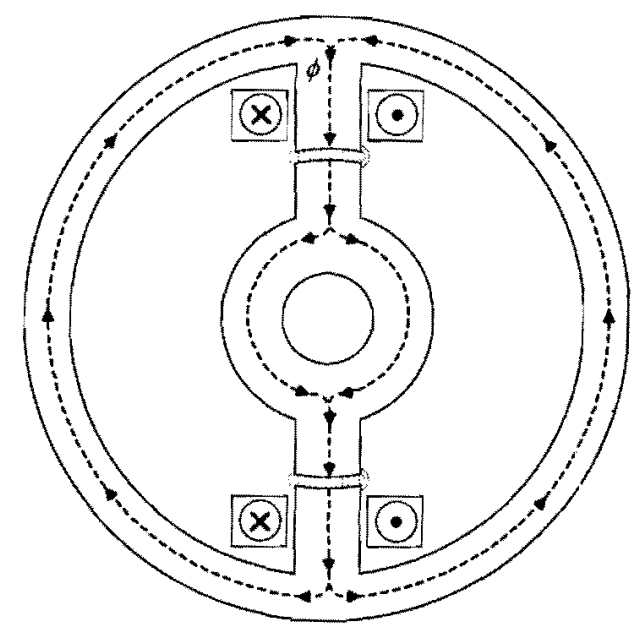

(a)

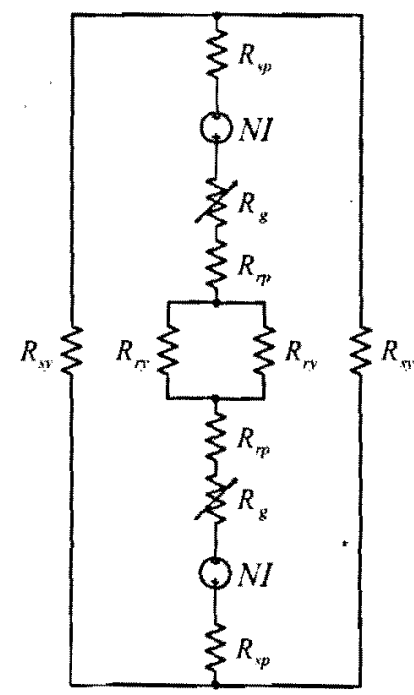

(b)

Figure 4.7: 2/2 SRM - aligned rotor, (a) core geometry, (b) equivalent circuit

To further simplify the equivalent circuit of Figure $4.7(\mathrm{~b})$, Thévenin's theorem is applied, which results in the simplified equivalent circuit of Figure 4.8. Here we have grouped the air gap reluctances and the MMF sources together and the core reluctances have been kept separate, to better facilitate estimation of the associated core loss.

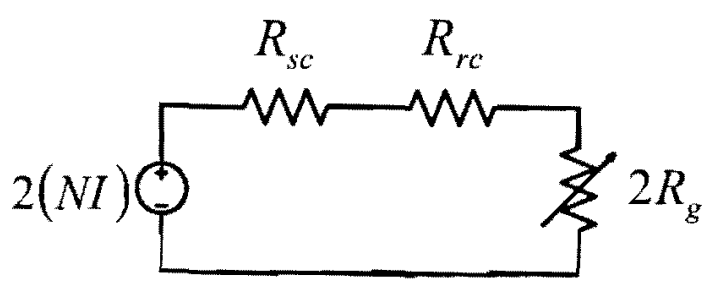

Figure 4.8: Simplified SRM equivalent circuit 
After application of Thévenin's theorem, the equivalent stator reluctance $\left(\mathcal{R}_{s c}\right)$ is defined by:

$$
\mathcal{R}_{s c}=\frac{\mathcal{R}_{s y}+4 \mathcal{R}_{s p}}{2}
$$

similarly, the equivalent rotor reluctance $\left(\mathcal{R}_{r c}\right)$ is defined by:

$$
\mathcal{R}_{r c}=\frac{\mathcal{R}_{r y}+4 \mathcal{R}_{r p}}{2}
$$

\subsubsection{Core Reluctance}

Using the nomenclature defined in Table 4.1 , the individual reluctance paths are resolved using the defined geometrical parameters. Consider first, the reluctance of the rotor, which can be resolved into two independent reluctances; the rotor pole reluctance $\left(\mathcal{R}_{r p}\right)$, and the rotor yoke reluctance $\left(\mathcal{R}_{r y}\right)$, where:

$$
\begin{gathered}
\mathcal{R}_{r p}=\frac{l_{r p}}{\mu A_{r p}}=\frac{T H_{R}+\frac{1}{2}\left(C W_{R}\right)}{\mu T W_{R}\left(S_{L} S_{F}\right)} ; \\
\mathcal{R}_{r y}=\frac{l_{r y}}{\mu A_{r y}}=\frac{\left[R_{R C}-\frac{1}{2}\left(C W_{R}\right)\right] \alpha_{R}}{\mu C W_{R}\left(S_{L} S_{F}\right)} .
\end{gathered}
$$

Similarly, the reluctance of the stator can be resolved into two independent reluctances; the stator pole reluctance $\left(\mathcal{R}_{s p}\right)$, and the stator yoke reluctance $\left(\mathcal{R}_{s y}\right)$, where:

$$
\begin{gathered}
\mathcal{R}_{s p}=\frac{l_{s p}}{\mu A_{s p}}=\frac{T H_{S}+\frac{1}{2}\left(C W_{S}\right)}{\mu T W_{S}\left(S_{L} S_{F}\right)} ; \\
\mathcal{R}_{s y}=\frac{l_{s y}}{\mu A_{s y}}=\frac{\left[R_{O D}-\frac{1}{2}\left(C W_{S}\right)\right] \alpha_{S}}{\mu C W_{S}\left(S_{L} S_{F}\right)} .
\end{gathered}
$$

The reluctance paths for both the stator and rotor have been completely resolved; as long as the material permeability $(\mu)$ is handled appropriately, the equivalent circuit predicts the aligned flux-linkage and inductance with reasonable accuracy [11]. 


\subsubsection{Air Gap Reluctance}

The cross-sectional area of the air gap is determined by calculating the surface integral of the area confined by the stator and rotor pole tips. By design the rotor pole arc is larger than the stator pole arc $\left(\beta_{R}>\beta_{S}\right)$, therefore the rotor pole arc is considered when evaluating air gap, as defined below:

$$
A_{g}=\int d \vec{S}=\left[R_{R}+\frac{1}{2}(g)\right]\left(S_{L} S_{F}\right) \beta_{R}
$$

The reluctance of the air gap in the aligned position can then be determined from:

$$
\mathcal{R}_{g}=\frac{g}{\mu_{0} A_{g}}=\frac{g}{\mu_{0}\left[R_{R}+\frac{1}{2}(g)\right]\left(S_{L} S_{F}\right) \beta_{R}} .
$$

To evaluate the effective air gap as a function of rotor position $(\theta)$, Figure 4.9 defines the relative rotor angle with respect to the aligned axis.

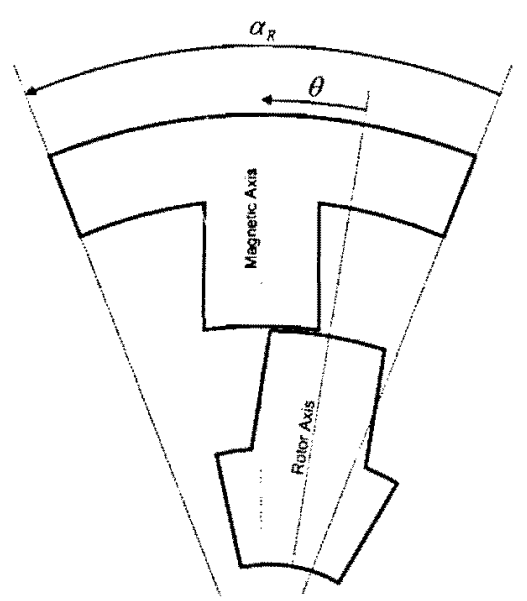

Figure 4.9: Coordinate system used to define rotor position

When the rotor is aligned with the stator $\left(\theta=0^{\circ}\right)$, the air-gap area is maximum and when the rotor pole is at the limit of overlap with the stator pole, we consider this the limit of the simplified model, this angle is defined as $\theta_{\min }=\frac{1}{2}\left(\beta_{S}+\beta_{R}\right)$. The effective air gap area, as a function of rotor position can then be determined from:

$$
A_{g}(\theta)=\left[R_{R}+\frac{1}{2}(g)\right]\left(S_{L} S_{F}\right)\left(\beta_{R}-\theta\right) .
$$




\subsection{Summary}

To begin the design phase for an SRM one needs to consider various performance factors and their associated trade-offs. For proper machine design, one needs to consider every detail, right down to the magnetic-flux distributions in the core across various sections. Development of the machine geometry is a complicated process, which must factor a variety of considerations.

The feasible triangle is a very important design tool, when considering the selection of the rotor and stator pole arcs $\left(\beta_{R}, \beta_{S}\right)$. Consider the unaligned rotor position, to minimize the inductance of the circuit, it is required that the effective distance between the tips of the rotor and stator poles be minimized. A narrower rotor tooth causes an increase in distance, but equally, the increase in Rotor tooth length (reducing the rotor yoke) also increases the 'effective air gap', thus reducing (or minimizing) the unaligned inductance.

An equivalent magnetic circuit model is presented which can be used to reasonably predict the aligned flux linkage and inductance. The reluctance paths of various core elements have been resolved, which can assist with preliminary estimations of core loss. A method of variable air gap area has been presented, however this is only valid during periods of pole overlap. As the overlap decreases the fringing fields begin to dominate and the effectiveness of the model diminishes significantly. 


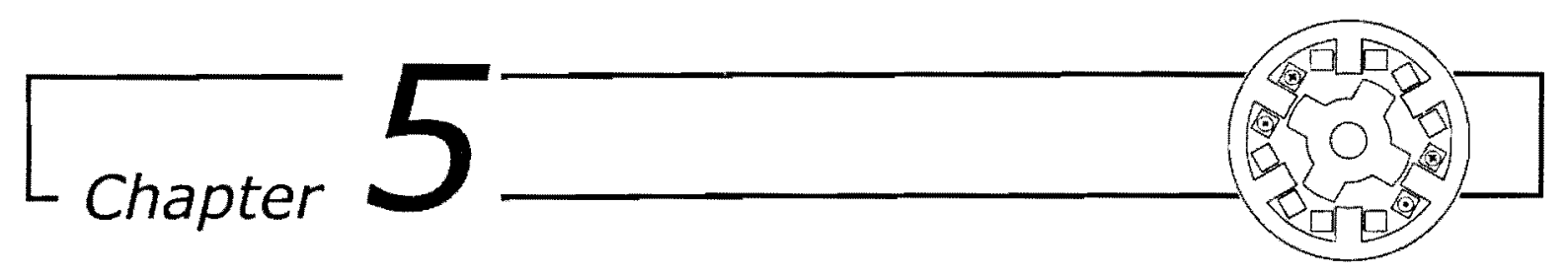

\section{Implementation}

This section details the methods of implementation for both, the factorial experimentation and the development of the FEA modelling environment that form the basis of experimentation for this thesis. The results of which are presented in Chapter 6 .

Factorial experimentation is the primary method of evaluation throughout this thesis. The methods introduced here facilitate the evaluation of the SRM's design parameters against key performance metrics. Therefore, a brief summary of the fundamental principles of factorial experimentation are introduced.

The experimental geometry of the SRM has been leveraged from the existing experimental machine of [27]. Due to the lack of a few key parameters, the model required a fair amount of initial tuning in order to reproduce the results, however after successful application of numerous design iterations, the results corroborated with a surprising degree of accuracy.

\subsection{Factorial Experimentation}

As summarized in Section 1.2; Factorial Experimentation or more commonly Factorial Design is a fundamental principal of Design of Experiments (DoE), whereby an experimenter can evaluate the effects of an individual factor with respect to combinations of factors on the system response(s). As discussed in $[25,26]$ : "The need for conducting such tests gives experimenters the ability to evaluate the effects of many factors on the response(s) and at the same time help identify any interactions between factors". Interaction is present when 
the effect of a factor on the response variable depends on the setting level of another factor. Visually, this can be seen as nonparallel lines when plotting the averages of the levels from all the possible combinations of input factors [26].

\subsubsection{Modelling a Process}

Frequently there is a need to evaluate a process with multiple input variables and output responses. When considering a classic parameters screening exercise, for example the traditional method of varying one factor at a time, the factor permutations become exceedingly complicated as the number of factors and/or responses is increased. The 'traditional' methods of, 'varying one factor at a time', lends little insight into the mutual interaction between factors. As a result, the methods of factorial experimentation when applied to complex processes tend to surpass expectation - which usually results in exceedingly accurate predictions about the parameters of significance and their mutual interactions. Since the tests are systematic and are constructed to vary all the factors at the same time, then the overall time invested in performing the experiment is reduced, all the while providing a higher level of insight into the 'complete' functioning of the process. Furthermore, for most practical cases, the output responses of the process are measureable. Having access to a measureable output response(s) is advantageous, because sometimes evaluating the system analytically can be quite complicated and time consuming.

It is common to begin the experiment with a process model (as shown in Figure 5.1), whereby the experimenter would identify several discrete or continuous factors and the appropriate output response(s).

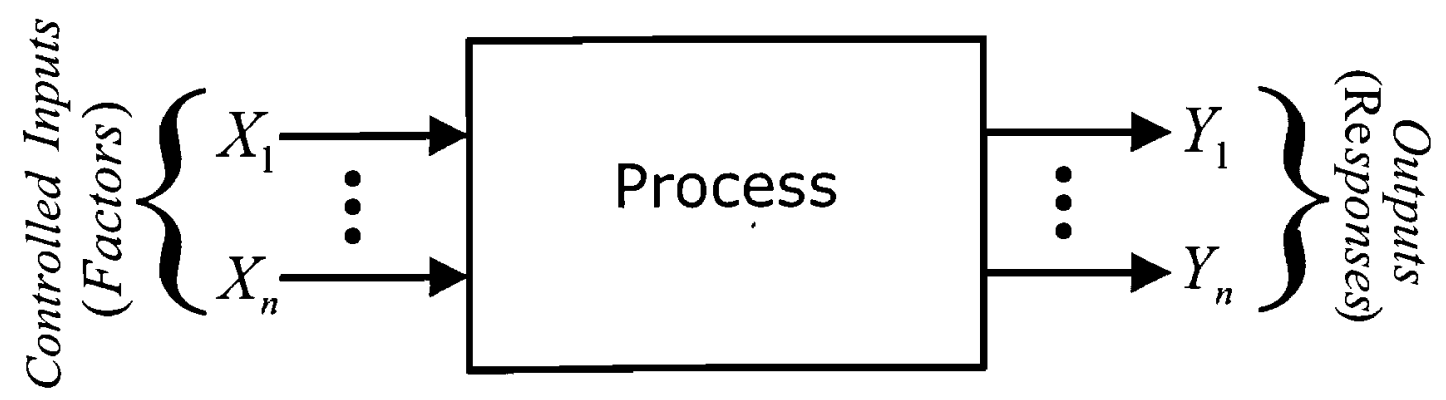

Figure 5.1: Process model used for factorial experimentation 
The responses of the system are assumed continuous over the entire experimental range. The outputs must not only be continuous, but also reasonably smooth - the polynomial equation that is used to model the response variable $(Y)$ as a function of the input factors $(X)$ is shown in Eq. 5.1 , as described in $[25,26]$ :

$$
Y=\beta_{0}+\sum_{i=1}^{p} \beta_{i} X_{i}+\sum_{i=1}^{p} \sum_{j=1}^{p} \beta_{i j} X_{i} X_{j}+\sum_{i=1}^{p} \sum_{j=1}^{p} \sum_{k=1}^{p} \beta_{i j k} X_{i} X_{j} X_{k}+\cdots
$$

Where:

$$
\begin{aligned}
& \beta_{0}=\text { the overall mean response, } \\
& \beta_{i}=\text { the main effect for factor }(i=1,2, \ldots, p), \\
& \beta_{i j}=\text { the two-way interaction between the } i^{i h} \text { and } j^{\text {th }} \text { factors, and } \\
& \beta_{i j k}=\text { the three-way interaction between the } i^{t h}, j^{t h} \text {, and } k^{h} \text { factors. }
\end{aligned}
$$

From Eq. 5.1 one can see that the main factor interactions are linearly combined with the two-way and three-way factor interactions. This represents a confounded solution [32]. Consequently, given a higher 'resolution' to the experiment the resulting solutions tend to be less confounded; as is discussed further in the next section.

\subsubsection{Full Factorial Designs}

As described in $[25,26,32]$, factorial designs are geometrically constructed and vary all the factors simultaneously and orthogonally. Data is then collected from a cube in $p$ dimensions, where ' $p$ ' represents the number of factors being studied. Figure 5.2 shows the data points for a three factor, two-level, full factorial design.

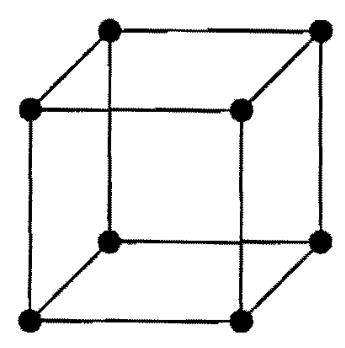

Figure 5.2: Full factorial, two-level design in three dimensions 
If data is collected from all the vertices of the cube, then the maximum resolution is obtained and the design is said to be full factorial. Consequently, no confounding occurs.

A full factorial design requires the following relation (Eq. 5.2) to be satisfied, as described in $[25-28,31]$ :

$$
N_{\text {exp }}=n^{p}
$$

Where:

$N_{\exp }=$ number of experiences (simulation runs) to be performed,

$p=$ number of parameters, and

$n=$ number of levels used for each parameter.

\subsubsection{Fractional Factorial Designs}

From Eq. 5.2, it can be seen that as the number of factors being studied increases, the number of required experiences increases exponentially. Therefore, fractions of the full factorial design can then be constructed. Eq. 5.3 describes the relationship between full and fractional factorial designs, as described in [25-28,31]:

$$
N_{\exp }=n^{p-q}
$$

Where:

$n^{-q}=$ fractional size of the design.

Fractional factorial designs collect data from a specific subset of possible vertices; whereby, the specific vertices are chosen based on the desired resolution [32]. Figure 5.3 shows the data points for a three factor, two-level, fractional factorial design.

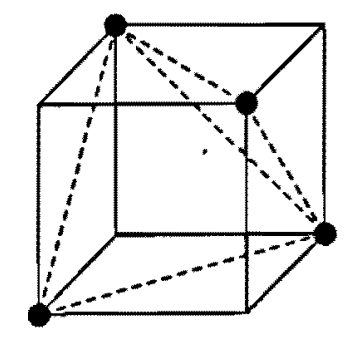

Figure 5.3: Fractional factorial, twolevel design in three dimensions 
Fractional factorial designs yield confounded solutions. The type of confounding that occurs depends on the resolution level used in the design. The following table (Table 5.1) details the resolution levels of fractional factorial designs $[25,26,32]$.

$\begin{array}{cl}\text { Level } & \text { Description } \\ \text { II } \quad \text { Main effects are linearly combined with each other }\left(\beta_{i}+\beta_{j}\right) \\ \text { III } \quad \text { Main effects are linearly combined with two-way interactions }\left(\beta_{i}+\beta_{j k}\right) \\ \text { IV } \quad \begin{array}{l}\text { Main effects are linearly combined with three-way interactions }\left(\beta_{i}+\beta_{j k l}\right) \text { and } \\ \text { two-way interactions with each other }\left(\beta_{i j}+\beta_{k l}\right)\end{array} \\ \text { Main effects and two-way interactions are not linearly combined except with } \\ \text { higher-order interactions }\left(\beta_{i}+\beta_{j k l m}\right) \text { and }\left(\beta_{i j}+\beta_{k l m}\right)\end{array}$

Table 5.1: Resolution Level of Fractional Factorial Designs

In order to analyze the results of a confounded solution when using a fractional factorial design we consider the following hypothesis, as discussed in $[27,28]$ :

- The high-order interactions (more than two) can be considered negligible.

- Once a contrast is negligible, all the effects that compose this contrast can be considered negligible too.

- Two significant factors (parameters) can also result in a significant interaction.

- However, two non-significant factors do not give significant interactions.

Notwithstanding the application of the aforementioned hypothesis, it is imperative that the experimenter appreciate the potential for inclusion of error in the resultant solution. Furthermore, if multiple simplifications are implemented there exists potential for the error to significantly magnify. However, since fractional factorial experiments are often used as a means to pre-screen a large amount of factors in an attempt to quickly remove the nonsignificant factors the optimization function, a follow-up full factorial experiment is usually implemented which tends to resolve any error that may have been introduced. Additionally, parameters screening is usually a precursor to an optimization process, therefore the absolute value of the contribution is of little importance as long as the 'significant' parameters are identified and included within the objective function of the optimization algorithm. 
Fractional factorial designs yield polynomial equations approximating the true response function, with better approximations from higher resolution level designs $[25,26,32]$. The following table (Table 5.2 ) shows the minimum required simulation runs needed for a resolution IV and $V$ fractional factorial design.

\begin{tabular}{|c|c|c|c|}
\hline \multicolumn{2}{|c|}{ Resolution IV } & \multicolumn{2}{|c|}{ Resolution V } \\
\hline Factors & Runs & Factors & Runs \\
\hline 1 & 2 & 1 & 2 \\
\hline 2 & $2^{2}=4$ & 2 & $2^{2}=4$ \\
\hline $3-4$ & $2^{3}=8$ & 3 & $2^{3}=8$ \\
\hline $5-8$ & $2^{4}=16$ & $4-5$ & $2^{4}=16$ \\
\hline $9-16$ & $2^{5}=32$ & 6 & $2^{5}=32$ \\
\hline $17-32$ & $2^{6}=64$ & $7-8$ & $2^{6}=64$ \\
\hline $33-64$ & $2^{7}=128$ & $9-11$ & $2^{7}=128$ \\
\hline $65-128$ & $2^{8}=256$ & $12-17$ & $2^{8}=256$ \\
\hline $126-256$ & $2^{9}=512$ & $18-22$ & $2^{9}=512$ \\
\hline
\end{tabular}

As outlined in $[25,26]$, when considering the effects of confounding on the solution, it is desirable to conduct a Resolution $V$ experiment, which separately estimates all the twoway interactions. However, for a large number of factors, it may not be feasible to perform the Resolution $V$ design. Because the significant two-way interactions are most likely to be combinations of the significant main effects, a Resolution IV design can be used first. Then a follow-up Resolution $V$ design can be performed to determine if there are any significant two-way interactions using only the factors found to have significant effects from the Resolution IV experiment.

\subsubsection{Screening Design Methodology}

Often it is difficult to predict the interactions of the various input parameters of a system. By inspection alone it is hard to tell what parameters are significant, and at the same time what interactions between parameters are significant. The classical approach to parameter screening was to vary one factor at a time while monitoring the response. This method is incapable of detecting the interactions between several factors potentially acting in combination. A screening exercise using factorial design methods prior to optimizing an 
objective function is extremely useful when the objective function has a large amount of factors to account for [27-31]. Factorial experimentation can identify the significant factors, thus effectively reducing the complexity of the objective function and as a result decreasing the simulation time.

\subsection{Modelling Switched Reluctance Motor}

The goal of this application is to perform a parameters screening exercise on a $6 / 4$ Switched Reluctance Motor, using factorial experimentation to further develop an intuitive understanding of how each design factors affect the performance characteristics of the machine. A 6/4 SRM has six stator poles $\left(N_{S}=6\right)$ and four rotor poles $\left(N_{R}=4\right)$ - coils are wound around the stator poles and divided into pairs. Two pole pairs make-up one electrical phase, therefore the 6/4 SRM is considered a three-phase machine. The geometry of the machine is shown in Figure 5.4 and the parameters to be evaluated and their respective ranges are given in Table 5.3.

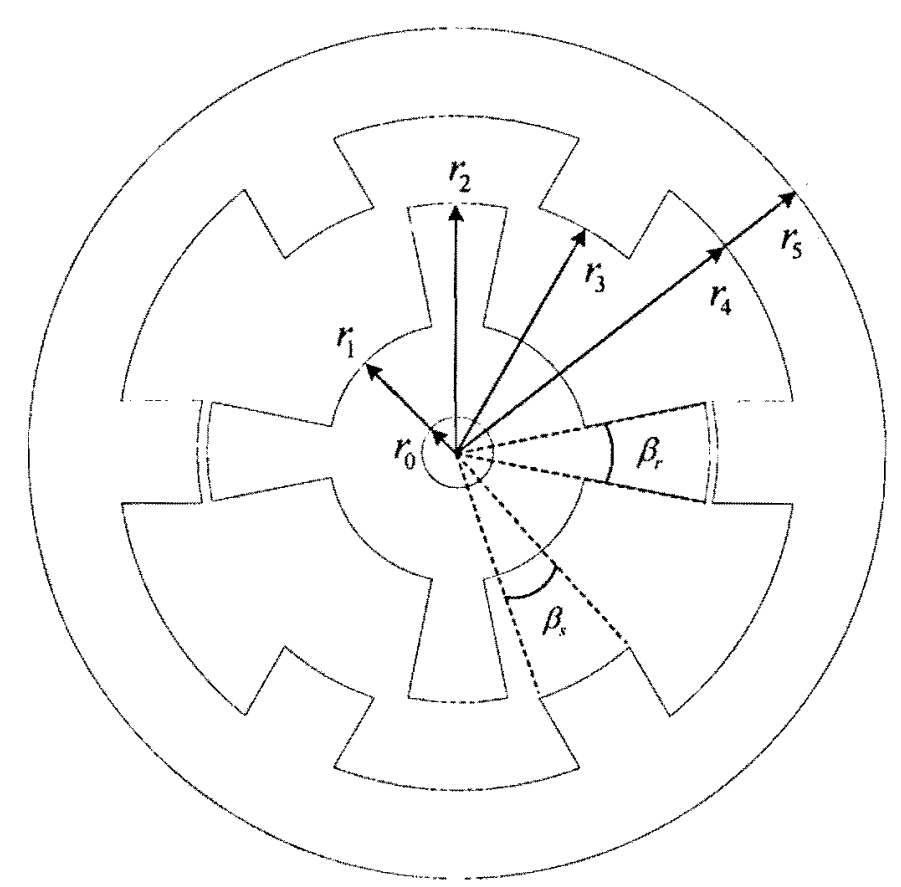

Figure 5.4: Geometry of the experimental 6/4 SRM

The experimental values selected are based on the machine variants purposed in [27]. Table 5.3 presents the parameters to be studied and their variation ranges. 


\begin{tabular}{cccc}
\hline Motor Parameter & Minimum Value & Fixed Value & Maximum Value \\
\hline$r_{0}$ & - & $5.0 \mathrm{~mm}$ & - \\
$r_{1}$ & $8 \mathrm{~mm}$ & - & $18 \mathrm{~mm}$ \\
$r_{2}$ & $20 \mathrm{~mm}$ & - & $35 \mathrm{~mm}$ \\
$r_{3}$ & - & $r_{2}+0.25 \mathrm{~mm}$ & - \\
$r_{4}$ & $46 \mathrm{~mm}$ & - & $53 \mathrm{~mm}$ \\
$r_{5}$ & $58 \mathrm{~mm}$ & - & $65 \mathrm{~mm}$ \\
$\beta_{r}$ & $0.40 \mathrm{rad}$ & - & $0.90 \mathrm{rad}$ \\
$\beta_{5}$ & $0.40 \mathrm{rad}$ & - & $0.72 \mathrm{rad}$ \\
\hline
\end{tabular}

Table 5.3: Experimental 6/4 SRM Design Parameters

To compare the effects of the design parameters, each machine variant was created as a combination of the discrete maximum and minimum values for each of the six design parameters. To highlight the differences of each of the design parameters, a few machine variants were selected and are presented in Figure 5.5. To facilitate rapid development of the models, the rotor pole has been modified so the width of the pole is proportional to the pole pitch $\left(\beta_{r}\right)$; similarly, this approach was also implemented in [27].
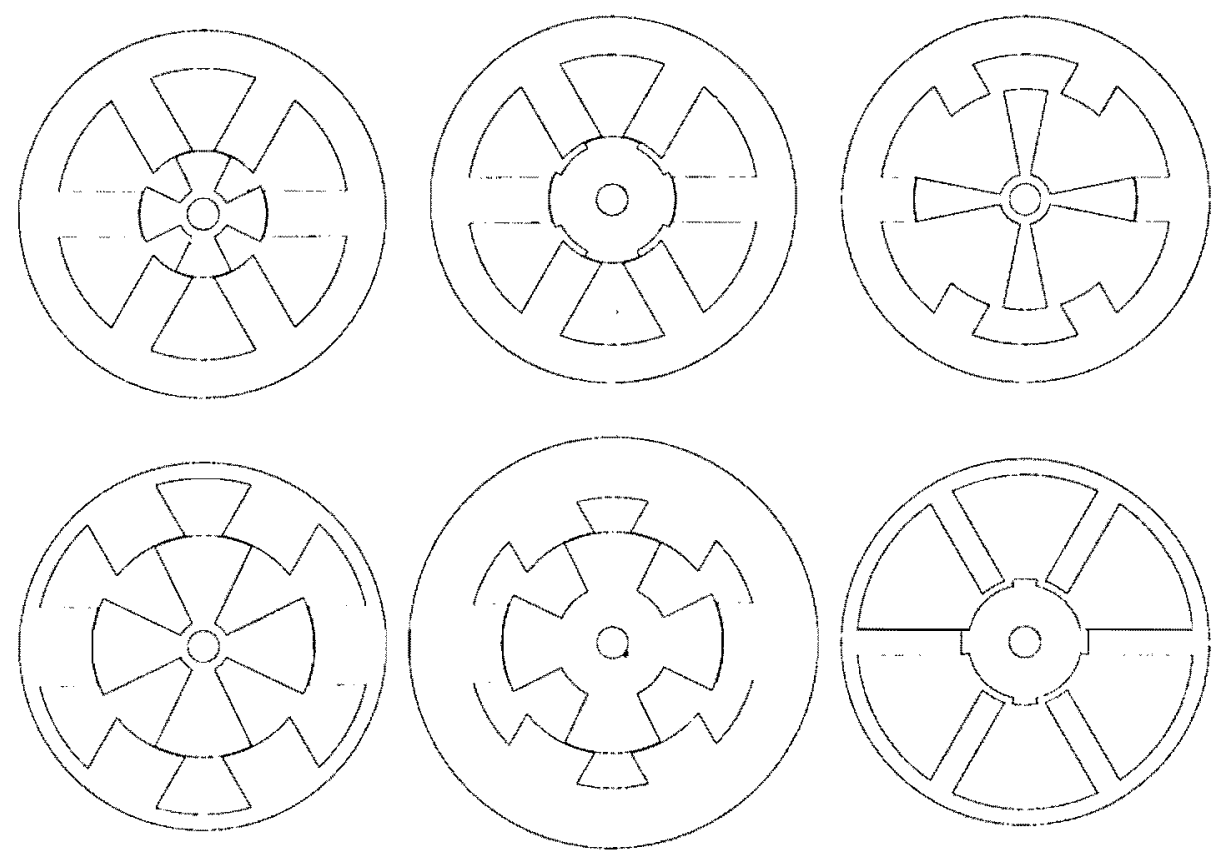

Figure 5.5: An Assorted Selection of the experimental 6/4 SRM Design Variants 


\subsubsection{The Modelling Environment}

A trial version of 'MagNet V7.1.3' was downloaded from Infolytica Corporation's website (www.infolytica.com) which was used to develop the required 2D magnetostatic finite-element models. A few critical model properties were left out of the published results in [27] - after some moderate trial and error, suitable values were chosen which closely mimic the results as presented. Table 5.4, summarizes the complete set of design parameters to be studied and their variation ranges.

\begin{tabular}{cccc}
\hline Motor Parameter & Minimum Value & Fixed Value & Maximum Value \\
\hline$r_{0}$ & - & $5.0 \mathrm{~mm}$ & - \\
$r_{1}$ & $8 \mathrm{~mm}$ & - & $18 \mathrm{~mm}$ \\
$r_{2}$ & $20 \mathrm{~mm}$ & - & $35 \mathrm{~mm}$ \\
$r_{3}$ & - & $r_{2}+0.25 \mathrm{~mm}$ & - \\
$r_{4}$ & $46 \mathrm{~mm}$ & - & $53 \mathrm{~mm}$ \\
$r_{5}$ & $58 \mathrm{~mm}$ & - & $65 \mathrm{~mm}$ \\
$\beta_{r}$ & $0.40 \mathrm{rad}$ & - & $0.90 \mathrm{rad}$ \\
$\beta_{s}$ & $0.40 \mathrm{rad}$ & - & $0.72 \mathrm{rad}$ \\
\hline Motor Length & - & $200 \mathrm{~mm}$ & - \\
Coil Turns & - & 115 Turns & - \\
Coil Current & - & 3.0 Arms & - \\
\hline Table 5.4: 6/4 SRM Design Parameters - Complete
\end{tabular}

To balance the trade-offs between simulation accuracy and solution time the following solver options were used:

- Solver Options: Material Type Default,

- Newton tolerance 1\%, Maximum Newton Iterations 20,

- CG tolerance $0.01 \%$.

- Polynomial order 2.

- Adaption Options: Use h-adaption,

- Percentage of Elements to Refine $25 \%$,

- Tolerance $0.1 \%$,

- Maximum Number of Steps 10.

- Core Material: M19: USS Transformer 72 -- 29 Gage. 


\subsection{Chapter Summary}

The fundamental concepts of parameter screening using factorial experimentation have been reviewed. Full factorial designs immediately identify the significant parameters and any mutual interactions. However, performing full factorial experiments requires a significant number of simulations as the number of factors increases. To alleviate this, the experimenter may choose to pre-screen the factors with a lower resolution fractional factorial design, whereby the less significant parameters can be identified and removed. Once this is completed, a more accurate full factorial design can be constructed to more accurately predict the parameters of significance. Furthermore, the resultant solutions from a fractional factorial design are confounded and a method of selective elimination was also presented to effectively isolate the main parameters from the higher order terms.

The geometry of the experimental 6/4 SRM was presented, which coincidently, is one of the most common SRM used in both academia and industry. The chosen machine geometry was pre-determined and presented in [27]. A fair amount of tuning of the model was required, because a few key characteristics were not reported; such as the material type, core length, coil turns and coil current. Once the performance of the model was verified against the referenced material, the construction of the numerous machine variants began. A few of the machine variants were presented, which served to highlight the differences between the various design permutations. 


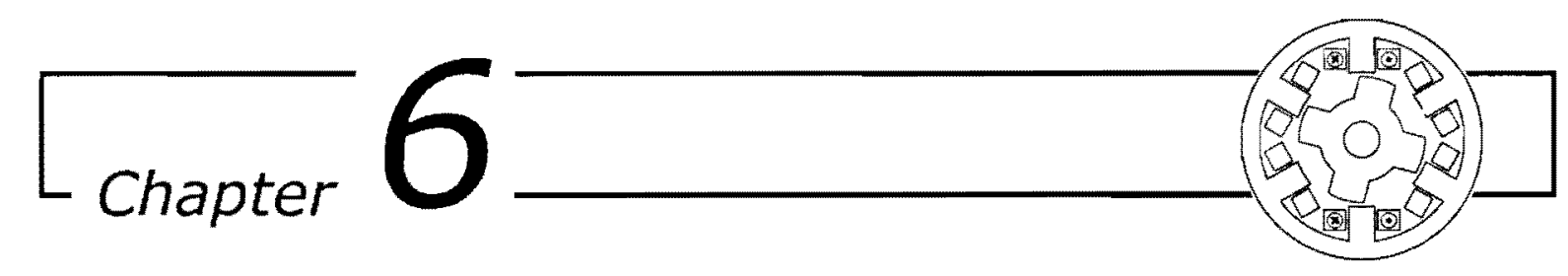

\section{Results and Discussions}

This section summarizes the results of the factorial experimentation; in Section 6.1 the model validation is presented, section 6.2 to section 6.4 presents the results from the parameters screening as applied to the starting torque, stroke torque and flux linkage, and a summary is offered in section 6.5 which tabulates the pertinent data for ease of comparison.

To construct a self-starting and fully reversible SRM, the machine should be able to produce torque in any direction, from any rotor position. Considering 6/4 three-phase SRM; when the active phase has pulled the rotor into perfect alignment, the distance between the unaligned rotor pole must be equidistance between the stator poles of adjacent phases. This condition is sufficient to ensure a fully reversible, self-starting SRM. Moreover, the distance between the stator and rotor poles in the unaligned position directly corroborates with the magnitude of the developed flux linkage. Similarly, the difference between the aligned and unaligned inductance, directly contrasts the developed torque over each successive stroke.

It follows that all of the abovementioned design criteria are either directly or indirectly related to torque production. Furthermore, by estimating the aligned and unaligned flux linkages, this directly corresponds to the maximum and minimum coil inductances. Therefore, the experiment has been constructed to identify the parameters of significance as related to all aspects of torque production. By means of factorial experimentation, the simplified core geometry of a 6/4 three-phase SRM was evaluated against the following performance metrics:

i) Starting torque,

ii) RMS stroke torque,

iii) Aligned and Unaligned flux linkage (saturated and unsaturated). 


\subsection{Model Validation}

Table 6.1 shows the application of Taguchi's L16 design, where each motor variant is created by setting the input factors to either their maximum or minimum value; as defined by the L16 design matrix - the starting torque is then computed by 2-D FEA [27].

\begin{tabular}{cccccccc}
\hline Motor & $r_{1}$ & $r_{2}$ & $r_{4}$ & $r_{5}$ & $\beta_{r}$ & $\beta_{s}$ & $T(N m)$ \\
\hline 1 & 8 & 20 & 46 & 58 & 0.40 & 0.40 & 0.376 \\
2 & 8 & 20 & 46 & 65 & 0.40 & 0.72 & 2.148 \\
3 & 8 & 20 & 53 & 58 & 0.90 & 0.72 & 1.442 \\
4 & 8 & 20 & 53 & 65 & 0.90 & 0.40 & 2.089 \\
5 & 8 & 35 & 46 & 58 & 0.90 & 0.72 & 2.838 \\
6 & 8 & 35 & 46 & 65 & 0.90 & 0.40 & 3.805 \\
7 & 8 & 35 & 53 & 58 & 0.40 & 0.40 & 0.334 \\
8 & 8 & 35 & 53 & 65 & 0.40 & 0.72 & 3.890 \\
9 & 18 & 20 & 46 & 58 & 0.90 & 0.40 & 1.576 \\
10 & 18 & 20 & 46 & 65 & 0.90 & 0.72 & 1.742 \\
11 & 18 & 20 & 53 & 58 & 0.40 & 0.72 & 1.687 \\
12 & 18 & 20 & 53 & 65 & 0.40 & 0.40 & 0.488 \\
13 & 18 & 35 & 46 & 58 & 0.40 & 0.72 & 3.987 \\
14 & 18 & 35 & 46 & 65 & 0.40 & 0.40 & 0.392 \\
15 & 18 & 35 & 53 & 58 & 0.90 & 0.40 & 3.629 \\
16 & 18 & 35 & 53 & 65 & 0.90 & 0.72 & 3.723 \\
\hline
\end{tabular}

Table 6.1: Experiments performed for Taguchi's L16 design - from [27]

To evaluate the percent contribution for each individual factor (and their interactions), a systematic method of hypothesis testing is performed using the Analysis of Variance (ANOVA) [32]. By application of the L-16 design, the following confusions were identified - Table 6.2 summarizes these significant confusions, and their percentcontribution towards the starting torque of the experimental SRM [27].

\begin{tabular}{ccc}
\hline Contrast & Confusions & Contribution (\%) \\
\hline A & $r_{1}+r_{2} r_{4} \beta_{r}+r_{5} \beta_{t} \beta_{5}+\left(^{*}\right)$ & 0.02 \\
B & $r_{2}+r_{1} r_{4} \beta_{r}+r_{4} r_{5} \beta_{s}+\left(^{*}\right)$ & 27.47 \\
C & $r_{4}+r_{1} r_{2} \beta_{r}+r_{2} r_{5} \beta_{s}+\left(^{*}\right)$ & 0.04 \\
D & $r_{5}+r_{2} r_{4} \beta_{s}+r_{1} \beta_{1} \beta_{s}+\left(^{*}\right)$ & 1.30 \\
E & $\beta_{r}+r_{1} r_{2} r_{4}+r_{1} r_{5} \beta_{s}+\left(^{*}\right)$ & 12.79 \\
F & $\beta_{s}+r_{2} r_{4} r_{5}+r_{1} r_{5} \beta_{r}+\left(^{*}\right)$ & 17.29 \\
- & $r_{1} r_{5}+\beta_{r} \beta_{s}+\left(^{*}\right)+\left(^{\wedge}\right)$ & 29.62 \\
\hline
\end{tabular}

(*)one fourth order interaction

$(\wedge)$ one fifth order interaction

Table 6.2: List of confusions - L16 fractional factorial design - from [27] 
From Table 6.2, the main factors are linearly confounded (or confused) with higher order terms; in order to analyze the resultant confounded solutions - Costa et al. $[27,28]$ considered the following hypotheses:

- The high-order interactions (more than two) can be considered negligible.

- Once a contrast is negligible, all the effects that compose this contrast can be considered negligible too.

- Two significant factors (parameters) can also result in a significant interaction. However, two non-significant factors do not give significant interactions.

By application of these hypotheses, the higher-order interactions and any variations that have less than 5\% contribution towards the starting torque can be eliminated. Table 6.3 lists the resultant significant parameters and their interactions; as reported in [27].

\begin{tabular}{|c|c|}
\hline Parameter or Interaction & Percent Contribution \\
\hline$r_{2}$ & 27.47 \\
\hline$\beta_{r}$ & 12.79 \\
\hline$\beta_{s}$ & 17.29 \\
\hline$\beta_{r} \beta_{s}$ & 29.62 \\
\hline Total: & 87.17 \\
\hline
\end{tabular}

From Table 6.3 , it has been shown that there is still an approximate $12 \%$ contribution that remains unaccounted for. This could potentially represent a collection of higher-order terms that were not resolved or could possibly be due to the resolution of the fractional factorial experiment. It is noted that for each resolution level of a fractional factorial design, a set of confounded solutions result. These solutions are quite predictable, and various methods can be used to extrapolate the parameters of significance [32].

Verifying the accuracy of the evaluation methods used throughout [27] are the primary focus for the remainder of this thesis. In order to extrapolate the parameters of significance from the resultant confounded solutions, MATLAB was chosen as the primary method of variance analysis. Using MATLAB function 'anovan' an N-way Analysis of Variance (ANOVA) is performed on the data presented in [27] (Table 6.1). The results are 
tabulated in Table 6.4 - where only the significant main effects have been determined. Note the approximate $41 \%$ remaining error and the 9 remaining degrees of freedom. This gives an indication that there still exist nine unaccounted parameters which make-up $41 \%$ of the contribution in the output.

\begin{tabular}{ccccccc}
\hline $\begin{array}{c}\text { Source of } \\
\text { Variation }\end{array}$ & $\begin{array}{c}\text { Sum of } \\
\text { Squares }\end{array}$ & $\begin{array}{c}\text { Degrees of } \\
\text { Freedom }\end{array}$ & $\begin{array}{c}\text { Mean } \\
\text { Square }\end{array}$ & $F_{0}$ & $\begin{array}{c}\text { P- } \\
\text { Value }\end{array}$ & $\begin{array}{c}\text { Percent } \\
\text { Contribution }\end{array}$ \\
\hline$r_{1}$ & 0.01 & 1 & 0.01 & 0.00 & 0.95 & 0.02 \\
$r_{2}$ & 7.63 & 1 & 7.63 & 6.02 & 0.04 & 27.47 \\
$r_{4}$ & 0.01 & 1 & 0.01 & 0.01 & 0.93 & 0.04 \\
$r_{5}$ & 0.36 & 1 & 0.36 & 0.29 & 0.61 & 1.30 \\
$\beta_{r}$ & 3.56 & 1 & 3.56 & 2.80 & 0.13 & 12.79 \\
$\beta_{s}$ & 4.80 & 1 & 4.80 & 3.79 & 0.08 & 17.29 \\
\hline Error: & 11.41 & 9 & 1.27 & & & 41.08 \\
Total: & 27.79 & 15 & - & & & - \\
\hline
\end{tabular}

Table 6.4: Application of MATLAB ANOVA on L16 design - from [27]

By Description: 'anovan' performs multi-way (n-way) analysis of variance (ANOVA) for testing the effects of multiple factors on the mean of the vector $y$. This test compares the variance explained by factors to the left over variance that cannot be explained .

The MATLAB function 'anovan' is unable to separate the multi-way interactions between factors due to confounding structure that is inherent with the L-16 design (recall the confusions listed in Table 6.2). However, the results of Table 6.4 correlate the main factors that were presented in Table 6.3 [27]. Therefore, this method of analysis is used throughout the remainder of this thesis.

The primary intention of this section was to perform a variance analysis on the resultant data from L16 fractional factorial design, as presented in [27]; whereby, the accuracy between solution methods could be corroborated. The MATLAB ANOVA functions were purposely chosen for their accuracy and speed, although the L16 set of confusions cannot be resolved completely, the significant one-way factors were reported with reasonable accuracy.

\footnotetext{
1 MATLAB R2011a Documentation; Statistics Toolbox; Users Guide; Functions; ANOVA Operations; anovan
} 


\subsection{Parameters Screening: SRM Starting Torque}

This section covers a variety of factorial experiments which focus on identifying the significant main factors, and multi-way factors that affect the starting torque of a SRM. An initial fractional factorial design is presented, which serves to pre-screen the parameters of significance; whereby follow-up full factorial experiments are then performed with a reduced design space, to further increase the accuracy. To further vet the process a full sixparameter experiment is performed to further corroborate the results.

\subsubsection{Six Parameter - Fractional Factorial Experiment}

In any screening exercise it is good practice to pre-screen the parameters with a fractional factorial design. This gives the experimenter an opportunity to quickly identify any parameters that can be neglected. This section covers a (1/4)-fractional factorial design that investigates the significant parameters affecting the starting torque of a $6 / 4$ SRM. Based on the Taguchi's L-16 table of confusions [27], Table 6.5 details the factor combinations required to construct a two-level Resolution IV (1/4)-fractional factorial design.

\begin{tabular}{ccccccc}
\hline RUN & $r_{1}$ & $r_{2}$ & $r_{4}$ & $r_{5}$ & $\beta_{r}$ & $\beta_{5}$ \\
\hline 1 & $\mathrm{~L}$ & $\mathrm{~L}$ & $\mathrm{~L}$ & $\mathrm{~L}$ & $\mathrm{~L}$ & $\mathrm{~L}$ \\
2 & $\mathrm{~L}$ & $\mathrm{~L}$ & $\mathrm{~L}$ & $\mathrm{H}$ & $\mathrm{L}$ & $\mathrm{H}$ \\
3 & $\mathrm{~L}$ & $\mathrm{~L}$ & $\mathrm{H}$ & $\mathrm{L}$ & $\mathrm{H}$ & $\mathrm{H}$ \\
4 & $\mathrm{~L}$ & $\mathrm{~L}$ & $\mathrm{H}$ & $\mathrm{H}$ & $\mathrm{H}$ & $\mathrm{L}$ \\
5 & $\mathrm{~L}$ & $\mathrm{H}$ & $\mathrm{L}$ & $\mathrm{L}$ & $\mathrm{H}$ & $\mathrm{H}$ \\
6 & $\mathrm{~L}$ & $\mathrm{H}$ & $\mathrm{L}$ & $\mathrm{H}$ & $\mathrm{H}$ & $\mathrm{L}$ \\
7 & $\mathrm{~L}$ & $\mathrm{H}$ & $\mathrm{H}$ & $\mathrm{L}$ & $\mathrm{L}$ & $\mathrm{L}$ \\
8 & $\mathrm{~L}$ & $\mathrm{H}$ & $\mathrm{H}$ & $\mathrm{H}$ & $\mathrm{L}$ & $\mathrm{H}$ \\
9 & $\mathrm{H}$ & $\mathrm{L}$ & $\mathrm{L}$ & $\mathrm{L}$ & $\mathrm{H}$ & $\mathrm{L}$ \\
10 & $\mathrm{H}$ & $\mathrm{L}$ & $\mathrm{L}$ & $\mathrm{H}$ & $\mathrm{H}$ & $\mathrm{H}$ \\
11 & $\mathrm{H}$ & $\mathrm{L}$ & $\mathrm{H}$ & $\mathrm{L}$ & $\mathrm{L}$ & $\mathrm{H}$ \\
12 & $\mathrm{H}$ & $\mathrm{L}$ & $\mathrm{H}$ & $\mathrm{H}$ & $\mathrm{L}$ & $\mathrm{L}$ \\
13 & $\mathrm{H}$ & $\mathrm{H}$ & $\mathrm{L}$ & $\mathrm{L}$ & $\mathrm{L}$ & $\mathrm{H}$ \\
14 & $\mathrm{H}$ & $\mathrm{H}$ & $\mathrm{L}$ & $\mathrm{H}$ & $\mathrm{L}$ & $\mathrm{L}$ \\
15 & $\mathrm{H}$ & $\mathrm{H}$ & $\mathrm{H}$ & $\mathrm{L}$ & $\mathrm{H}$ & $\mathrm{L}$ \\
16 & $\mathrm{H}$ & $\mathrm{H}$ & $\mathrm{H}$ & $\mathrm{H}$ & $\mathrm{H}$ & $\mathrm{H}$ \\
\hline
\end{tabular}

Table 6.5: Six parameter L-16 fractional factorial design matrix - starting torque

Table 6.6 lists the individual machine variants. The starting torque is found by application of the 2D magneto-static solver. The relative error $(\epsilon)$ has also been given which compares the differences between our results and the results presented in Table 6.1. 


\begin{tabular}{ccccccccc}
\hline Motor & $r_{1}$ & $r_{2}$ & $r_{4}$ & $r_{5}$ & $\beta_{r}$ & $\beta_{s}$ & $\mathrm{~T}(\mathrm{Nm})$ & $\epsilon(\%)$ \\
\hline 1 & 8 & 20 & 46 & 58 & 0.40 & 0.40 & 0.212 & 43.59 \\
2 & 8 & 20 & 46 & 65 & 0.40 & 0.72 & 2.229 & 3.77 \\
3 & 8 & 20 & 53 & 58 & 0.90 & 0.72 & 1.724 & 19.56 \\
4 & 8 & 20 & 53 & 65 & 0.90 & 0.40 & 2.116 & 1.31 \\
5 & 8 & 35 & 46 & 58 & 0.90 & 0.72 & 2.291 & 19.28 \\
6 & 8 & 35 & 46 & 65 & 0.90 & 0.40 & 3.747 & 1.52 \\
7 & 8 & 35 & 53 & 58 & 0.40 & 0.40 & 0.212 & 36.61 \\
8 & 8 & 35 & 53 & 65 & 0.40 & 0.72 & 3.892 & 0.04 \\
9 & 18 & 20 & 46 & 58 & 0.90 & 0.40 & 2.003 & 27.10 \\
10 & 18 & 20 & 46 & 65 & 0.90 & 0.72 & 1.969 & 13.04 \\
11 & 18 & 20 & 53 & 58 & 0.40 & 0.72 & 1.971 & 16.81 \\
12 & 18 & 20 & 53 & 65 & 0.40 & 0.40 & 0.101 & 79.21 \\
13 & 18 & 35 & 46 & 58 & 0.40 & 0.72 & 3.989 & 0.05 \\
14 & 18 & 35 & 46 & 65 & 0.40 & 0.40 & 0.196 & 49.95 \\
15 & 18 & 35 & 53 & 58 & 0.90 & 0.40 & 3.672 & 1.18 \\
16 & 18 & 35 & 53 & 65 & 0.90 & 0.72 & 3.639 & 2.26 \\
\hline
\end{tabular}

Table 6.6: Experiments performed by application of the L16 design - starting torque

After application of the MATLAB function 'anovan', only the main (one-way) factors have been identified - Table 6.7 tabulates the results.

\begin{tabular}{ccccccc}
\hline $\begin{array}{c}\text { Source of } \\
\text { Variation }\end{array}$ & $\begin{array}{c}\text { Sum of } \\
\text { Squares }\end{array}$ & $\begin{array}{c}\text { Degrees of } \\
\text { Freedom }\end{array}$ & $\begin{array}{c}\text { Mean } \\
\text { Square }\end{array}$ & $F_{0}$ & $\begin{array}{c}P- \\
\text { Value }\end{array}$ & $\begin{array}{c}\text { Percent } \\
\text { Contribution }\end{array}$ \\
\hline$r_{1}$ & 0.078 & 1 & 0.078 & 0.052 & 0.826 & 0.27 \\
$r_{2}$ & 5.421 & 1 & 5.421 & 3.578 & 0.091 & 18.49 \\
$r_{4}$ & 0.030 & 1 & 0.030 & 0.020 & 0.892 & 0.10 \\
$r_{5}$ & 0.206 & 1 & 0.206 & 0.136 & 0.721 & 0.70 \\
$\beta_{r}$ & 4.367 & 1 & 4.367 & 2.883 & 0.124 & 14.90 \\
$\beta_{s}$ & 5.576 & 1 & 5.576 & 3.680 & 0.087 & 19.02 \\
\hline Error: & 13.635 & 9 & 1.515 & & & 46.52 \\
Total: & 29.312 & 15 & - & & & - \\
\hline
\end{tabular}

Table 6.7: ANOVA on L16 design - starting torque

Consequently, only the significant main factors have been resolved. However, the results strongly corroborate with the data presented in [27]. Note the approximate 46\% remaining error and the 9 remaining degrees of freedom (as before). Using the L-16 method has quickly allowed a pre-screening exercise to be performed on the factors, easily eliminating the two of the factors allowing a higher resolution experiment to be performed in order to determine whether or not any higher order interactions can be resolved. 


\subsubsection{Four Parameter - Full Factorial Experiment}

To perform a full factorial design with four independent parameters; sixteen experiments are required:

$$
N_{\exp }=2^{p}=16
$$

Based on the results of the six-parameter experiment, two factors $\left(r_{1}, r_{4}\right)$ were determined to have little contribution towards the starting torque; a four-parameter, higher resolution experiment is then conducted. Table 6.8 details the factor combinations required; which were determined by application of the MATLAB function ' $f f 2 n$ ' - which defines the required design matrix to implement a full factorial design.

\begin{tabular}{|c|c|c|c|c|}
\hline RUN & $r_{2}$ & $r_{5}$ & $\beta_{r}$ & $\beta_{s}$ \\
\hline 1 & L & $L$ & $L$ & $L$ \\
\hline 2 & L & L & L & $\mathrm{H}$ \\
\hline 3 & L & $\mathrm{L}$ & $H$ & L \\
\hline 4 & $\mathrm{~L}$ & $L$ & $\mathrm{H}$ & $\mathrm{H}$ \\
\hline 5 & $L$ & $\mathrm{H}$ & $L$ & L \\
\hline 6 & $\mathrm{~L}$ & $\mathrm{H}$ & $L$ & $\mathrm{H}$ \\
\hline 7 & L & $\mathrm{H}$ & $H$ & $L$ \\
\hline 8 & L & $\mathrm{H}$ & $\mathrm{H}$ & $\mathrm{H}$ \\
\hline 9 & $H$ & L & $\mathrm{L}$ & L \\
\hline 10 & $\mathrm{H}$ & L & L & $\mathrm{H}$ \\
\hline 11 & $\mathrm{H}$ & L & $\mathrm{H}$ & $\mathrm{L}$ \\
\hline 12 & $H$ & $\mathrm{~L}$ & $\mathrm{H}$ & $H$ \\
\hline 13 & $\mathrm{H}$ & $\mathrm{H}$ & $L$ & $\mathrm{~L}$ \\
\hline 14 & $H$ & $H$ & $L$ & $H$ \\
\hline 15 & $H$ & $\mathrm{H}$ & $\mathrm{H}$ & L \\
\hline 16 & $\mathrm{H}$ & $H$ & $\mathrm{H}$ & $\mathrm{H}$ \\
\hline
\end{tabular}

By using as much design re-use from the previous six-parameter experiment sixteen additional models were constructed and evaluated for starting torque, as summarized in Table 6.9 . 


\begin{tabular}{cccccc}
\hline Motor & $r_{2}$ & $r_{5}$ & $\beta_{r}$ & $\beta_{s}$ & $T(\mathrm{Nm})$ \\
\hline 1 & 20.0 & 58.0 & 0.40 & 0.40 & 0.102 \\
2 & 20.0 & 58.0 & 0.40 & 0.72 & 2.025 \\
3 & 20.0 & 58.0 & 0.90 & 0.40 & 2.003 \\
4 & 20.0 & 58.0 & 0.90 & 0.72 & 1.955 \\
5 & 20.0 & 65.0 & 0.40 & 0.40 & 0.102 \\
6 & 20.0 & 65.0 & 0.40 & 0.72 & 2.034 \\
7 & 20.0 & 65.0 & 0.90 & 0.40 & 2.021 \\
8 & 20.0 & 65.0 & 0.90 & 0.72 & 1.969 \\
9 & 35.0 & 58.0 & 0.40 & 0.40 & 0.196 \\
10 & 35.0 & 58.0 & 0.40 & 0.72 & 3.990 \\
11 & 35.0 & 58.0 & 0.90 & 0.40 & 3.856 \\
12 & 35.0 & 58.0 & 0.90 & 0.72 & 3.671 \\
13 & 35.0 & 65.0 & 0.40 & 0.40 & 0.197 \\
14 & 35.0 & 65.0 & 0.40 & 0.72 & 3.954 \\
15 & 35.0 & 65.0 & 0.90 & 0.40 & 3.878 \\
16 & 35.0 & 65.0 & 0.90 & 0.72 & 3.712 \\
\hline Table 6.9: & Results - four parameter full factorial design - &
\end{tabular}

The results of ANOVA are summarized in Table 6.10.

\begin{tabular}{ccccccc}
\hline $\begin{array}{c}\text { Source of } \\
\text { Variation }\end{array}$ & $\begin{array}{c}\text { Sum of } \\
\text { Squares }\end{array}$ & $\begin{array}{c}\text { Degrees of } \\
\text { Freedom }\end{array}$ & $\begin{array}{c}\text { Mean } \\
\text { Square }\end{array}$ & $\begin{array}{c}F_{0} \\
\text { Value }\end{array}$ & $\begin{array}{c}\text { Percent } \\
\text { Contribution }\end{array}$ \\
\hline$r_{2}$ & 7.900 & 1 & 7.900 & - & - & 23.69 \\
$r_{5}$ & 0.000 & 1 & 0.000 & - & - & 0.00 \\
$\beta_{r}$ & 6.845 & 1 & 6.845 & - & - & 20.52 \\
$\beta_{s}$ & 7.501 & 1 & 7.501 & - & - & 22.49 \\
$r_{2}^{*} r_{5}$ & 0.000 & 1 & 0.000 & - & - & 0.00 \\
$r_{2} * \beta_{r}$ & 0.599 & 1 & 0.599 & - & - & 1.80 \\
$r_{2} * \beta_{s}$ & 0.742 & 1 & 0.742 & - & - & 2.22 \\
$r_{5} * \beta_{r}$ & 0.001 & 1 & 0.001 & - & - & 0.00 \\
$r_{5} * \beta_{s}$ & 0.000 & 1 & 0.000 & - & - & 0.00 \\
$\beta_{r} * \beta_{s}$ & 8.787 & 1 & 8.787 & - & - & 26.35 \\
$r_{2} * r_{5}^{*} \beta_{r}$ & 0.000 & 1 & 0.000 & - & - & 0.00 \\
$r_{2} * r_{5}^{*} \beta_{s}$ & 0.000 & 1 & 0.000 & - & - & 0.00 \\
$r_{2} * \beta_{r} * \beta_{s}$ & 0.974 & 1 & 0.974 & - & - & 2.92 \\
$r_{5} * \beta_{r} * \beta_{s}$ & 0.000 & 1 & 0.000 & - & - & 0.00 \\
$r_{2} * r_{5} * \beta_{r} * \beta_{s}$ & 0.000 & 1 & 0.000 & - & - & 0.00 \\
\hline Error: & 0.000 & 0 & 0.000 & & & \\
Total: & 33.349 & 15 & & & & \\
\hline
\end{tabular}

Table 6.10: ANOVA - four parameter full factorial design - starting torque 
Table 6.10 presents the results from the full factorial analysis, as expected all the parameters have been accounted, which corroborate the main effects found from the application of the fractional factorial design (Table 6.7); with the added interaction $\left(\beta_{r} * \beta_{s}\right)$.

\subsubsection{Three Parameter - Full Factorial Experiment}

To perform a full factorial design with three independent parameters; eight experiments are required:

$$
N_{e x p}=2^{p}=8
$$

Table 6.11 details the factor combinations that were given by application of the MATLAB function 'ff $2 n$ ' - which lists the design matrix required for a full factorial design.

\begin{tabular}{cccc}
\hline RUN & $r_{2}$ & $\beta_{r}$ & $\beta_{5}$ \\
\hline 1 & $\mathrm{~L}$ & $\mathrm{~L}$ & $\mathrm{~L}$ \\
2 & $\mathrm{~L}$ & $\mathrm{~L}$ & $\mathrm{H}$ \\
3 & $\mathrm{~L}$ & $\mathrm{H}$ & $\mathrm{L}$ \\
4 & $\mathrm{~L}$ & $\mathrm{H}$ & $\mathrm{H}$ \\
5 & $\mathrm{H}$ & $\mathrm{L}$ & $\mathrm{L}$ \\
6 & $\mathrm{H}$ & $\mathrm{L}$ & $\mathrm{H}$ \\
7 & $\mathrm{H}$ & $\mathrm{H}$ & $\mathrm{L}$ \\
8 & $\mathrm{H}$ & $\mathrm{H}$ & $\mathrm{H}$ \\
\hline
\end{tabular}

Table 6.11: Design matrix - three parameter full factorial - starting torque

By using as much design re-use from the previous experiments - eight additional models were constructed and evaluated for starting torque and has been summarized in Table 6.12.

\begin{tabular}{ccccc}
\hline Motor & $r_{2}$ & $\beta_{r}$ & $\beta_{s}$ & $T(\mathrm{Nm})$ \\
\hline 1 & 20.0 & 0.40 & 0.40 & 0.102 \\
2 & 20.0 & 0.40 & 0.72 & 2.025 \\
3 & 20.0 & 0.90 & 0.40 & 2.003 \\
4 & 20.0 & 0.90 & 0.72 & 1.955 \\
5 & 35.0 & 0.40 & 0.40 & 0.196 \\
6 & 35.0 & 0.40 & 0.72 & 3.990 \\
7 & 35.0 & 0.90 & 0.40 & 3.856 \\
8 & 35.0 & 0.90 & 0.72 & 3.671 \\
\hline
\end{tabular}

Table 6.12: Results - three parameter full factorial design - starting torque 
The results of ANOVA are summarized in Table 6.13.

\begin{tabular}{ccccccc}
\hline $\begin{array}{c}\text { Source of } \\
\text { Variation }\end{array}$ & $\begin{array}{c}\text { Sum of } \\
\text { Squares }\end{array}$ & $\begin{array}{c}\text { Degrees of } \\
\text { Freedom }\end{array}$ & $\begin{array}{c}\text { Mean } \\
\text { Square }\end{array}$ & $\begin{array}{c}F_{0} \\
\text { P- } \\
\text { Value }\end{array}$ & $\begin{array}{c}\text { Percent } \\
\text { Contribution }\end{array}$ \\
\hline$r_{2}$ & 3.959 & 1 & 3.959 & - & - & 23.78 \\
$\beta_{r}$ & 3.344 & 1 & 3.344 & - & - & 20.08 \\
$\beta_{s}$ & 3.759 & 1 & 3.759 & - & - & 22.57 \\
$r_{2}^{*} \beta_{r}$ & 0.285 & 1 & 0.285 & - & - & 1.71 \\
$r_{2}^{*} \beta_{s}$ & 0.376 & 1 & 0.376 & - & - & 2.26 \\
$\beta_{r}^{*} \beta_{s}$ & 4.425 & 1 & 4.425 & - & - & 26.57 \\
$r_{2}^{*} \beta_{r}^{*} \beta_{s}$ & 0.504 & 1 & 0.504 & - & - & 3.03 \\
\hline Error: & 0.000 & 0 & 0.000 & & & \\
Total: & 16.653 & 7 & & & & \\
\hline
\end{tabular}

Table 6.13: ANOVA - three parameter full factorial design - starting torque

\subsubsection{Six Parameter - Full Factorial Experiment}

To perform a full factorial design with six independent parameters; 64 experiments are required:

$$
N_{\text {exp }}=2^{p}=64
$$

By using as much design re-use from the previous experiments - sixty four additional models were constructed and evaluated for starting torque. The ANOVA results are summarized in Table 6.14; for the complete design parameters matrix (see, Table A.1), and for the results of the full ANOVA (see, Table A.2).

\begin{tabular}{ccccccc}
\hline $\begin{array}{c}\text { Source of } \\
\text { Variation }\end{array}$ & $\begin{array}{c}\text { Sum of } \\
\text { Squares }\end{array}$ & $\begin{array}{c}\text { Degrees of } \\
\text { Freedom }\end{array}$ & $\begin{array}{c}\text { Mean } \\
\text { Square }\end{array}$ & $F_{0}$ & $\begin{array}{c}P- \\
\text { Value }\end{array}$ & $\begin{array}{c}\text { Percent } \\
\text { Contribution }\end{array}$ \\
\hline$r_{2}$ & 19.525 & 1 & 19.525 & - & - & 16.90 \\
$\beta_{r}$ & 15.918 & 1 & 15.918 & - & - & 13.78 \\
$\beta_{s}$ & 19.867 & 1 & 19.867 & - & - & 17.20 \\
$\beta_{r}{ }^{*} \beta_{s}$ & 47.414 & 1 & 47.414 & - & - & 41.04 \\
$r_{2}{ }^{*} \beta_{r}^{*} \beta_{s}$ & 6.619 & 1 & 6.619 & - & - & 5.73 \\
\hline Error: & 0 & 0 & 0.000 & & & 0.00 \\
Total: & 115.528 & 63 & - & & - \\
\hline
\end{tabular}

Table 6.14: ANOVA - six parameter full factorial design - starting torque

Table 6.14 lists the significant contributions. It can be observed that the $\left(\beta_{r} * \beta_{s}\right)$ interaction has increased significantly over the previous evaluation. It can be assumed that because the sample space is so large a better approximation is obtained. 


\subsection{Parameters Screening: Stroke Torque}

Section 6.2 focused strictly on the starting torque of the machine; consider the case where the design requirements are insensitive to the starting torque. Figure 6.1 \& Figure 6.2 plot the variation of rotor torque as angular displacement of the rotor changes.

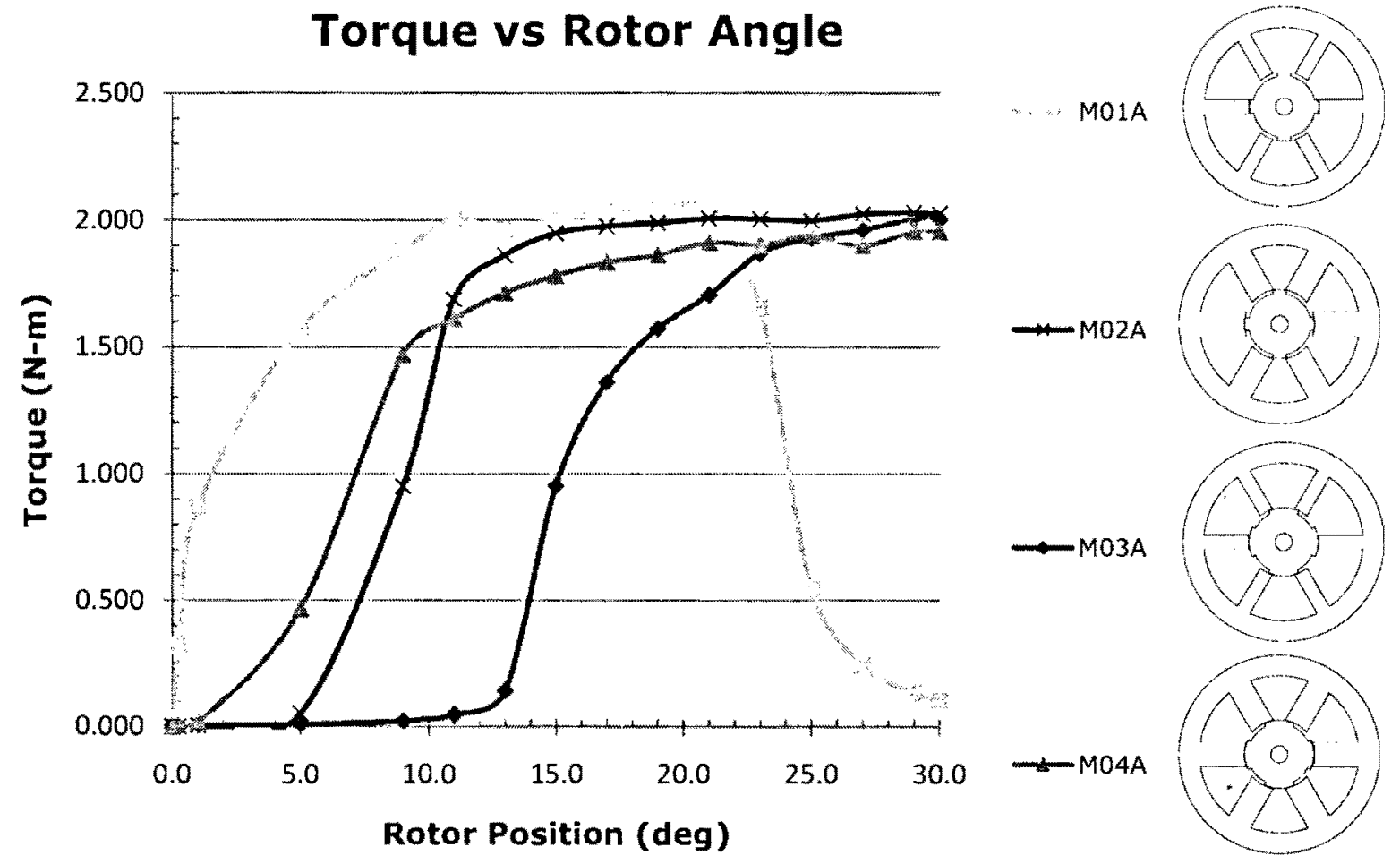

Figure 6.1: Torque vs. rotor angle M01A - M04A

The following parameters were tested; a constant coil current of (3A) was used, as summarized in Table 6.15.

\begin{tabular}{ccccc}
\hline Motor & $r_{2}$ & $\beta_{r}$ & $\beta_{s}$ & $\begin{array}{c}\text { RMS Stroke Torque } \\
(\mathrm{Nm})\end{array}$ \\
\hline M01A & 20.0 & 0.40 & 0.40 & 1.603 \\
M02A & 20.0 & 0.40 & 0.72 & 1.624 \\
M03A & 20.0 & 0.90 & 0.40 & 1.244 \\
M04A & 20.0 & 0.90 & 0.72 & 1.584 \\
M05A & 35.0 & 0.40 & 0.40 & 2.774 \\
M06A & 35.0 & 0.40 & 0.72 & 2.594 \\
M07A & 35.0 & 0.90 & 0.40 & 2.675 \\
M08A & 35.0 & 0.90 & 0.72 & 2.675 \\
\hline
\end{tabular}

Table 6.15: Results - three parameter full factorial design - stroke torque 


\subsection{Parameters Screening: Stroke Torque}

Section 6.2 focused strictly on the starting torque of the machine; consider the case where the design requirements are insensitive to the starting torque. Figure 6.1 \& Figure 6.2 plot the variation of rotor torque as angular displacement of the rotor changes.

\section{Torque vs Rotor Angle}
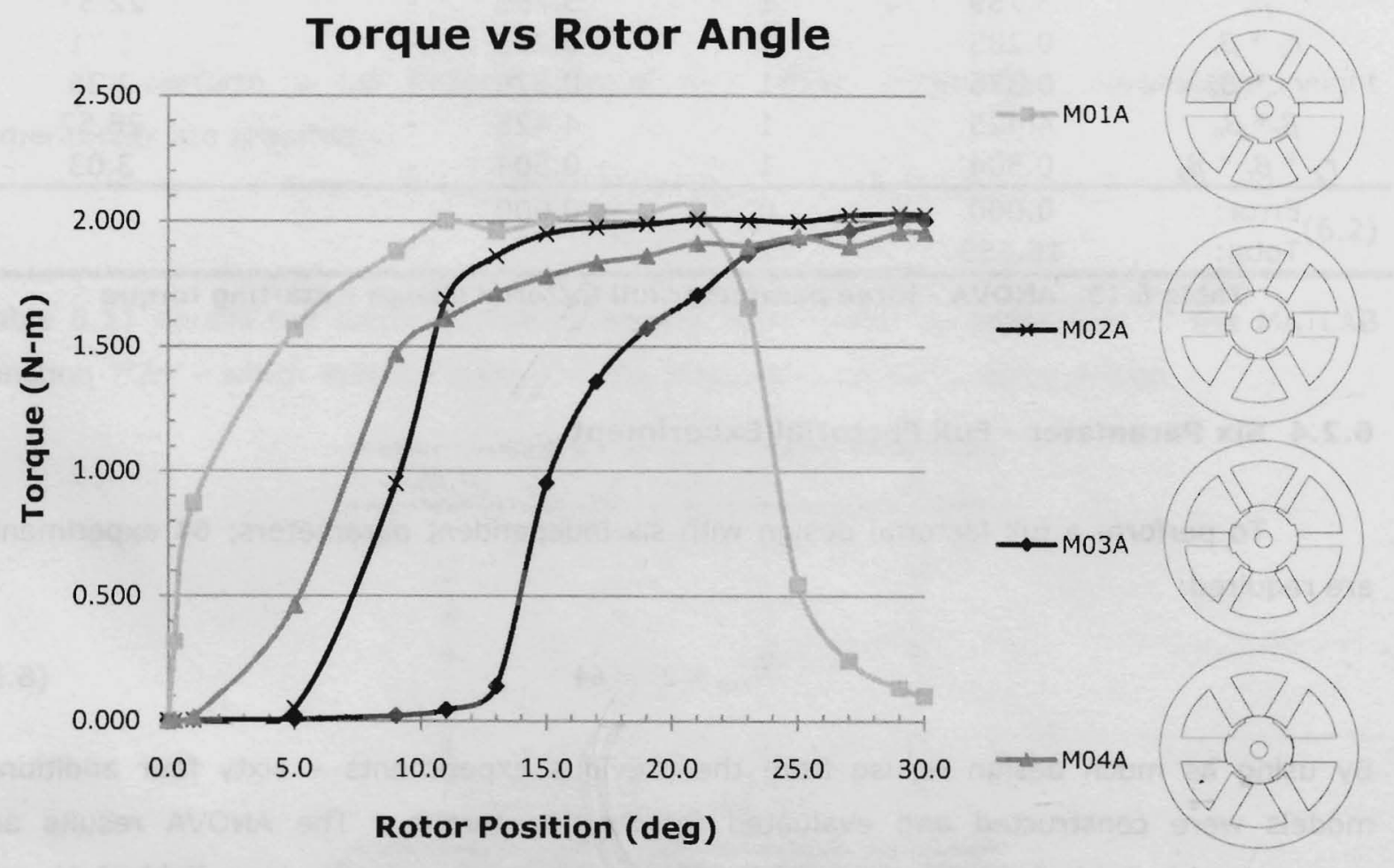

Figure 6.1: Torque vs. rotor angle M01A - M04A

The following parameters were tested; a constant coil current of ( $3 A$ ) was used, as summarized in Table 6.15.

\begin{tabular}{ccccc}
\hline Motor & $r_{2}$ & $\beta_{r}$ & $\beta_{s}$ & $\begin{array}{c}\text { RMS Stroke Torque } \\
(\mathrm{Nm})\end{array}$ \\
\hline M01A & 20.0 & 0.40 & 0.40 & 1.603 \\
M02A & 20.0 & 0.40 & 0.72 & 1.624 \\
M03A & 20.0 & 0.90 & 0.40 & 1.244 \\
M04A & 20.0 & 0.90 & 0.72 & 1.584 \\
M05A & 35.0 & 0.40 & 0.40 & 2.774 \\
M06A & 35.0 & 0.40 & 0.72 & 2.594 \\
M07A & 35.0 & 0.90 & 0.40 & 2.675 \\
M08A & 35.0 & 0.90 & 0.72 & 2.675 \\
\hline
\end{tabular}

Table 6.15: Results - three parameter full factorial design - stroke torque 
Notice how both machines (M01A, M05A) have negligible starting torque at the start of rotation (which is defined as a rotor position of $30^{\circ}$ ), yet the RMS stroke torque is comparable to the other variants. Interestingly all the machine variants reach the approximately same maximum, just slightly shifted from one another.

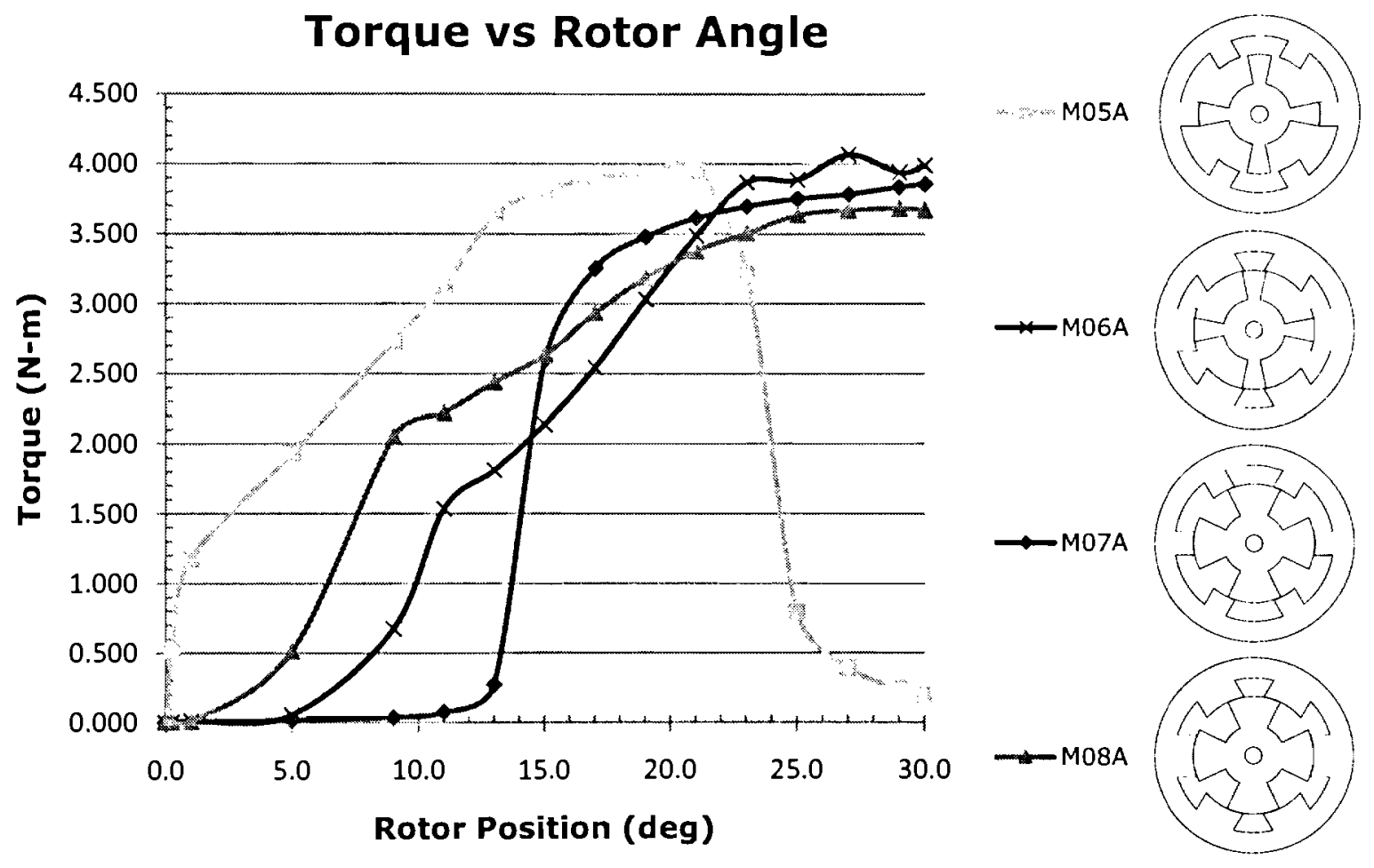

Figure 6.2: Torque vs. rotor angle M05A - M08A

The results of ANOVA are summarized in Table 6.16 - notice that the term $\left(r_{2}\right)$ completely dominates the RMS stroke torque over all other parameters.

\begin{tabular}{ccccccc}
\hline $\begin{array}{c}\text { Source of } \\
\text { Variation }\end{array}$ & $\begin{array}{c}\text { Sum of } \\
\text { Squares }\end{array}$ & $\begin{array}{c}\text { Degrees of } \\
\text { Freedom }\end{array}$ & $\begin{array}{c}\text { Mean } \\
\text { Square }\end{array}$ & $\begin{array}{c}\mathrm{F}_{0} \\
\text { V- } \\
\text { Value }\end{array}$ & $\begin{array}{c}\text { Percent } \\
\text { Contribution }\end{array}$ \\
\hline$r_{2}$ & 2.718 & 1 & 2.718 & - & - & 95.97 \\
$\beta_{r}$ & 0.022 & 1 & 0.022 & - & - & 0.77 \\
$\beta_{s}$ & 0.004 & 1 & 0.004 & - & - & 0.14 \\
$r_{2}^{*} \beta_{r}$ & 0.018 & 1 & 0.018 & - & - & 0.64 \\
$r_{2} * \beta_{s}$ & 0.037 & 1 & 0.037 & - & - & 1.29 \\
$\beta_{r}^{*} \beta_{s}$ & 0.031 & 1 & 0.031 & - & - & 1.10 \\
$r_{2}^{*} \beta_{r}^{*} \beta_{s}$ & 0.002 & 1 & 0.002 & - & - & 0.09 \\
\hline Error: & 0.000 & 0 & 0.000 & & & 0.00 \\
Total: & 2.832 & 7 & - & & & - \\
\hline
\end{tabular}

Table 6.16: ANOVA - three parameter full factorial design - stroke torque 
Notice how both machines (M01A, M05A) have negligible starting torque at the start of rotation (which is defined as a rotor position of $30^{\circ}$ ), yet the RMS stroke torque is comparable to the other variants. Interestingly all the machine variants reach the approximately same maximum, just slightly shifted from one another.

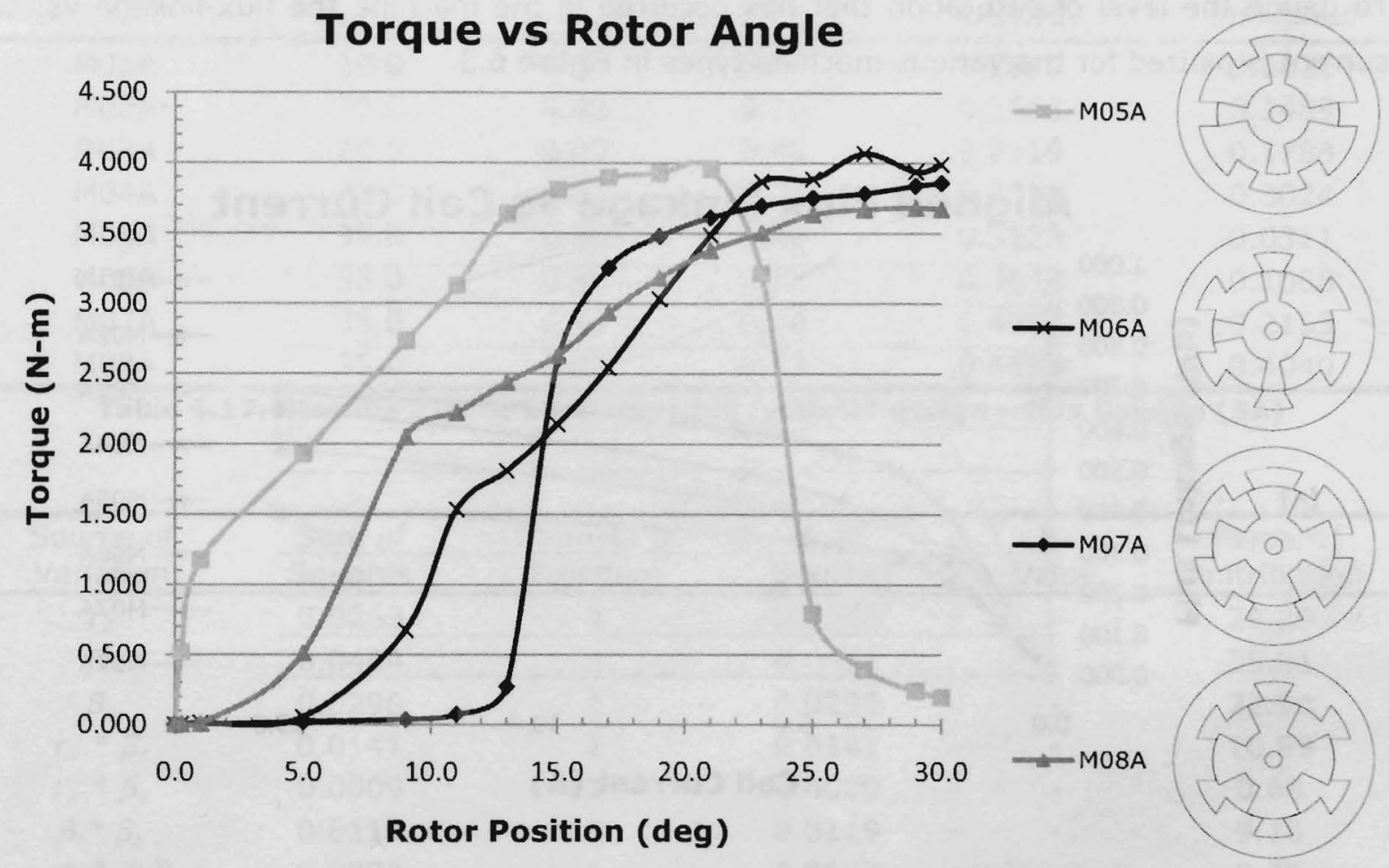

Figure 6.2: Torque vs. rotor angle M05A - M08A

The results of ANOVA are summarized in Table 6.16 - notice that the term $\left(r_{2}\right)$ completely dominates the RMS stroke torque over all other parameters.

\begin{tabular}{ccccccc}
\hline $\begin{array}{c}\text { Source of } \\
\text { Variation }\end{array}$ & $\begin{array}{c}\text { Sum of } \\
\text { Squares }\end{array}$ & $\begin{array}{c}\text { Degrees of } \\
\text { Freedom }\end{array}$ & $\begin{array}{c}\text { Mean } \\
\text { Square }\end{array}$ & $\begin{array}{c}F_{0} \\
\text { Value }\end{array}$ & $\begin{array}{c}\text { Percent } \\
\text { Contribution }\end{array}$ \\
\hline$r_{2}$ & 2.718 & 1 & 2.718 & - & - & 95.97 \\
$\beta_{r}$ & 0.022 & 1 & 0.022 & - & - & 0.77 \\
$\beta_{s}$ & 0.004 & 1 & 0.004 & - & - & 0.14 \\
$r_{2}^{*} \beta_{r}$ & 0.018 & 1 & 0.018 & - & - & 0.64 \\
$r_{2} * \beta_{s}$ & 0.037 & 1 & 0.037 & - & - & 1.29 \\
$\beta_{r}^{*} \beta_{s}$ & 0.031 & 1 & 0.031 & - & - & 1.10 \\
$r_{2}^{*} \beta_{r}^{*} \beta_{s}$ & 0.002 & 1 & 0.002 & - & - & 0.09 \\
\hline Error: & 0.000 & 0 & 0.000 & & & 0.00 \\
Total: & 2.832 & 7 & - & & & - \\
\hline
\end{tabular}

Table 6.16: ANOVA - three parameter full factorial design - stroke torque 


\subsection{Parameters Screening: SRM Aligned Flux Linkage}

When the rotor poles of the SRM are fully-aligned with the magnetic axis of the stator poles, the reluctance is minimized and the magnetic circuit saturates considerably. To gauge the level of saturation that has occurred in the machine the flux-linkage vs, coil current is plotted for the various machine types in Figure 6.3.

(a)

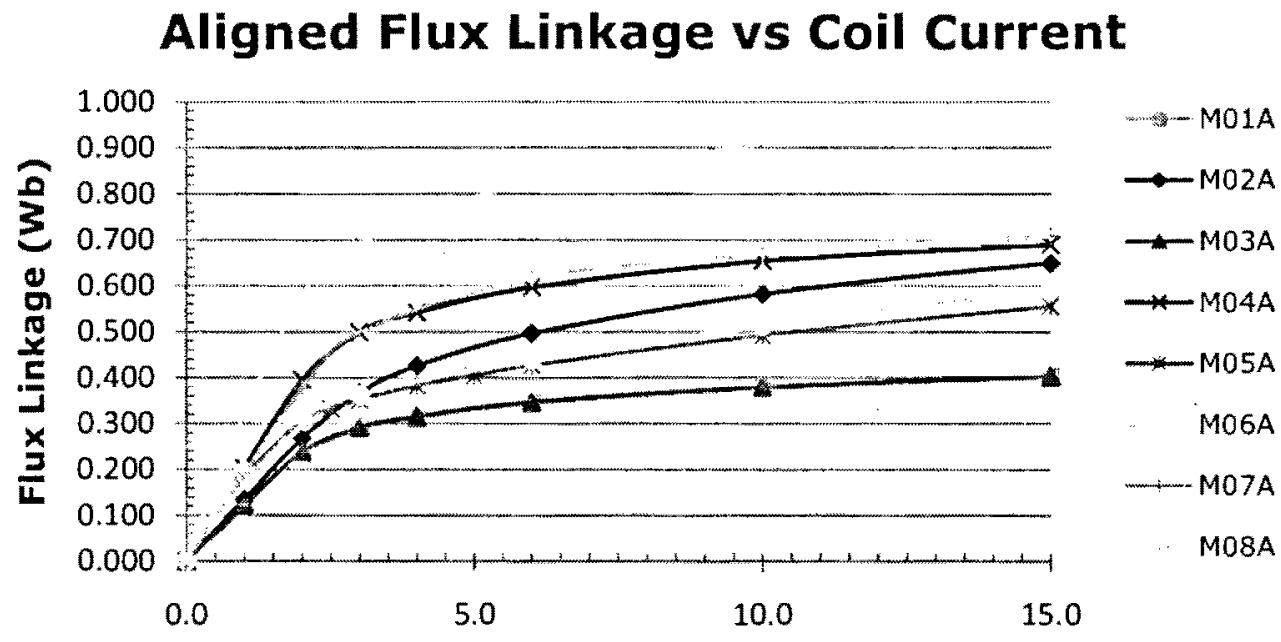

Coil Current (A)

\section{Unaligned Flux Linkage vs Coil Current}

(b)

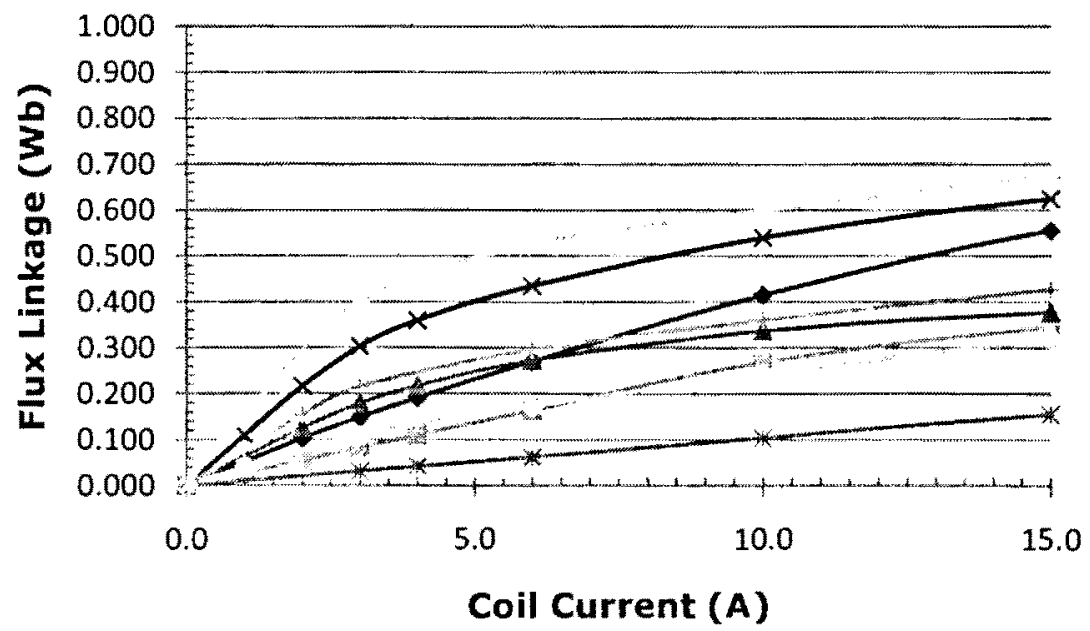

- - M01A

$-M 02 A$

$\rightarrow-M 03 A$

- M04A

- MOSA

M06A

$M 07 \mathrm{~A}$

M08A

Coil Current (A)

Figure 6.3: Flux linkage vs. coil current M01A - M08A, (a) aligned, (b) unaligned 


\subsection{Parameters Screening: SRM Aligned Flux Linkage}

When the rotor poles of the SRM are fully-aligned with the magnetic axis of the stator poles, the reluctance is minimized and the magnetic circuit saturates considerably. To gauge the level of saturation that has occurred in the machine the flux-linkage vs. coil current is plotted for the various machine types in Figure 6.3.

(a)

\section{Aligned Flux Linkage vs Coil Current}

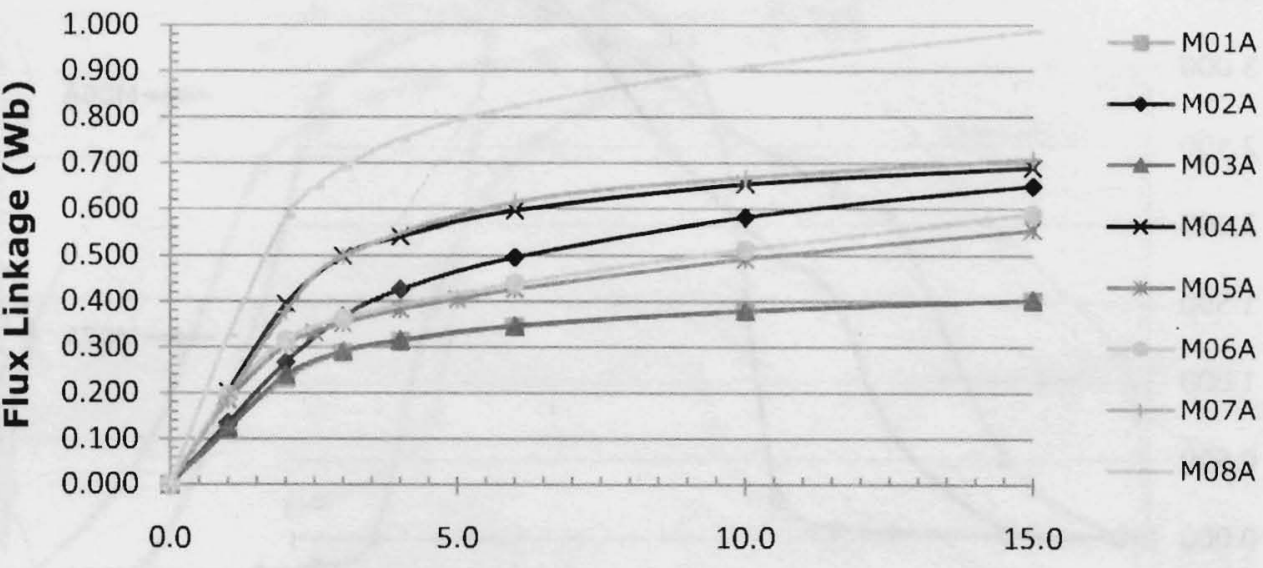

\section{Coil Current (A)}

\section{Unaligned Flux Linkage vs Coil Current}

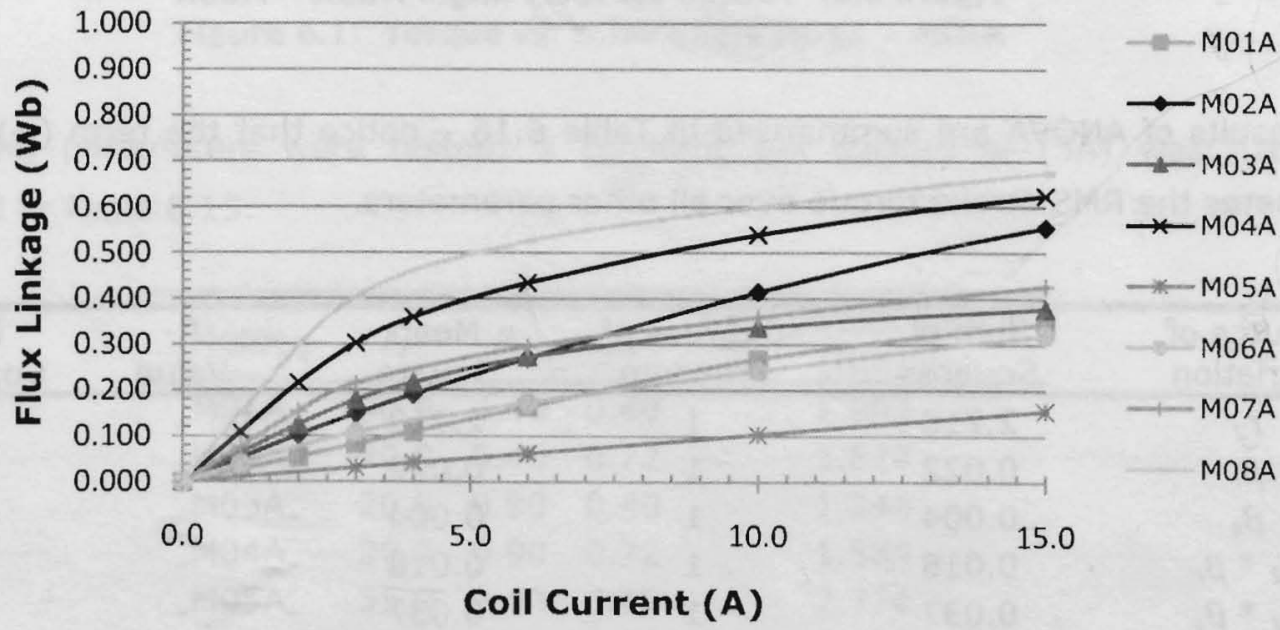

Figure 6.3: Flux linkage vs. coil current M01A - M08A, (a) aligned, (b) unaligned 
For a constant coil current of (3A), the following parameters were tested; as summarized in Table 6.17. The results of ANOVA are summarized in Table 6.18 \& Table 6.19.

\begin{tabular}{cccccc}
\hline & & & & \multicolumn{2}{c}{$\lambda(\mathrm{Wb})$} \\
\cline { 5 - 6 } Motor & $r_{2}$ & $\beta_{r}$ & $\beta_{s}$ & Aligned & Unaligned \\
\hline M01A & 20.0 & 0.40 & 0.40 & 0.2880 & 0.0821 \\
M02A & 20.0 & 0.40 & 0.72 & 0.3663 & 0.1489 \\
M03A & 20.0 & 0.90 & 0.40 & 0.2919 & 0.1788 \\
M04A & 20.0 & 0.90 & 0.72 & 0.4990 & 0.3024 \\
M05A & 35.0 & 0.40 & 0.40 & 0.3523 & 0.0311 \\
M06A & 35.0 & 0.40 & 0.72 & 0.3633 & 0.1088 \\
M07A & 35.0 & 0.90 & 0.40 & 0.4987 & 0.2155 \\
M08A & 35.0 & 0.90 & 0.72 & 0.6893 & 0.4040 \\
\hline
\end{tabular}

Table 6.17: Results - three parameter full factorial design - flux linkage (3A)

\begin{tabular}{ccccccc}
\hline $\begin{array}{c}\text { Source of } \\
\text { Variation }\end{array}$ & $\begin{array}{c}\text { Sum of } \\
\text { Squares }\end{array}$ & $\begin{array}{c}\text { Degrees of } \\
\text { Freedom }\end{array}$ & $\begin{array}{c}\text { Mean } \\
\text { Square }\end{array}$ & $\begin{array}{c}F_{0} \\
\text { Value }\end{array}$ & $\begin{array}{c}\text { Percent } \\
\text { Contribution }\end{array}$ \\
\hline$r_{2}$ & 0.0263 & 1 & 0.0263 & - & - & 20.29 \\
$\beta_{r}$ & 0.0464 & 1 & 0.0464 & - & - & 35.81 \\
$\beta_{s}$ & 0.0296 & 1 & 0.0296 & - & - & 22.90 \\
$r_{2}^{*} \beta_{r}$ & 0.0141 & 1 & 0.0141 & - & - & 10.89 \\
$r_{2}^{*} \beta_{s}$ & 0.0009 & 1 & 0.0009 & - & - & 0.68 \\
$\beta_{r}^{*} \beta_{s}$ & 0.0119 & 1 & 0.0119 & - & - & 9.18 \\
$r_{2}^{*} \beta_{r} * \beta_{s}$ & 0.0003 & 1 & 0.0003 & - & - & 0.25 \\
\hline Error: & 0.0000 & 0 & 0.0000 & & & 0.00 \\
Total: & 0.1295 & 7 & - & & & - \\
\hline
\end{tabular}

Table 6.18: ANOVA - three parameter full factorial design - aligned flux linkage (3A)

\begin{tabular}{ccccccc}
\hline $\begin{array}{c}\text { Source of } \\
\text { Variation }\end{array}$ & $\begin{array}{c}\text { Sum of } \\
\text { Squares }\end{array}$ & $\begin{array}{c}\text { Degrees of } \\
\text { Freedom }\end{array}$ & $\begin{array}{c}\text { Mean } \\
\text { Square }\end{array}$ & $\begin{array}{c}F_{0} \\
\text { P- } \\
\text { Value }\end{array}$ & $\begin{array}{c}\text { Percent } \\
\text { Contribution }\end{array}$ \\
\hline$r_{2}$ & 0.0003 & 1 & 0.0003 & - & - & 0.27 \\
$\beta_{r}$ & 0.0666 & 1 & 0.0666 & - & - & 63.96 \\
$\beta_{s}$ & 0.0261 & 1 & 0.0261 & - & - & 25.04 \\
$r_{2}^{*} \beta_{r}$ & 0.0066 & 1 & 0.0066 & - & - & 6.32 \\
$r_{2}^{*} \beta_{s}$ & 0.0007 & 1 & 0.0007 & - & - & 0.69 \\
$\beta_{r}^{*} \beta_{s}$ & 0.0035 & 1 & 0.0035 & - & - & 3.37 \\
$r_{2}^{*} \beta_{r}^{*} \beta_{s}$ & 0.0004 & 1 & 0.0004 & - & - & 0.35 \\
\hline Error: & 0 & 0 & 0 & & & 0.00 \\
Total: & 0.1041 & 7 & - & & & - \\
\hline
\end{tabular}

Table 6.19: ANOVA - three parameter full factorial design - unaligned flux linkage (3A) 
For a constant coil current of (6A), the following parameters were tested; as summarized in Table 6.20. The results of ANOVA are summarized in Table $6.21 \&$ Table 6.22.

\begin{tabular}{|c|c|c|c|c|c|}
\hline \multirow{2}{*}{ Motor } & \multirow{2}{*}{$r_{2}$} & \multirow{2}{*}{$\beta_{r}$} & \multirow{2}{*}{$\beta_{s}$} & \multicolumn{2}{|c|}{$\lambda(W b)$} \\
\hline & & & & Aligned & Unaligned \\
\hline M01A & 20.0 & 0.40 & 0.40 & 0.3439 & 0.1641 \\
\hline $\mathrm{MO} 2 \mathrm{~A}$ & 20.0 & 0.40 & 0.72 & 0.4961 & 0.2699 \\
\hline M03A & 20.0 & 0.90 & 0.40 & 0.3475 & 0.2723 \\
\hline MO4A & 20.0 & 0.90 & 0.72 & 0.5963 & 0.4346 \\
\hline M05A & 35.0 & 0.40 & 0.40 & 0.4265 & 0.0622 \\
\hline M06A & 35.0 & 0.40 & 0.72 & 0.4393 & 0.1726 \\
\hline M07A & 35.0 & 0.90 & 0.40 & 0.6149 & 0.2956 \\
\hline M08A & 35.0 & 0.90 & 0.72 & 0.8235 & 0.5254 \\
\hline
\end{tabular}

Table 6.20: Results - three parameter full factorial design - flux linkage (6A)

\begin{tabular}{ccccccc}
\hline $\begin{array}{c}\text { Source of } \\
\text { Variation }\end{array}$ & $\begin{array}{c}\text { Sum of } \\
\text { Squares }\end{array}$ & $\begin{array}{c}\text { Degrees of } \\
\text { Freedom }\end{array}$ & $\begin{array}{c}\text { Mean } \\
\text { Square }\end{array}$ & $\begin{array}{c}\text { Fo } \\
\text { Squalue }\end{array}$ & $\begin{array}{c}\text { Percent } \\
\text { Vantribution }\end{array}$ \\
\hline$r_{2}$ & 0.0339 & 1 & 0.0339 & - & - & 18.51 \\
$\beta_{r}$ & 0.0572 & 1 & 0.0572 & - & - & 31.27 \\
$\beta_{s}$ & 0.0484 & 1 & 0.0484 & - & - & 26.48 \\
$r_{2}^{*} \beta_{r}$ & 0.0275 & 1 & 0.0275 & - & - & 15.02 \\
$r_{2}^{*} \beta_{s}$ & 0.004 & 1 & 0.004 & - & - & 2.20 \\
$\beta_{r}^{*} \beta_{s}$ & 0.0107 & 1 & 0.0107 & - & - & 5.84 \\
$r_{2}^{*} \beta_{r}^{*} \beta_{s}$ & 0.0012 & 1 & 0.0012 & - & - & 0.67 \\
\hline Error: & 0 & 0 & 0 & & & 0.00 \\
Total: & 0.1829 & 7 & - & & & - \\
\hline
\end{tabular}

Table 6.21: ANOVA - three parameter full factorial design - aligned flux linkage (6A)

\begin{tabular}{ccccccc}
\hline $\begin{array}{c}\text { Source of } \\
\text { Variation }\end{array}$ & $\begin{array}{c}\text { Sum of } \\
\text { Squares }\end{array}$ & $\begin{array}{c}\text { Degrees of } \\
\text { Freedom }\end{array}$ & $\begin{array}{c}\text { Mean } \\
\text { Square }\end{array}$ & $F_{0}$ & $\begin{array}{c}\text { P- } \\
\text { Value }\end{array}$ & $\begin{array}{c}\text { Percent } \\
\text { Contribution }\end{array}$ \\
\hline$r_{2}$ & 0.0009 & 1 & 0.0009 & - & - & 0.58 \\
$\beta_{r}$ & 0.0923 & 1 & 0.0923 & - & - & 58.88 \\
$\beta_{s}$ & 0.0463 & 1 & 0.0463 & - & - & 29.52 \\
$r_{2}^{*} \beta_{r}$ & 0.0123 & 1 & 0.0123 & - & - & 7.83 \\
$r_{2}^{*} \beta_{s}$ & 0.0006 & 1 & 0.0006 & - & - & 0.41 \\
$\beta_{r}^{*} \beta_{s}$ & 0.0039 & 1 & 0.0039 & - & - & 2.47 \\
$r_{2}^{*} \beta_{r}^{*} \beta_{s}$ & 0.0005 & 1 & 0.0005 & - & - & 0.32 \\
\hline Error: & 0 & 0 & 0 & & & 0.00 \\
Total: & 0.1567 & 7 & - & & & - \\
\hline
\end{tabular}

Table 6.22: ANOVA - three parameter full factorial design - unaligned flux linkage (6A) 


\subsection{Summary}

Costa et al. [27], presented a method of parameters screening which served as the preliminary step in an optimization process. Based on the available package envelope, an experimental SRM was identified and a range of specific core geometries was selected. In order to reduce computing time of the objective function, a factorial experiment was conducted, which focused on reducing the number of significant factors to be optimized. Initially, six factors required consideration; however, after application of the parameters screening exercise, only three factors were identified as being significant. With the understanding that many of the performance characteristics associated with the SRM presents a multifaceted and multi-variable objective criterion, the usefulness of parameter screening, as applied to the SRM has only begun to show promise.

Methods presented in [27], were revitalized and served as the basis for the work that was continued here. In order to correlate the results, the models and methods used in [27] were reproduced and an initial parameters screening exercise was conducted. The results of the model calibration phase reasonably corroborated the findings in [27]. As a result, we now had a vehicle to further test the identified factors against additional key performance criterion of the SRM.

An initial six-parameter fractional factorial study was performed, which identified a group of significant factors; however, because of the resolution of the experiment, the interactions between the factors was not revealed - therefore, two of the least significant factors were removed from the experiment and a higher resolution experiment was performed. A four-parameter full factorial experiment was conducted, which confirmed that there were only three primary contributors, and a single two-way interaction. To further improve the accuracy, a third, three-parameter full factorial experiment was performed which contained the identified parameters of significance from the previous experiment. The results of the three-parameter experiment directly corroborated the results from the four-parameter.

To further the understanding of the factorial experimentation process, a sixparameter full factorial experiment was performed with the recognition that perhaps a single factor element of significance may have been overlooked by the fractional experiment, the more costly experiment was performed. The significance of the cost must be 
appreciated, because a full set of sixty-four (64) models required construction, a monumental task on its own - but, the effort was considered as a necessity in order to insure that an important design element was not overlooked. Table 6.23 summarizes the results of the factorial experimentation as applied to the starting torque of the SRM.

\begin{tabular}{ccccc}
\hline \multirow{2}{*}{ Source of } & \multicolumn{4}{c}{ Percent Contribution } \\
\cline { 2 - 5 } Variation & \multicolumn{4}{c}{ Starting Torque } \\
\cline { 2 - 5 } & $\begin{array}{c}\text { Six-Parameter } \\
\text { Full Factorial }\end{array}$ & $\begin{array}{c}\text { Six-Parameter } \\
\text { Fractional Factorial }\end{array}$ & $\begin{array}{c}\text { Four-Parameter } \\
\text { Full Factorial }\end{array}$ & $\begin{array}{c}\text { Three-Parameter } \\
\text { Full Factorial }\end{array}$ \\
\hline$r_{2}$ & 16.90 & 18.49 & 23.69 & 23.78 \\
$\beta_{r}$ & 13.78 & 14.90 & 20.52 & 20.08 \\
$\beta_{s}$ & 17.20 & 19.02 & 22.49 & 22.57 \\
$r_{2}^{*} \beta_{r}$ & 0.44 & - & 1.80 & 1.71 \\
$r_{2}^{*} \beta_{s}$ & 0.76 & - & 2.22 & 2.26 \\
$\beta_{r}^{*} \beta_{s}$ & 41.04 & - & 26.35 & 26.57 \\
$r_{2} * \beta_{r}^{*} \beta_{s}$ & 5.73 & - & 2.92 & 3.03 \\
\hline
\end{tabular}

Table 6.23: Summary of results - various factorial experiments - starting torque

From the summarized results presented in Table 6.23 , both the three-parameter and four-parameter full factorial experiment directly correlate, with only slight numerical differences between them. As a result it would have been reasonable to perform the fractional factorial experiment, and then if necessary, perform a follow-up three-parameter full factorial design. The results from the six-parameter full factorial experiment did reveal some rather interesting numbers; the two-way interaction between $\left(\beta_{r}{ }^{*} \beta_{s}\right)$ rose from a $26 \%$ contribution, to over $40 \%$ - without lending towards a more formal analysis, this drastic change in prediction accuracy may result from the increased size of the sample space; however, these erroneous differences are left as future work.

To further investigate the design parameters associated with torque production, a three-parameter full factorial screening experiment was performed on two other key performance parameters; the aligned and unaligned flux linkage and the RMS stroke torque. The results of the experiment are summarized in Table 6.24.

The stroke torque is simply the net RMS output torque that is generated as the rotor is drawn from the unaligned to aligned position, while keeping the coil current fixed. By inspection of the results from the starting torque analysis, it was expected that only threeparameters would be deemed significant, namely $\left(r_{2}, \beta_{r}, \beta_{s}\right)$. Therefore, only a three- 
parameter experiment was conducted. However, the results of the ANOVA identified the factor $\left(r_{2}\right)$, which is the rotor radius, has an astonishing $96 \%$ percent contribution towards the RMS stroke torque. Referring to Figure 6.1 and Figure 6.2 ; the experimental machines are grouped in terms of their rotor radius, a closer examination reveals that all machines with the same value of rotor radius $\left(r_{2}\right)$, achieved the same maximum torque over their respective stroke cycle - however, the shape of the torque profile was quite different.

\begin{tabular}{|c|c|c|c|c|c|c|}
\hline \multirow{3}{*}{$\begin{array}{l}\text { Source of } \\
\text { Variation }\end{array}$} & \multicolumn{6}{|c|}{ Percent Contribution } \\
\hline & \multirow{2}{*}{$\begin{array}{l}\text { Starting } \\
\text { Torque }\end{array}$} & \multirow{2}{*}{$\begin{array}{c}\text { RMS Stroke } \\
\text { Torque }\end{array}$} & \multicolumn{4}{|c|}{ Flux Linkage } \\
\hline & & & $\begin{array}{c}\text { Aligned } \\
(3 A)\end{array}$ & $\begin{array}{c}\text { Unaligned } \\
(3 A)\end{array}$ & $\begin{array}{c}\text { Aligned } \\
(6 \mathrm{~A})\end{array}$ & $\begin{array}{c}\text { Unaligned } \\
(6 \mathrm{~A})\end{array}$ \\
\hline$r_{2}$ & 23.78 & 95.97 & 20.29 & 0.27 & 18.51 & 0.58 \\
\hline$\beta_{r}$ & 20.08 & 0.77 & 35.81 & 63.96 & 31.27 & 58.88 \\
\hline$\beta_{s}$ & 22.57 & 0.14 & 22.90 & 25.04 & 26.48 & 29.52 \\
\hline$r_{2}^{*} \beta_{r}$ & 1.71 & 0.64 & 10.89 & 6.32 & 15.02 & 7.83 \\
\hline$r_{2} * \beta_{s}$ & 2.26 & 1.29 & 0.68 & 0.69 & 2.20 & 0.41 \\
\hline$\beta_{r}^{*} \beta_{s}$ & 26.57 & 1.10 & 9.18 & 3.37 & 5.84 & 2.47 \\
\hline$r_{2} * \beta_{r} * \beta_{s}$ & 3.03 & 0.09 & 0.25 & 0.35 & 0.67 & 0.32 \\
\hline
\end{tabular}

Table 6.24: Cumulative summary of results - starting torque, stroke torque, flux linkage

With respect to both the aligned and the unaligned flux linkage, the effects of saturation were considered. The nominal operating current was chosen such that, a flux density is produced in the core, which is just below the point of saturation. For both the aligned and unaligned flux linkage, it can be observed that the significant parameters become affected, as the SRM is driven harder into saturation. For instance, consider the rotor arc $\left(\beta_{r}\right)$ for both the aligned and unaligned rotor position, a $5 \%$ reduction was observed as the machine was driven further into saturation; conversely, the stator arc $\left(\beta_{s}\right)$, exhibited an approximate $5 \%$ increase due to saturation.

In summary, consider if the unaligned inductance were a key design consideration; the resulting parameter screening has identified two significant parameters that directly impact the unaligned inductance, namely $\left(\beta_{r}, \beta_{s}\right)$. Armed with this useful insight, the nonsignificant factors could then be eliminated from the objective function and the optimization would require much less computational effort. The intent of this exercise was to further develop the insight required to begin conducting specific test, with a specific subset of SRM's; although the machine studied throughout this thesis is not ideal, the processes and discussions can be easily leveraged and applied to future work. 


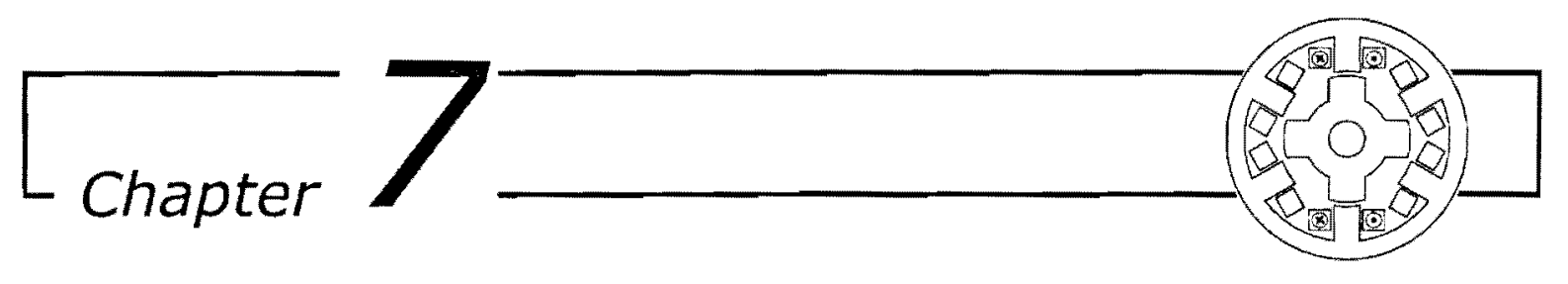

\section{Conclusions}

On the key performance factors which influence the relative sizing of the SRM core geometry, by far the most restrictive is the available package claim. When considering an SRM for hybrid automotive applications, in most cases the tooling has been leveraged from existing production platforms; as such, the available package claim for the motor and drive may be defined simply by what room is remaining. In some cases, performance trade-off are necessary, simply to fit the machine on the vehicle. From firsthand experience, machine design often balances careful consideration between tradeoffs in motor performances vs. package requirements (such as size, weight and volume). The take away message here is: by personal experience the author feels that the SRM has a much wider avenue of optimization over other motor types, and given the competitive nature of the automotive industry, the niche performance characteristics of the SRM may prove to be quite indispensible. Furthermore, parameters screening with factorial experimentation has shown to add an extra level of resolution to the already complex and intermingled design factors associated with the SRM.

A principal focus of this thesis was to identify the significant design parameters of a switched reluctance motor using both full and fractional design methods. A pre-screening exercise was performed using a fractional factorial design in order to identify non-significant parameters, whereby a follow-up full factorial design was performed to confirm the main interactions as well as identify any significant interactions between parameters. As a result of the application of the factorial design analysis the number of significant parameters was decreased to approximately half the original, which lends towards decreasing the complexity of the optimization objective functions. An alternative procedure would be to include all relevant input parameters in the optimization problem and proceed by accepting the computational complexity and increased computational time. 
Furthermore, a summary review of the fundamentals of magnetic theory and the principal operation of the SRM was discussed. This review summarized a very large cross section of research and development of the SRM; from the fundamental principles of operation, modelling and prediction methods and summarizing and understanding the well tested and reviewed empirical design ratios. Although the element of actual design may seem a little underdeveloped, the methods of review were deemed necessary simply because one must understand the history of the developments, so that the progress can be maintained. And the most fundamental design consideration, is actually knowing what you are doing, and for what reason.

\subsection{Future Work}

In this thesis factorial experimentation was used as a method of testing a limited set of SRM performance criteria. Given that the potential SRM design/performance variables are much more numerous than could be covered in this thesis, the logical question to be raised is; what should be the next set of SRM design/performance variables that can be subjected to review using this design methodology?

The answer may be to perform such additional investigations that leverage the existing SRM topology that was presented herein. Following is an outline of those tests that attempts to further the evolution of SRM design so as to elevate the use of SRM technology into mainstream industrial applications:

i) Inclusion of additional performance parameters:

a. Torque ripple, torque/power density, base speed, critical speed, efficiency (core loss, copper loss components), energy ratio, firing angles, acoustic noise, mechanical stresses and vibration, thermal considerations, price, reliability, high speed characteristics.

ii) Refinement of the screening process with the inclusion of new factors:

a. Quantity of poles, number of phases, pole repetitions, machine length, stacking factor, pole taper, rotor skew, stator skew, material properties, effects of temperature, cost, temperature effects.

iii) Investigate the elements of core loss components and the effects of:

a. Switching frequency, transition rates, local saturation, eddy current loss, flux reversals.

iv) Attempt to validate existing empirical design ratios, via factorial experimentation. 


\section{References}

[1] M. R. Harris, et al., "Static toque production in saturated doubly-salient machines," Proc. IEEE, vol. 122, no. 10, pp. 1121-1127, Oct. 1975.

[2] P. J. Lawrenson, et al., "Variable-speed switched reluctance motors," Proc. IEE, vol. 127, pt. B, no. 4, pp. 253-265, Jul. 1980.

[3] R. Arumugam, et al., "Magnetic field analysis of switched reluctance motor using two dimensional finite element model," IEEE Trans. Magnetics, vol. 21, no. 5, pp. 18831885, Sep. 1985.

[4] T. J. E. Miller, "Converter volt-ampere requirements of the switched reluctance motor drive," IEEE Trans. Industry Applications, vol. IA-2I, no. 5, pp. 1136-1144, Sep. 1985.

[5] R. Arumugam, et al., "Sensitivity of pole arc/pole pitch ratio on switched reluctance motor performance," Industry Applications Society Annual Meeting, Pittsburgh, PA, vol. 1, pp. 50-54, Oct. 1988.

[6] R. Krishnan, et al., "Design procedure for switched reluctance motors," IEEE Trans. Industry Applications, vol. 24, no. 3, pp. 456-461, May/Jun. 1988.

[7] ]. Faiz, and J. W. Finch, "Aspects of design optimization for switched reluctance motors," IEEE Tran. Energy Conversion, vol. 8, no. 4, pp. 704-713, Dec. 1993.

[8] A. V. Radun, "Design considerations for the switched reluctance motor," IEEE Trans. Industry Applications, vol. 31, no. 5, pp. 1079-1087, Sep./Oct. 1995.

[9] L. Chang, "Design procedures of a switched reluctance motor for automotive applications," Canadian Conference on Electrical and Computer Engineering, Calgary, $A B$, vol. 2, pp. 947-950, May 1996.

[10] M. N. Anwar, et al., "A comprehensive design methodology of switched reluctance motor," IEEE Industry Applications Conference, Rome, vol. 1, pp. 63-70, Oct. 2000. 
[11] M. H. Ravichandran, et al., "A simplified design methodology for switched reluctance motor using analytical and finite element method," International Conference on Power Electronics, Drives and Energy Systems, New Delhi, pp. 1-4, Dec. 2006.

[12] N. C. Lenin, R. Arumugam, "A unified design procedure for switched reluctance motor," Information and Communication Technology in Electrical Sciences, Chennai, pp. 420-426, Dec. 2007.

[13] K. Vijayakumar, et al., "Switched reluctance motor modeling, design, simulation, and analysis: a comprehensive review," IEEE Trans. Magnetics, vol. 44, no. 10, pp. 46054617, Dec. 2008.

[14] T. J. E. Miller, "Optimal design of switched reluctance motors," IEEE Trans. Industrial Electronics, vol. 49. no. 1, pp. 15-27, Feb. 2002.

[15] R. Jarvis, "Davidson's locomotive: how did he do it?," Engineering Science And Education Journal, vol. 5. no. 6, pp. 281-288, Dec. 1996.

[16] S. A. Nasar, "D.C. - switched reluctance motor," Proc. IEE, vol. 116. no. 6, pp. 10481049, Jun. 1969.

[17] P. Andrada, et al., "Switched reluctance drives for electric vehicle applications," To be presented at International Conference on Renewable Energies and Power Quality, Las Palmas de Gran Canaria, Spain, April 2011.

[18] A. E. Fitzgerald, et al., Electric Machinery, vol. 6, New York: McGraw-Hill, 2003.

[19] M. N. O. Sadiku, Elements of Electromagnetics, vol. 3, New York: Oxford University Press, 2001.

[20] T. Davenport, "Improvement in propelling machinery by magnetism and electromagnetism," U.S. Patent 132, Feb. 25, 1837.

[21] N. Tesla, "Electro-magnetic motor," U.S. Patent 381968, May 1, 1888.

[22] J. Jarret, et al., "Variable-reluctance electric machines," U.S. Patent 3062979, Nov. $6,1962$. 
[23] Capt. T. Savery, The Miner's Friend; or, An Engine to Raise Water by Fire, Described. And of the manner of fixing it in mines; with an account of the several other uses it is applicable unto; and an answer to the objections made against it, London: Printed for S. Crouch, at the corner of Pope's Head-Alley in Cornhill, 1702.

[24] M. Faraday, "New electro-magnetic apparatus," Quarterly Journal of Science, Literature and the Arts, vol. XII, pp. 186-187, 1821.

[25] J. K. Telford, "A brief introduction to design of experiments," Johns Hopkins APL Technical Digest, vol. 27, no. 3, pp. 224-232, 2007.

[26] M. Uy, and 3. K. Telford, "Optimization by design of experiment techniques," IEEE Aerospace Conference, pp. 1-10, Mar. 2009.

[27] M. C. Costa, et al., "Optimisation of a switched reluctance motor using experimental design method and diffuse elements response surface," Proc. IEE Science, Measurement and Technology, vol. 151, no. 6, pp. 411-413, Nov. 2004.

[28] M.C. Costa, et al., "Parameters screening of TEAM workshop problem 25 by the application of experimental design method," COMPEL: The International Journal for Computation and Mathematics in Electrical and Electronic Engineering, vol. 22, no. 3, pp 616-629, 2003.

[29] F. Gillon, and P. Brochet; "Screening and response surface method applied to the numerical optimisation of electromagnetic devices," IEEE Trans. Magnetics, vol. 36, no. 4, pp 1163-1167, Jul. 2000.

[30] F. Gillon, and P. Brochet, "Shape optimization of a permanent magnet motor using the experimental design method," IEEE Trans. Magnetics, vol. 35, no. 3, pp. 12781281, May 1999.

[31] F. Gillon, and P. Brochet, "Optimization of a brushless permanent magnet motor with the experimental design method," IEEE Trans. Magnetics, vol. 34, no. 5, pp. 36483651 , Sep. 1998.

[32] D. C. Montgomery, Design and Analysis of Experiments, vol. 7, New York: Wiley, 2009. 


\section{Appendix A}

\begin{tabular}{|c|c|c|c|c|c|c|}
\hline Motor & $r_{1}$ & $r_{2}$ & $r_{4}$ & $r_{5}$ & $\beta_{r}$ & $\beta_{s}$ \\
\hline 1 & $\bar{L}$ & $L$ & $\mathrm{~L}$ & $L$ & $\mathrm{~L}$ & $\mathrm{~L}$ \\
\hline 2 & $L$ & $\bar{L}$ & $\bar{L}$ & $\bar{L}$ & $\mathrm{~L}$ & $\vec{H}$ \\
\hline 3 & $\mathrm{~L}$ & $L$ & L & $L$ & $H$ & $L$ \\
\hline 4 & $L$ & $L$ & $L$ & $L$ & $\mathrm{H}$ & $\mathrm{H}$ \\
\hline 5 & $L$ & $L$ & $L$ & $\mathrm{H}$ & $L$ & $L$ \\
\hline 6 & $L$ & $L$ & $\mathbf{L}$ & $H$ & $\bar{L}$ & $H$ \\
\hline 7 & $\bar{L}$ & $\vec{L}$ & $\vec{L}$ & $H$ & $\mathrm{H}$ & L \\
\hline 8 & $L$ & L & $L$ & $\mathrm{H}$ & $\mathrm{H}$ & $H$ \\
\hline 9 & $L$ & $L$ & $H$ & $L$ & $\mathrm{~L}$ & $\mathrm{~L}$ \\
\hline 10 & $L$ & $L$ & $H$ & $L$ & L & $H$ \\
\hline 11 & $L$ & $\bar{L}$ & $\mathrm{H}$ & $L$ & $H$ & $L$ \\
\hline 12 & $\tilde{L}$ & $\bar{L}$ & $H$ & $L$ & $\mathrm{H}$ & $\vec{H}$ \\
\hline 13 & $L$ & $L$ & $H$ & $\mathrm{H}$ & L & $L$ \\
\hline 14 & $L$ & $L$ & $H$ & $H$ & L & $\mathrm{H}$ \\
\hline 15 & $L$ & $L$ & $H$ & $\mathrm{H}$ & $\mathrm{H}$ & $L$ \\
\hline 16 & $\mathrm{~L}$ & $\mathrm{~L}$ & $H$ & $H$ & $H$ & $\mathrm{H}$ \\
\hline 17 & $\bar{L}$ & $\bar{H}$ & L & $\mathrm{L}$ & L & $\mathrm{L}$ \\
\hline 18 & $\bar{L}$ & $\mathrm{H}$ & $\vec{L}$ & $\bar{L}$ & $\bar{L}$ & $\vec{H}$ \\
\hline 19 & $L$ & $H$ & $L$ & $L$ & $H$ & $L$ \\
\hline 20 & L & $\mathrm{H}$ & $\mathrm{L}$ & $L$ & $H$ & $\mathrm{H}$ \\
\hline 21 & $L$ & $\mathrm{H}$ & L & $\mathrm{H}$ & L & $L$ \\
\hline 22 & $\mathrm{~L}$ & $H$ & $\bar{L}$ & $\mathrm{H}$ & L & $\mathrm{H}$ \\
\hline 23 & $L$ & $\mathrm{H}$ & $\bar{L}$ & $\mathrm{H}$ & $\vec{H}$ & $\mathrm{~L}$ \\
\hline 24 & $L$ & $H$ & L & $\mathrm{H}$ & $\mathrm{H}$ & $H$ \\
\hline 25 & $L$ & $\mathrm{H}$ & $H$ & $L$ & $\mathbf{L}$ & $L$ \\
\hline 26 & $L$ & $H$ & $H$ & $L$ & $L$ & $H$ \\
\hline 27 & $\bar{L}$ & $H$ & $H$ & $L$ & $H$ & $L$ \\
\hline 28 & $\bar{L}$ & $H$ & $H$ & L & $H$ & $H$ \\
\hline 29 & $\bar{L}$ & $\mathrm{H}$ & $\mathrm{H}$ & $\vec{H}$ & $\mathrm{~L}$ & L \\
\hline 30 & $\bar{L}$ & $\mathrm{H}$ & $H$ & $\mathrm{H}$ & $L$ & $\mathrm{H}$ \\
\hline 31 & $L$ & $H$ & $H$ & $\mathrm{H}$ & $H$ & $L$ \\
\hline 32 & $L$ & $H$ & $H$ & $\mathrm{H}$ & $H$ & $H$ \\
\hline 33 & $\vec{H}$ & $\mathrm{~L}$ & L & $L$ & L & $L$ \\
\hline 34 & H & $L$ & $\mathrm{~L}$ & $L$ & L & $\mathrm{H}$ \\
\hline 35 & $H$ & $L$ & $L$ & $L$ & $H$ & L \\
\hline 36 & $H$ & L & L & $L$ & $H$ & $\mathrm{H}$ \\
\hline 37 & $\mathrm{H}$ & $L$ & L & $\mathrm{H}$ & $\mathbf{L}$ & $L$ \\
\hline 38 & $\mathbf{H}$ & L & $L$ & $\mathrm{H}$ & L & $H$ \\
\hline 39 & $\mathrm{H}$ & $L$ & $\overline{\mathrm{L}}$ & $H$ & $H$ & L \\
\hline 40 & $H$ & $\bar{L}$ & $\overline{\mathrm{L}}$ & $\mathrm{H}$ & $H$ & $H$ \\
\hline 41 & $\mathrm{H}$ & L & $H$ & $L$ & L & $L$ \\
\hline 42 & $\mathrm{H}$ & $L$ & $H$ & $L$ & L & $\mathbf{H}$ \\
\hline 43 & $\mathrm{H}$ & $L$ & $H$ & $L$ & $H$ & $L$ \\
\hline 44 & $H$ & L & $H$ & $L$ & $H$ & $H$ \\
\hline 45 & $\mathrm{H}$ & $\mathrm{L}$ & $H$ & $H$ & $L$ & $\mathrm{~L}$ \\
\hline 46 & $\mathrm{H}$ & $\bar{L}$ & $H$ & $H$ & $\bar{L}$ & $H$ \\
\hline 47 & $H$ & L & $H$ & $H$ & $\mathrm{H}$ & $L$ \\
\hline 48 & $H$ & $L$ & $H$ & $\mathrm{H}$ & $\mathrm{H}$ & $\mathrm{H}$ \\
\hline 49 & $H$ & $H$ & $\mathrm{~L}$ & $L$ & L & $L$ \\
\hline 50 & $H$ & $H$ & L & $L$ & $L$ & $H$ \\
\hline 51 & $\mathrm{H}$ & $H$ & L & $L$ & $H$ & L \\
\hline 52 & $\mathrm{H}$ & $H$ & $\bar{L}$ & $\bar{L}$ & $H$ & $\mathrm{H}$ \\
\hline 53 & $\mathrm{H}$ & $H$ & $L$ & $H$ & $L$ & $L$ \\
\hline 54 & $\mathrm{H}$ & $H$ & L & $H$ & L & $H$ \\
\hline 55 & $\mathrm{H}$ & $H$ & L & $H$ & $H$ & L \\
\hline 56 & $\mathrm{H}$ & $H$ & $\mathrm{~L}$ & $\mathrm{H}$ & $H$ & $\mathrm{H}$ \\
\hline 57 & $\mathrm{H}$ & $H$ & $H$ & $L$ & $\mathbf{L}$ & $L$ \\
\hline 58 & $H$ & $\mathrm{H}$ & $H$ & $L$ & $\mathbf{L}$ & $\mathrm{H}$ \\
\hline 59 & $H$ & $H$ & $\mathrm{H}$ & $L$ & $H$ & $L$ \\
\hline 60 & $H$ & $H$ & $H$ & $L$ & $H$ & $\mathbf{H}$ \\
\hline 61 & $H$ & $H$ & $\mathrm{H}$ & $\mathrm{H}$ & $\mathbf{L}$ & $L$ \\
\hline 62 & $\mathrm{H}$ & $H$ & $\mathrm{H}$ & $H$ & $\mathbf{L}$ & $\mathrm{H}$ \\
\hline 63 & $H$ & $H$ & $\mathrm{H}$ & $H$ & $\mathrm{H}$ & $L$ \\
\hline 64 & $\mathrm{H}$ & $\mathrm{H}$ & $\mathrm{H}$ & $\mathrm{H}$ & $H$ & $H$ \\
\hline
\end{tabular}

Table A.1: Design matrix - four parameter full factorial - starting torque 


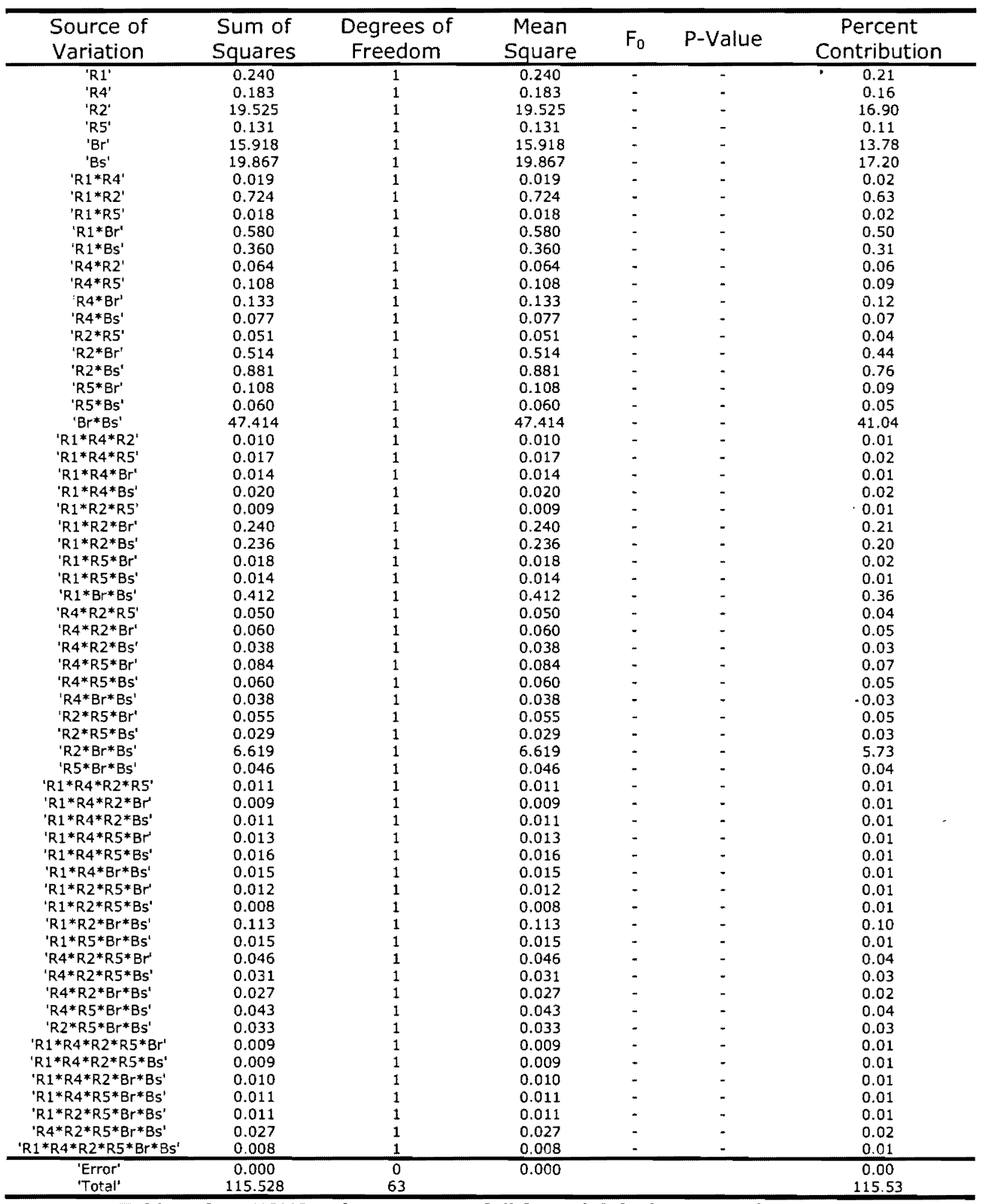

Table A.2: ANOVA - six parameter full factorial design - starting torque 